UNIVERSIDADE DE SÃO PAULO

INSTITUTO DE FÍSICA DE SÃO CARLOS

FRANKLIN ADÁN JULCA VIVANCO

Análise da viabilidade experimental da produção de moléculas fotônicas em uma armadilha de sódio 



\section{Análise da viabilidade experimental da produção de moléculas fotônicas em uma armadilha de sódio.}

Dissertação apresentada ao programa de Pósgraduação em Física do Instituto de Física de São Carlos de Universidade de São Paulo, para a obtenção do título de Mestre em ciências.

Área de concentração: Física

Opção: Física Básica

Orientado: Prof. Dr. Vanderlei Salvador Bagnato

Versão Corrigida

(versão original disponível na Unidade que aloja o Programa)

São Carlos 
AUTORIZO A REPRODUÇÃO E DIVULGAÇÃO TOTAL OU PARCIAL DESTE TRABALHO, POR QUALQÜER MEIO CONVENCIONAL OU ELETRÔNICO PARA FINS DE ESTUDO E PESQUISA, DESDE QUE CITADA A FONTE.

Ficha catalográfica elaborada pelo Serviço de Biblioteca e Informação do IFSC, com os dados fornecidos pelo(a) autor(a)

Julca Vivanco, Franklin Adán

Análise da viabilidade experimental da produção de moléculas fotônicas em uma armadilha de sódio /

Franklin Adán Julca Vivanco; orientador Vanderlei

Salvador Bagnato - versão corrigida -- São Carlos, 2013.

$114 \mathrm{p}$.

Dissertação (Mestrado - Programa de Pós-Graduação em Física Básica) -- Instituto de Física de São Carlos, Universidade de São Paulo, 2013.

1. Moléculas frias. 2. Fotoionização associativa. 3. Blindagem óptica. 4. Armadilha magneto-óptica. 5. Molécula fotônica. I. Salvador Bagnato, Vanderlei, orient. II. Título. 


Para Isabela ...

... a minha mãe. 



\section{AGRADECIMENTOS}

Nenhuma letra nesta dissertação teria sido colocada sem o apoio do Professor Vanderlei Bagnato. A ele devo a minha feliz estadia em São Carlos. Quero agradecer-lhe pela constante motivação, motivação que muitas vezes se sente com a apenas a sua presença nos laboratórios, quando tudo parece estar dando errado. Obrigado por ser o meu orientador.

À Kilvia, por sempre estar cuidando do experimento, por seu valioso socorro nos momentos de maior incerteza e pela correção final do português.

Ao Rafael Rothganger, um dos últimos brasileiros que conhece todos os mistérios dos lasers de corante 699 e 899, demônios que nunca pude dominar. Seu enorme conhecimento experimental foi vital no laboratório. Sem a sua ajuda não teria conseguido terminar este trabalho.

Ao Edwin, meu companheiro nas trocas de corante, que ajudou incansavelmente nas medidas. Ele e o Rafael sempre sabiam por um sorriso no meu rosto com as suas discussões, fossem elas sobre física ou não.

Aos IC Jhonas e Alexandre pelas brincadeiras e a ajuda nas medidas.

Aos companheiros de laboratório: Guilherme, Freddy, Pedro, Amilson, Sergio, Gustavo, Rodrigo, Patricia, Cora e Áttis, pelos momentos compartilhados.

À Professora Cristina por me dar carona até Águas de Lindóia.

Ao LIEPO e à Oficina Mecânica. Também a todo o Grupo de Óptica.

Às secretarias Isabel, Benê e Cristiane por serem sempre solícitas.

Ao Elmer e a sua esposa Erika, meus grandes amigos peruanos em São Carlos.

Aos meus amigos Raphael Munhoz, Felipe e Oscar, por me suportar.

Ao Fito, meu amigo em Curitiba, pelas correções iniciais do texto, as correrias nas correções finais, pelo apoio em todo momento e pela valiosa amizade.

À CAPES, CNPq e FAPESP pelo apoio financeiro.

Aos meus irmãos Ronald, Efraín e José pelo apoio e a vida compartilhada.

À Isabela, a minha mãe, por todo o amor, por nos ensinar o valor do trabalho a mim e aos meus irmãos, por me ensinar a caminhar sozinho e me valer por mim mesmo, por ser a minha guia e suporte quando fiquei muito doente, e por fazer de mim e dos meus irmãos as pessoas que somos. E apesar de nossos inúmeros defeitos, sabemos do amor e o sacrifício que ela fez por nós. 

The problem with the world is that the intelligent people are full of doubts, while the stupid ones are full of confidence.

Charles Bukowski. 



\section{Resumo}

VIVANCO, F. A. J. Análise da viabilidade experimental da produção de moléculas fotônicas numa armadilha de sódio. 2013. 114 p. Dissertação (Mestrado em Ciências) - Instituto de Física de São Carlos, Universidade de São Paulo, São Carlos, 2013.

O progresso nas pesquisas no campo de átomos a baixíssimas temperaturas tem possibilitado o estudo de fenômenos de fotoassociação e blindagem óptica. Estes dois fenômenos são tipicamente produzidos quando um campo de luz externo é incidido em um MOT. Dependendo das dessintonias das frequências dos lasers em relação à ressonância atômica, se podem realizar seletivamente estes processos. Neste trabalho, os estudos são feitos em átomos de sódio e a exploração apresentada faz parte dos estudos que envolvem a formação e detecção de moléculas fotônicas. Uma exploração dos espetros de fotoionização associativa por dois fótons na região de 0 até $-30 \mathrm{GHz}$ foi realizada e a identificação dos estados de longo alcance foi feita. Os níveis vibracionais identificados pertencem majoritariamente aos estados $1_{g}, 0_{g}^{-}$e $0_{u}^{+}$, sendo o estado $0_{g}^{-}$um estado puramente de longo alcance. Um estudo da blindagem óptica em alguns picos do espectro de fotoionização associativa foi realizada com a adição de outro laser azul de frequência $\omega_{A 2}$, e se comprovou saturação na blindagem das colisões inelásticas quando se aumenta a potência deste laser. Com estes estudos demonstramos que os potenciais moleculares intermediários são modificados na presença de campos de luz intensos.

Palavras-chave: Moléculas frias. Fotoionização associativa. Blindagem óptica. 



\section{ABSTRACT}

VIVANCO, F. A. J. Analysis of the experimental viability to produce photonic molecules in a sodium MOT. 2013. 114 p. Dissertação (Mestrado em Ciências) Instituto de Física de São Carlos, Universidade de São Paulo, São Carlos, 2013.

The progress of research in the field of atoms in low temperatures has opened the possibility to study phenomena called fotoassociation and optical shielding. These two phenomena are typically produced when an external light field is focused on a MOT. Depending on the detuning of frequencies of the laser with respect to the atomic resonance can be selectively induced these processes. In this work, the studies are made for sodium atoms, and the presented exploration has been a part of the first studies involving the formation and detection of photonic molecules. An exploration of the fotoasociation spectrum of two colors fotoionizative association between 0 and $-30 \mathrm{GHz}$ was performed, and a labeling of the states of long range was carried out. These vibrational levels belong mostly to the states $1_{g}, 0_{g}^{-}$and $0_{u}^{+}$, being the state $0_{g}^{-}$, a purely long range state. A study of optical shielding of some peaks in the fotoasociation spectrum, as identified to be important in forming the photonic molecule. With respect to the blue laser detuning frequency $\omega_{A}$ and its intensity was performed with the addition of another blue laser frequency $\omega_{A 2}$, and can show a saturation in the shielding for inelastic collisions when increasing the laser intensity. The studies have showed modification in the intermediary potentials in the presence of an intense light field.

Keywords: Cold molecules. Photoionizative association. Optical shielding. 



\section{Lista de Figuras}

Figura 2.2.1 Potenciais de interação para átomos alcalinos. $\mathrm{S}+\mathrm{S}$ denota o estado fundamental molecular, $\mathrm{S}+\mathrm{P}$ o estado simplesmente excitado e $\mathrm{P}+\mathrm{P}$ o estado molecular duplamente excitado. . . . . . . . . .

Figura 2.3.1 Curva que mostra a blindagem óptica medida para moléculas $\mathrm{Na}_{2}$ (6).

Figura 3.1.1 Processo de dois passos para fotoionização por uma só cor. $\omega_{L}$ indica a frequência do laser que faz o processo de fotoassociação e que está presente nos dois passos.

Figura 3.1.2 Espectro típico de fotoionização associativa por um só fóton. Tomado da referencia (35)

Figura 3.2.1 Processo de dois passos para fotoionização associativa por dois fótons. Inicialmente o laser de prova de frequência $\omega_{L}$ leva o par atômico para um estado atrativo intermediário, ai este pode ser levado para o estado duplamente excitado por um fóton azul de frequência $\omega_{A}$ longas distancia interatômicas e sobreviver até cruzar com o estado ionizante (PAI); ou o par atômico pode ser excitado pelo fóton $\omega_{L}$ para o estado intermediário e ser ionizado diretamente a curtas distancias interatômicas (PAPI). Um processo onde o fóton $\omega_{A}$ leva o par atômico para o estado duplamente excitado a curtas distancias interatômicas pode também acontecer. . . . . . . . . . . 40

Figura 3.3.1 Processos que acontecem pela presença do fóton azul: $V_{e}(R)$ é o potencial molecular excitado e $V_{g}(R)$ o estado molecular fundamental. $E_{\infty}=E_{D}$ é a energia de dissociação da molécula, $R_{t p}$ o ponto de retorno a partir do qual o par se repele e a separação entre eles aumenta. $E_{\text {cin }}^{0}$ é a energia cinética efetiva adquirida pelo par de átomos colidindo, e que é usada para "subir" no potencial até a distância $R_{t p} \ldots \ldots \ldots \ldots \ldots \ldots \ldots$. . . . . . . . . . . .

Figura 3.4.1 Esquema da produção da molécula fotônica. O caminho seguido pelo par atômico pode ser observado. 
Figura 4.1.1 Desenho do novo forno implementado. Para um melhor aquecimento resistências de alta temperatura foram usadas. . . . . . . . . . . 47

Figura 4.1.2 Foto do dispositivo que permite o aquecimento automatizado e o monitoramento em tempo real das temperaturas para os átomos de sódio. 47

Figura 4.1.3 Perfil do campo do desacelerador Zeeman usado em nosso experimento. 49

Figura 4.1.4 Perfil de campo magnético de uma das bobinas de compensação para a câmara de aprisionamento. . . . . . . . . . . . . . . . . . . . 50

Figura 4.2.1 Estrutura de níveis hiperfinos do átomo de sódio. Podem-se observar as transições correspondentes para o aprisionamento e o rebombeio. . . 51

Figura 4.2.2 Laser de estado sólido utilizado na produção do MOT. . . . . . . . . . 53

Figura 4.2.3 Um dos lasers de corante Coherent ${ }^{\circledR}$ 699, utilizado nos nossos experimentos. . . . . . . . . . . . . . . . 53

Figura 4.3.1 Sistema experimental utilizado nesta dissertação para a produção de átomos de sódio frios numa armadilha magneto-óptica. . . . . . . . . . 54

Figura 4.3.2 Sistema de produção do Dark MOT. . . . . . . . . . . . . . . . 566

Figura 4.4.1 Diagrama do sistema de controle e aquisição implementado para os nossos experimentos. . . . . . . . . . . . . . . 57

Figura 4.4.2 Captura na tela do programa desenvolvido em Labview® para o monitoramento e aquisição de dados no experimento. . . . . . . . . . . . . 58

Figura 5.1.1 Esquema experimental para a produção das moléculas fotônicas. . 60

Figura 5.1.2 Esquema da sequência temporal implementada para a produção das moléculas fotônicas e controlada pela interface comercial Labview®. "Fundo" indica a contagem de íons que será tomada como contagem de fundo, e "Medida" a contagem total. A diferença desta contagem dá o número de íons produzidos efetivos para o espectro de fotoassociação. . . . . . . . . . . . . 62 62

Figura 5.2.1 a) Potencial molecular aproximado por um oscilador harmônico. Pode-se ver que os níveis com menor $v$ são melhor aproximados. b) O gráfico mostra que quanto maior a largura do potencial do oscilador harmônico, mais níveis de energia podem ser admitidos para o mesmo intervalo de energia. Assim os deslocamentos nas energias dos mesmos $n$ para diferentes osciladores se fazem maiores conforme $n$ aumenta. . . . . . . . . . . . . . . . . . . . 6 64

Figura 5.2.2 Deslocamento dos níveis vibracionais de um potencial molecular para a) um potencial mais profundo que mantém uma forma proporcional ao potencial original, e b) um potencial mais profundo, mas que é apenas modificado no fundo. O potencial original é dado pelas linhas pontoadas. . . . . . . . . . . . . . 66 
Figura 5.2.3 Deslocamento dos níveis intermediários quando a) o potencial é modificado na sua região intermediária se deslocando para um só lado, e b) quando existem dois tipos de deslocamentos. . . . . . . . 67

Figura 6.1.1 Esquemas vetoriais para os casos $a$ ) e $b$ ) de Hund. $a$ ) A energia de interação é maior que a energia de acoplamento spin-órbita, assim $\mathbf{L}$ e $\mathbf{S}$ podem ser projetados no eixo internuclear. Junto com o momento angular $\mathbf{N}$ se acoplam para formar o momento angular J. b) $\boldsymbol{\Lambda}$ se acopla com $\mathbf{N}$ para gerar o momento angular $\mathbf{K}$. Este por sua vez se acopla com $\mathbf{S}$ para gerar $\mathbf{J}$, o momento angular total. [70]

Figura 6.3.1 Curvas potenciais para o caso c) de Hund para o $\mathrm{Na}_{2}$. a) Vista dos estados moleculares da molécula de $\mathrm{Na}_{2}$ conetados com as assíntotas $3^{2} S_{1 / 2}+3^{2} P_{1 / 2}$ e $3^{2} S_{1 / 2}+3^{2} P_{3 / 2}$, com diferença entre elas de $515,52 \mathrm{GHz}$. b) Estados moleculares conetados com a assíntota $3^{2} S_{1 / 2}+3^{2} P_{3 / 2}$. c) Aqui se podem apreciar os estados atrativos de interesse neste trabalho. d) A figura mostra a estrutura hiperfina para o estado 2 . . . . . . . . . . . . . . . .

Figura 6.4.1 Estado ligados calculados por Molenaar (49) para o estado $0_{g}^{-} \mathrm{em}$ átomos de sódio. O inset mostra os estados mais próximos do limite de dissociação. Pode se observar também que a maioria dos estados $0_{g}^{-}$estão conectados a $3^{2} S_{1 / 2}\left(F_{g}=1\right)+3^{2} P_{3 / 2}$; só três estados estão conectados a $3^{2} S_{1 / 2}\left(F_{g}=2\right)+3^{2} P_{3 / 2}$. . . . . . .

Figura 6.4.2 Esquema mostrando o processo pelo qual se justifica a ausência do estado $1_{u}$ dos espectros de fotoionização associativa. . . . . . . . .

Figura 6.5.1 Interação do MOT com um feixe gaussiano do laser. A é a área com a qual o feixe gaussiano incide no MOT. . . . . . . . . . 779

Figura 6.5.2 Esquema da sequência temporal implementada neste experimento e controlada pelo programa de controle e aquisição Labview®. . . . 80

Figura 6.5.3 Espectro de Espectro A onde se mostra as contagens de fundo e de medida. . . . . . . . . . . . . . . 81

Figura 6.5.4 Espectro de Espectro $B$ onde se mostra as contagens de fundo e de medida.

Figura 6.5.5 Espectro de fotoionização associativa por dois fótons para átomos de sódio na região de 0 até -30 GHz. Se pode ver que as estruturas na região de -10 até $-30 \mathrm{GHz}$ estão melhor resolvidas. . . . . . . . . 
Figura 6.5.6 Espectro de fotoionização associativa por dois fótons para átomos de sódio na região de 0 até $-30 \mathrm{GHz}$. As estruturas na região de 0 até -10 GHz estão neste espectro, mais claras. Nota-se que a partir dos $26 \mathrm{GHz}$ não se tem mais picos do que aqueles encontrados no espectro "A". . . . . . . . . . . . . . . . . . 83

Figura 6.5.7 Ajuste por lorentzianas do espectro de fotoionização associativa obtido na figura 6.5.5. O nosso ajuste reproduz quase todas as estruturas presentes no gráfico original com a exceção de uma situada em -26,216 GHz. As curvas de cor verde são os picos individuais ajustados por lorentzianas que serviram para reproduzir cada série vibracional presente no espectro. . . . . . . . . . . . . . . 84

Figura 6.5.8 Ajuste por lorentzianas do espectro de fotoionização associativa obtido da figura 6.5.6, o espectro "B". Este ajuste reproduz todas as estruturas presentes no gráfico original. Os picos têm sido etiquetados para um reconhecimento posterior das séries vibracionais presentes. . . . . . . . . . . . . . . . 8

Figura 6.5.9 Espectro das energias dos picos do espectro "A" elevadas ao exponente $1 / 6$. Os picos regularmente espaçados correspondem a uma determinada série vibracional identificada. Temos etiquetado os valores das dessintonias a $1 / 6$ para poder comprovar a lei de escala. 86

Figura 6.5.10 Espectro das energias dos picos do espectro "B" elevadas ao exponente $1 / 6$. Novamente têm se etiquetado os picos com os valores do eixo das abscisas. . . . . . . . . . . . . . . . . 87

Figura 6.5.11 Espectros para cada série vibracional reproduzidos com um ajuste por lorentzianas do espectro original do 0 até $-30 \mathrm{GHz}$ a) $\mathrm{O}$ espectro para o estado $0_{g}^{-}, b$ ) o espectro para o estado $1_{g}$ e $c$ ) espectro com as estruturas do estado $0_{u}^{+}$. Para cada estado temos incluído também um inset que verifica a lei de escala para estes estados de longo alcance. As setas vermelhas indicam onde falta um pico nas séries. . . . . . . . . . . . . . . .

Figura 6.5.12 Subtraímos progressivamente cada série vibracional para identificar os picos residuais no espectro. Pode-se ver que os picos marcados com os círculos vermelhos obedecem a uma lei de escala para estados intermediários, que chamamos de $X_{g}$, enquanto que os dois picos com os círculos azuis ficam sem identificação, e aqui os chamamos de $Y_{g}$. Um inset mostra a lei de escala se cumprindo para a série $X_{g}$. No capítulo 7 será visto que estes picos aparecem novamente no espectro. . . . . . . . . . . . . . . . 
Figura 6.5.13 Séries vibracionais obedecendo à lei de escala para estados intermediários de ambos os espectros, "A" e "B". . . . . . . . . . . . . 91

Figura 6.5.14 Comparativo dos espectros "A" e "B" que mostra que existe um deslocamento entre estes a partir da frequência de $-23 \mathrm{GHz}$. Os deslocamentos são tanto para o vermelho como para o azul, sendo essa frequência onde ambos os espectros coincidem. . . . . . . . . 92

Figura 6.5.15 Se podem ver os desvios entre os mesmos picos para cada espectro. Mas perto do limite de dissociação as diferenças entre um pico e seu análogo no outro espectro são maiores, se reduzindo conforme nos afastamos deste limite, até inverter e ir aumentando conforme nos afastamos. . . . . . . . . . . . . . . . .

Figura 6.5.16 Nesta figura mostramos os efeitos causados devido à presença de uma estrutura hiperfina. Os círculos vermelhos mostram os efeitos da estrutura hiperfina no espectro de fotoionização associativa. . . 94

Figura 7.1.1 Cruzamento evitado (avoiding crossing). . . . . . . . . . 97

Figura 7.1.2 Esquema que mostra como os dois lasers para o azul suprimem as colisões inelásticas.

Figura 7.2.1 Esquema da sequência temporal implementada para os estudos da blindagem óptica na presença de campos intensos e controlada pela interface comercial Labview®. "Fundo" indica a contagem de íons que será tomada como contagem de fundo, e "Medida" é a contagem total. A diferença desta contagem fornece o número de íons efetivos produzidos. . . . . . . . . . . . . . . . . . . 100

Figura 7.3.1 Espectro mostrando os picos a serem estudados com efeito do laser azul 2. Os círculos em verde indicam os estados $Y_{g}$ não reconhecidos.101

Figura 7.3.2 Picos do estado $0_{u}^{+}$correspondentes às frequências de 28,9 GHz e 28,62 GHz de deslocamento para o vermelho, mostrando as mudanças no tamanho dos picos (a contagem de íons) pela ação da variação da intensidade do laser azul 2. . . . . . . . . . . . . . . 102

Figura 7.3.3 Resultados obtidos para a blindagem nos 4 picos de interesse. Pode-se observar claramente a diminuição na contagem de íons com o aumento da potência do laser azul 2. Se vê também que para maiores potências há uma saturação no efeito de blindagem. . 103

Figura 7.3.4 Comparação das curvas da blindagem para cada pico. . . . . . . . 104

Figura 7.3.5 Deslocamentos dos picos por efeito da variação da intensidade do laser azul 2. Os círculos em verde indicam a série vibracional não identificada, e que cumprem a lei de escala de potenciais intermediários. . . . . . . . . . . . . . . . . . . . . . 105 
Figura 7.3.6 Deslocamentos dos picos por efeito da variação da intensidade do laser azul 2. Zoom para um pico $1_{g}$. . . . . . . . . . . . . 105

Figura 7.3.7 Deslocamentos dos picos por efeito da variação da intensidade do laser azul 2. . . . . . . . . . . . . . . . . . . . . 106 


\section{Sumário}

10 que contém este trabalho

2 Uma introdução às moléculas frias

2.1 Processos de colisão em átomos frios . . . . . . . . . . . . . . . . . . 28 28

2.2 Formação das moléculas frias: mais sobre as colisões de átomos frios . . . . 28

2.2.1 Conceitos básicos envolvidos nas colisões . . . . . . . . . . . . . . 30

2.2 .2 Potenciais de Interação . . . . . . . . . . . . . . . . . . . . . . 31

2.2.3 Ressonâncias no espalhamento . . . . . . . . . . . . . . . 32

2.3 Colisões em uma armadilha magneto óptica na presença de um feixe laser . 33

2.3.1 Espectroscopia de Fotoassociação . . . . . . . . . . . . . . . . . . . 34

2.3.2 Blindagem Óptica . . . . . . . . . . . . . . . . 35

3 A idéia das moléculas fotônicas de sódio e o uso da PAl para testes 37

3.1 Fotoionização associativa por um só fóton . . . . . . . . . . . . . . 37

3.2 Fotoionização associativa por dois fótons . . . . . . . . . . . . . . . 39

3.3 O estado repulsivo . . . . . . . . . . . . . . . . . . . . . 41

3.4 A molécula fotônica . . . . . . . . . . . . . . . . . . . . 41

4 Resfriamento e aprisionamento de átomos de sódio

4.1 Sistema experimental . . . . . . . . . . . . . . . . . 45

4.1.1 Sistema de vácuo e produção de átomos . . . . . . . . . . . . 4 46

4.1.1.1 Forno . . . . . . . . . . . . . . . . . . 46

4.1 .1 .2 Câmara para o MOT . . . . . . . . . . . 47

4.1 .2 Campos magnéticos . . . . . . . . . . . . . . . 48

4.1.2.1 Desacelerador Zeeman . . . . . . . . . . . . . . . . 48

4.1.2.2 Bobinas de aprisionamento magnético-óptico . . . . . . . . 49

4.1.2.3 Bobinas de compensação . . . . . . . . . . . . . . . . 50

4.2 Sistema de Resfriamento Laser . . . . . . . . . . . . . . . . . . 50 50

4.2 .1 Laser de estado Sólido . . . . . . . . . . . . . . . . . . . 52 5

4.2 .2 Lasers de Corante . . . . . . . . . . . . . . . . 5 52

4.3 Produção do MOT de Sódio . . . . . . . . . . . . . . . . . 53 
4.3.1 MOT em configuração Dark Spot . . . . . . . . . . . 555

4.4 Sistema de controle e aquisição de Dados . . . . . . . . . . . . . . . 56

5 Indícios da formação da molécula fotônica através modificação dos potenciais

5.1 Descrição do sistema experimental para a produção das moléculas fotônicas de sódio . . . . . . . . . . . . . . . . . . . . . 60 60

5.2 Indícios da produção das moléculas fotônicas nos potenciais . . . . . . . . 63 5.2.1 O modelo do oscilador harmônico e anarmônico . . . . . . . . . . 63 63

5.2.2 Modificação nos potenciais moleculares realísticos . . . . . . . . . 65

5.3 Como associar as mudanças em potenciais realísticos com uma molécula fotônica de sódio . . . . . . . . . . . . . . . . . 67 67

6 Estudo dos estados ligados de longo alcance: 0 até $-30 \mathrm{GHz}$

6.1 Interações de curto alcance . . . . . . . . . . . . . . . . . . . 69

6.2 Interações de longo alcance . . . . . . . . . . . . . . . . . . 71

6.3 Regras de seleção para potenciais moleculares . . . . . . . . . . . . . . . 733

6.4 Estados moleculares intermediários de longo alcance no sódio . . . . . . . 75

6.4 .1 O estado $1_{g} \ldots \ldots \ldots \ldots \ldots \ldots$

6.4 .2 O estado $0_{g}^{-} \ldots \ldots \ldots \ldots \ldots$

6.4 .3 O estado $1_{u} \ldots \ldots \ldots \ldots \ldots$

6.4.4 Outros Estados . . . . . . . . . . . . . . 77

6.5 Resultados experimentais: espectro de fotoionização associativa por dois fótons para a região de 0 até $-30 \mathrm{GHz}$. . . . . . . . . . . . 78

6.5.1 Espectro na região de 0 até $-30 \mathrm{GHz}$. . . . . . . . . . . . . . 80

7 Alteração dos estados repulsivos na presença de campos de blindagem óptica

7.1 Colisões de átomos frios com laser com dessintonias para o azul . . . . . . 95

7.2 Sistema Experimental . . . . . . . . . . . . . . . . . . . . 99

7.3 Resultados experimentais . . . . . . . . . . . . . . . . . . . . 101

8 Conclusões 107

Referências . . . . . . . . . . . . . . . . . . . . . . . . . . 109 


\section{Capítulo 1}

\section{O que contém este trabalho}

As moléculas frias têm aberto novas perspectivas em espectroscopia de alta resolução (1). Muitas propostas têm aparecido também para o uso das moléculas frias ou ultrafrias em informação quântica e medições precisas relacionadas a estados moleculares (2), que vêm sendo atualmente exploradas por diversos grupos de pesquisa no mundo. Além disso, é importante mencionar também que o tópico das moléculas frias está fortemente relacionado a temas atuais de pesquisa como a produção de condensados, redes ópticas, interferometria atômica, óptica molecular e demais, que têm sido temas recorrentes na área da física atômica (3). Uma importante realização dos estudos em moléculas frias na década dos 1990 foi a observação experimental de um novo tipo de estados eletrônicos moleculares exitados, usualmente chamados de moléculas puramente de longo alcance, que foram preditas trinta anos antes em estudos teóricos por Movre, Prichler (4) e Stwaley (5) para a maioria de dímeros homonucleares alcalinos (desde o $\mathrm{Na}_{2}$ até o $\mathrm{Cs}_{2}$ ). Em alguns casos, ocorre competição entre a interação dipolo-dipolo de longo alcance do estado fundamental $\mathrm{S}$ de um átomo com outro átomo da mesma espécie no estado excitado $\mathrm{P}$ (que varia com $R^{-3}$ ) com a interação spin-órbita. Esta competição cria uma estrutura de dois poços no potencial molecular excitado: o poço comumente existente é agora acompanhado por outro menos profundo e mais externo, com estados ligados mais próximos do limite de dissociação e localizado a grandes distâncias atômicas. Os átomos do par ligado estão separados a distâncias de vários raios de Bohr, com pequenas energias de ligação (da ordem de $\mathrm{MHz}$ ) no caso do sódio. Os níveis vibracionais de tais moléculas excitadas geralmente decaem em poucas dezenas de nanosegundos em um par de átomos no estado fundamental, mas eles vivem o suficiente para poderem ser caracterizados espectroscopicamente.

O objetivo principal na realização deste trabalho foi o estudo da viabilidade da produção de estados moleculares singulares, os quais temos denominado de moléculas fotônicas, já que são produzidas pela absorção de fótons. Portanto, poderíamos dizer que se tratam de moléculas fotoassociadas não convencionais. Neste contexto, o estudo e reconhecimento das séries vibracionais formadas quando fazemos espectroscopia dos estados excitados moleculares é de vital importância, já que permitiram identificar os potenciais que são modificados na formação do estado molecular singular de nosso interesse. Assim, 
foi feita espectroscopia de fotoassociação por duas cores na região de 0 a $-30 \mathrm{GHz}$ de dessintonia ao vermelho da transição ressonante. Foram identificadas séries vibracionais que comumente não foram consideradas em trabalhos similares. Uma reprodução do espectro de fotoassociação com lorentzianas permite uma posterior subtração de cada série vibracional identificada e verificar a lei de escala, presente para os estados moleculares de longo alcance. Com isto, podemos analisar as modificações sofridas pelos potenciais na presença de fótons e assim verificar as evidências que indicam os fatos essenciais para a existência das nossas moléculas fotônicas.

Para estudar estas evidências, desenvolvemos experimentos de fotoionização associativa por dois fótons com a adição de um laser azul, o qual permitirá estudar a modificação do potencial repulsivo com a variação da potência deste laser. É sabido que a excitação do potencial repulsivo existente cria efeitos de supressão das colisões inelásticas. Também é importante estudar os fatos que indicam evidências na modificação dos potenciais e como são os deslocamentos em energia das estruturas na região estudada quando adicionamos lasers intensos com dessintonias para o azul da transição de ressonância.

O trabalho desenvolvido para esta dissertação consiste basicamente na análise dos primeiros $30 \mathrm{GHz}$ do espectro de fotoassociação por duas cores em átomos de sódio e um estudo da blindagem óptica por feixes laser azul em alguns picos, escolhidos por serem de interesse na futura formação de uma molécula fotônica.

Uma breve introdução às moléculas frias será apresentada no capítulo seguinte, assim como uma revisão sobre a teoria envolvendo a mecânica quântica dos processos de colisão que permitem a formação das mesmas. No capítulo 3 fazemos uma explicação mais detalhada da idéia da produção da molécula fotônica, sendo este o objetivo final do conjunto de estudos do qual faz parte este trabalho. O capítulo 4 mostra o sistema experimental desenvolvido para a produção da nossa amostra, uma armadilha magnetoóptica (MOT) na configuração conhecida como Dark MOT, a qual possibilita a captura de átomos na armadilha nos seus estados fundamentais hiperfinos e, desta forma, permite um reconhecimento dos estados vibracionais de nosso interesse, além dos recursos experimentais usados para os nossos estudos. O capítulo 5 mostra um sistema experimental para produzir moléculas fotônicas e discute a viabilidade experimental da formação das mesmas, onde se apresenta uma descrição de como a presença dos fótons altera a forma dos potenciais através da fotoassociação. O capítulo 6 apresenta a análise dos nossos resultados nos $30 \mathrm{GHz}$, os estudos dos estados de longo alcance e o reconhecimento das séries vibracionais envolvidas nessa região com a nossa configuração de MOT particular. Estudos de efeitos no estado repulsivo, como a blindagem óptica e deslocamento de certas estruturas de interesse, são apresentados e analisados no capítulo 7. Finalmente, as conclusões e as perspectivas são apresentadas. 


\section{Capítulo 2}

\section{Uma introdução às moléculas frias}

O que é uma molécula fria? Essa é uma pergunta que podemos nos fazer quando vemos o termo nas diversas publicações referentes ao tema. O termo molécula fria é usado quando tratarmos as moléculas formadas em temperaturas acima de $\mu \mathrm{K}$ e abaixo de $1 \mathrm{~K}$, como aquelas formadas em armadilhas ópticas, magnéticas, magneto-ópticas e de dipolo (6). O termo moléculas ultrafrias tem sido usado amplamente nos últimos anos quando se trata com moléculas formadas a temperaturas menores que $\mu \mathrm{K}$, como acontece em condensados de Bose-Einstein (7). As moléculas com as quais tratamos para a realização deste trabalho não são moléculas convencionais, pois estas se formam pelo acoplamento de fótons com dois átomos colidindo. Com tudo, podemos dizer que as moléculas que formamos podem se categorizar como moléculas frias, já que a ordem da temperaturas dos átomos envolvidos é de $\mu \mathrm{K}$.

Com o advento das técnicas de armadilhamento de átomos neutros (8), os diversos estudos de fotoassociação foram beneficiados, já que a formação de moléculas frias era melhor controlada. Assim, dois átomos frios absorvem ressonantemente um fóton e produzem uma molécula excitada em um estado rotovibracional bem definido. Algo que deve ser tomado em conta nestes processos de formação molecular é que a estrutura hiperfina dos átomos, aquela que acopla os momentos eletrônicos com o momento nuclear, tem grande importância na fotoassociação dos átomos frios, especialmente quando tratarmos com níveis de energias moleculares muito próximos do limite de dissociação relacionado aos átomos nos estados fundamental S e excitado $\mathrm{P}$ da mesma espécie. Alguns estudos nesta direção tem sido realizados já para átomos de sódio (9).

Várias formas de criar moléculas frias em diferentes condições de temperatura e densidades tem sido utilizadas e demostradas; assim se pode dizer que na verdade as técnicas laser foram adotadas para as espécies nas quais as frequências laser ressonantes estavam disponíveis. Deste modo, temos a maioria dos estudos envolvendo átomos alcalinos, alcalinos terrosos e gases raros metaestáveis. Por outro lado, o resfriamento de moléculas preexistentes por campos externos é ainda um desafio devido à dificuldade proveniente da complexidade dos estados eletrônicos moleculares. Por isso, a maioria dos estudos estão dirigidos às moléculas criadas a partir de átomos neutros frios no estado fundamental, sem 
terem sido abandonados os esforços na outra direção. Assim, todos os estudos realizados neste trabalho foram feitos em uma armadilha magneto-óptica de átomos de sódio. Para compreender melhor os processos que estão envolvidos é útil fazer um revisão da teoria de colisões de átomos, fotoassociação e blindagem óptica.

\subsection{Processos de colisão em átomos frios}

Processos de colisão tem um papel muito importante na natureza. Diversos estudos em física de colisões de partículas subatômicas permitiram o desenvolvimento da física nuclear e de partículas a altas energias (10). A física atômica e molecular não podia deixar de lado o estudo destes fenômenos entre fótons e átomos. Com o desenvolvimento das técnicas que permitem aprisionar átomos frios numa armadilha, tem se aberto todo um excitante panorama novo de pesquisas, que nos últimos anos permitiram a realização dos condensados de Bose-Einstein (11), a produção de redes ópticas (12), relógios atômicos (13), experimentos de interferometria atômica (14), entre outros, que estão ainda sendo explorados em mais detalhe (15). Em uma armadilha de átomos aprisionados, podem acontecer diversos eventos devido à dinâmica interna da amostra, assim como podem ser induzidos processos mediante campos externos, como a luz (16). Os processos de colisão são os que mais contribuem na dinâmica da armadilha. Muitos estudos de colisão tem sido feitos na presença de campos de luz, e tem permitido o desenvolvimento de técnicas espectroscópicas como a fotoionização associativa (1). Com as técnicas que permitem aprisionar átomos neutros a baixas temperaturas, os processos de colisão foram amplamente estudados devido ao fato que a sua compreensão permitiria uma melhor manipulação das técnicas que posteriormente tornariam possível a condensação de BoseEinstein (11, 17, 18). As colisões em átomos frios não geram apenas perdas e aquecimento das espécies aprisionadas, mas também permitem a realização de medições precisas e a caraterização dos efeitos produzidos por campos magnéticos, elétricos ou luz nos átomos colidindo.

\subsection{Formação das moléculas frias: mais sobre as co- lisões de átomos frios}

As colisões a baixas energias entre átomos neutros no estado fundamental tem sido amplamente descritas em diversas revisões relevantes ao tema (6). Os tratamentos do tipo 
semi-clássico e quântico são os mais comuns para abordar estes fenômenos, e tem sido amplamente divulgados (19 24). Na presença de um campo externo que induz diversos processos, muitas vezes um tratamento independente do tempo não consegue levar em conta todas as contribuições existentes no fenômeno. No entanto, para colisões entre átomos sem a presença de campos externos, um tratamento independente do tempo é suficiente para tratar o problema, e pode ser encontrado nos livros básicos de mecânica quântica (25, 26).

Um átomo alcalino no estado fundamental, tal como o sódio, é do tipo hidrogenoide ${ }^{2} \mathrm{~S}_{1 / 2}$, com um só elétron na camada mais externa. O estado excitado de uma transição empregada para processos de resfriamento laser é tipicamente ${ }^{2} \mathrm{P}_{j}$, com o momento angular eletrônico $j=1 / 2$ ou $3 / 2$, sendo $j=3 / 2$ no caso do sódio. Além disso, se tem que considerar o acoplamento spin-órbita LS, onde $\mathbf{L}_{a}$ e $\mathbf{S}_{a}$ representam o momento angular orbital e o momento angular intrínseco de um átomo $a$, respectivamente; e $\mathbf{j}=\mathbf{L}_{a}+\mathbf{S}_{a}$ é o momento angular total resultante. Os átomos alcalinos tem um spin nuclear $\mathbf{I}_{a}$, o qual se acopla com o momento angular total $\mathbf{j}$ para formar um momento angular hiperfino resultante $\mathbf{f}_{a}$. Isto é valido ainda quando se tem $I_{a}=0$. Para átomos alcalinos o spin nuclear é usualmente um semi-inteiro, sendo $3 / 2$ no caso do sódio.

Vamos denominar os canais de espalhamento para a colisão de dois átomos $a$ e $b$ como sendo $|\alpha\rangle=|a b\rangle\left|\ell m_{\ell}\right\rangle$, onde $a b$ designa os números quânticos necessários para especificar os estados dos dois átomos interagindo. Esta representação é chamada de representação atômica. O momento angular do movimento relativo ao par de átomos acoplados é $\left|\ell m_{\ell}\right\rangle=Y_{\ell m_{\ell}}(\hat{\mathbf{R}})$, onde $Y_{\ell m_{\ell}}$ é um harmônico esférico com argumento $\hat{\mathbf{R}}$, o vetor direção sobre a esfera unitária.

Podemos ter uma caraterização total só com estes números quânticos para os canais de entrada (estados iniciais) nas colisões frias. Mas às vezes é preciso uma modificação nos números quânticos para poder considerar outras contribuições, como nos casos que envolvem emissão espontânea na formação de estados moleculares ligados. Assim o símbolo $\alpha$, dado para o canal, vai nos dizer como é nosso sistema no início e depois do processo de colisão.

Uma molécula fria é formada como resultado da colisão de dois átomos nos seus estados fundamentais com a interação adicional de um campo de luz. São chamadas de moléculas frias porque elas são formadas por átomos frios com baixas energias cinéticas. Outro enfoque seria produzir estas moléculas a partir do resfriamento de moléculas, mas embora se tenham avanços a este respeito (27), em termo gerais, a complicada estrutura das moléculas impossibilita o resfriamento direto das mesmas. Para entender melhor a formação destas moléculas é necessário entender como ocorrem os processos de colisão em uma armadilha, ou mais ainda como processos de colisões acontecem entre duas partículas. 


\subsubsection{Conceitos básicos envolvidos nas colisões}

Quando tratamos um sistema com dois átomos interagindo, o primeiro passo que devemos fazer é reduzir o problema para que este seja abordado adequadamente. Uma transformação de coordenadas das posições individuais dos átomos $\mathbf{R}_{a}$ e $\mathbf{R}_{b}$ (relativas ao centro de massa do sistema) deve ser realizada, e a coordenada $\mathbf{R}=\mathbf{R}_{a}-\mathbf{R}_{b}$ é a mais satisfatória para isto. A função de onda para um estado ligado ou um estado livre de movimento relativo pode ser descrita como

$$
\Psi_{\alpha}(E, \mathbf{R})=\sum_{\alpha^{\prime}} \frac{\phi_{\alpha^{\prime} \alpha}(E, R)}{R}\left|\alpha^{\prime}(\mathbf{R})\right\rangle
$$

onde $R$ é o módulo de $\mathbf{R}$, e $E$ é a energia total dos estados internos. Os estados $\left|\alpha^{\prime}(\mathbf{R})\right\rangle$ são funções implícitas de $\mathbf{R}$ que são iguais aos estados do canal assimptótico quando $R \rightarrow \infty$. A solução $\phi(E, R)$ é determinada das equações acopladas de Schrodinger,

$$
\sum_{\alpha^{\prime}}\left\{-\delta_{\alpha^{\prime} \alpha} \frac{\hbar^{2}}{2 \mu} \frac{d^{2}}{d R^{2}}+V_{\alpha^{\prime} \alpha}(R)\right\} \phi_{\alpha^{\prime} \alpha}=E \phi_{\alpha^{\prime} \alpha}
$$

com $\mu$ sendo a massa reduzida do par interagindo, e $V_{\alpha^{\prime} \alpha}(R)$ é um elemento da matriz do potencial de interação, que já inclui o termo centrífugo $\hbar^{2} \ell_{\alpha}\left(\ell_{\alpha}+1\right) /\left(2 \mu R^{2}\right)$ na diagonal da matriz. $V_{\alpha^{\prime}, \alpha}$ é zero, exceto quando a diferença $\ell_{\alpha^{\prime}}-\ell_{\alpha}$ seja um número par. As condições de fronteira sobre $\phi$ dependem do estado ser um estado ligado ou um estado espalhado. Em ambos os casos, $\phi_{\alpha^{\prime} \alpha}\left(E_{\alpha}, R\right) \rightarrow 0$ quando $R \rightarrow 0$. Para os estados ligados, $\phi_{\alpha^{\prime} \alpha}\left(E_{\alpha}, R\right) \rightarrow 0$ quando $R \rightarrow \infty$, e a equação 2.2 .2 passa ser uma equação matricial de autovalores para as autoenergias discretas $E_{\alpha}$. Para estados espalhados, $E$ é uma variável continua e as condições de fronteira são impostas como para estados colidentes com energia normalizada:

$$
\frac{\phi_{\alpha^{\prime} \alpha}^{+}}{R}=\left(\frac{2 \mu k_{\alpha}}{\pi \hbar^{2}}\right)^{1 / 2}\left(j_{\ell}\left(k_{\alpha} R\right) \delta_{\alpha^{\prime} \alpha}+h_{\ell^{\prime}}^{+}\left(k_{\alpha^{\prime}} R\right) T_{\alpha^{\prime} \alpha}\right)
$$

onde $j_{\ell}(r) \rightarrow \frac{1}{z} \sin \left(r-\frac{\pi}{2} \ell\right)$ e $h_{\ell}^{+}(r) \rightarrow \frac{1}{z} e^{i\left(r-\frac{\pi}{2} \ell\right)}$ são as funções de Bessel e Hankel, respectivamente. O momento do canal é $p_{\alpha}=\hbar k_{\alpha}=\sqrt{2 \mu\left(E-E_{\alpha}\right)}$, e $E_{\alpha}=E_{a}+E_{b}$ é a energia do canal dos átomos separados. O primeiro termo da equação 2.2.3 representa a onda plana que entra no canal $\alpha$ e a segunda representa a onda espalhada no canal $\alpha^{\prime}$ caraterizado pela amplitude $T_{\alpha^{\prime} \alpha}$. Esta matriz $T$ esta relacionada à matriz unitária $S$ por

$$
\mathbb{S}(E)=\mathbb{I}+2 \mathbb{T}(E)
$$

As funções de onda espalhadas quando $R \rightarrow \infty$ são 


$$
\Psi_{a b}^{+}(E, \hat{\mathbf{k}}, \mathbf{R}) \rightarrow \sqrt{\frac{2 \mu}{\pi \hbar^{2} k_{a b}}}\left[|a b\rangle e^{i \mathbf{k}_{a b} \cdot \mathbf{R}}+\sum_{a^{\prime} b^{\prime}}\left|a^{\prime} b^{\prime}\right\rangle \sqrt{\frac{k_{a b}}{k_{a^{\prime} b^{\prime}}}} \frac{e^{i k_{a^{\prime} b^{\prime}} R}}{R} f_{a^{\prime} b^{\prime}, a b}(E, \hat{\mathbf{k}}, \hat{\mathbf{R}})\right]
$$

onde $\mathbf{k}=\hat{\mathbf{k}}_{a b} / k_{a b}$ e $\hat{\mathbf{R}}=\mathbf{R} / R$ são vetores unitários indicando a direção da onda plana inicial e das partículas espalhadas, respectivamente. A amplitude de espalhamento

$$
f_{a^{\prime} b^{\prime}, a b}(E, \hat{\mathbf{k}}, \hat{\mathbf{R}})=-\frac{4 \pi}{k_{a b}} \sum_{\ell m_{\ell}, \ell^{\prime} m_{\ell}^{\prime}} i^{\ell-\ell^{\prime}} Y_{\ell m_{\ell}}^{*}(\hat{\mathbf{k}}) Y_{\ell^{\prime} m_{\ell}^{\prime}}^{*}(\hat{\mathbf{R}}) T_{a^{\prime} b^{\prime} \ell^{\prime} m_{\ell}^{\prime}, a b \ell m_{\ell}}(E)
$$

define a saída de qualquer possível experimento de espalhamento e depende de três direções diferentes: a direção inicial de colisão $\hat{\mathbf{k}}$, a direção da partícula espalhada $\hat{\mathbf{R}}$, e os eixos de quantização para $m_{a}$ e $m_{b}$. Para colisões de átomos frios é importante conhecer a seção de choque total, onde todas as direções de $\hat{\mathbf{k}}$ são possíveis. Tirando a média de $|f|^{2}$ sobre todos os $\hat{\mathbf{k}}$ iniciais e integrando sobre todos os $\hat{\mathbf{R}}$ finais temos:

$$
\begin{aligned}
\sigma_{a^{\prime} b^{\prime}, a b}(E) & =\int_{4 \pi} \frac{d \hat{\mathbf{k}}}{4 \pi} \int_{4 \pi} d \hat{\mathbf{R}}|f(E, \hat{\mathbf{k}}, \hat{\mathbf{R}})|^{2} \\
& =\frac{4 \pi}{k_{a b}^{2}} \sum_{\ell m_{\ell} \ell^{\prime} m_{\ell}^{\prime}}\left|T_{a^{\prime} b^{\prime} \ell^{\prime} m_{\ell}^{\prime}, a b \ell m_{\ell}}(E)\right|^{2}
\end{aligned}
$$

As colisões, quando $a^{\prime}=b^{\prime}=a=b$ são colisões elásticas, ou seja, trocam momento entre as partículas. Se há um só canal de espalhamento, caraterizado por um simples potencial de interação isotrópico $V(R)$, então a matriz unitária $S$ para a onda parcial $\ell$ é expressa em termos do deslocamento de fase da colisão $\eta_{\ell}$ como $S_{\ell}=e^{2 i \eta_{\ell}}$. Para um só canal, unicamente as colisões elásticas são possíveis, com $T_{\ell}=e^{i \eta_{\ell}} \sin \left(\eta_{\ell}\right)$ e

$$
\sigma_{a a, a a}(E)=\frac{4 \pi}{k_{a a}^{2}} \sum_{\ell=0}^{\infty}(2 \ell+1) \sin ^{2}\left(\eta_{\ell}\right)
$$

Colisões nas quais $a^{\prime} \neq a$ ou $b^{\prime} \neq b$, ou ambos, são colisões inelásticas que liberam energia se $k_{a^{\prime} b^{\prime}}>k_{a b}$ e frequentemente levam a perdas e aquecimento dos átomos armadilhados. Colisões inelásticas são possíveis se há mais de um canal presente.

\subsubsection{Potenciais de Interação}

Os elementos da matriz do potencial $V_{\alpha^{\prime} \alpha}$ na equação 2.2 .2 descrevem todas as contribuições possíveis, o enlace químico entre os dois átomos, os vários spins e o momento angular no problema, suas interações mútuas e interações com campos externos. Os 


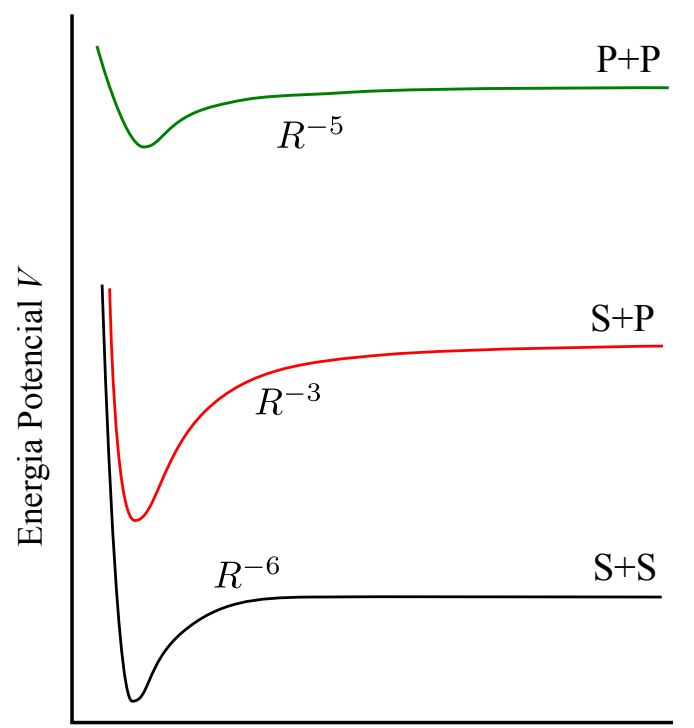

Distância Internuclear

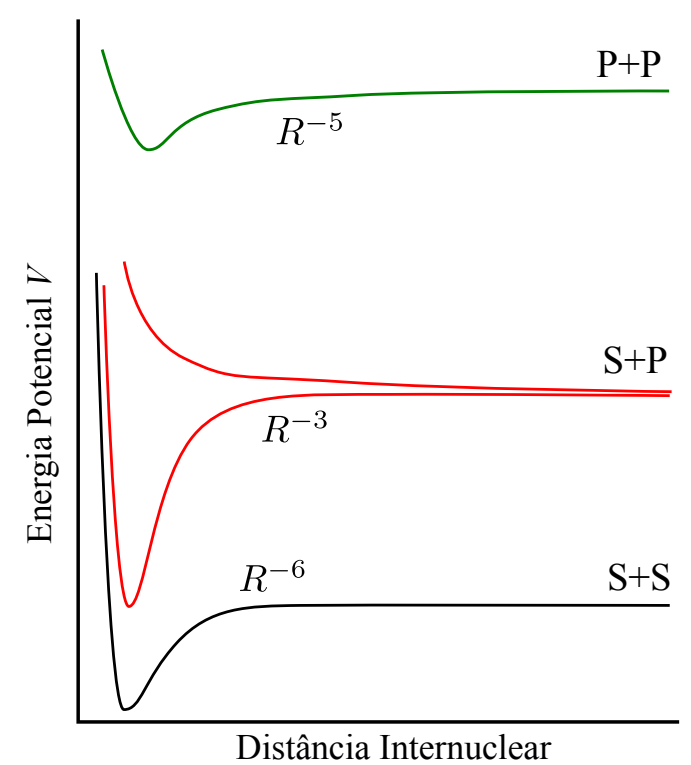

Distância Internuclear

Figura 2.2.1 - Potenciais de interação para átomos alcalinos. $\mathrm{S}+\mathrm{S}$ denota o estado fundamental molecular, $\mathrm{S}+\mathrm{P}$ o estado simplesmente excitado e $\mathrm{P}+\mathrm{P}$ o estado molecular duplamente excitado.

átomos alcalinos tem estados fundamentais com $\operatorname{spin} S_{a}=1 / 2$ do seu único elétron ativo e tem momento angular orbital $L_{\alpha}=0$. A interação de dois destes átomos dá lugar à aparição de duas curvas de energias potenciais adiabáticas moleculares $V_{S}(r)$ com spin eletrônico total $S=0$ ou 1 , tendo as simetrias moleculares denotadas como ${ }^{1} \Sigma_{g}^{+}$e ${ }^{3} \Sigma_{u}^{+}$, respectivamente. Estes estados tem idênticas interações de van der Waals de longo alcance variando como $-C_{6} / R^{6}$, contudo estão separados pela forte interação química de troca para pequenos valores de $R$. A interação de troca só acopla estados que tem os mesmos números quânticos $m$ e $\ell$. Assim, a simetria da matriz potencial de interação $\mathbb{V}$ e da matriz $\mathbb{T}$ para o átomo alcalino no estado espalhado fundamental é muito útil, e é classificada por $m$ e $\ell$. Os potenciais de interação vão definir qualquer possível movimento ou transição dos átomos em presença de campos externos dependendo de como estes se acoplam com os estados ligados que existem nos potenciais.

\subsubsection{Ressonâncias no espalhamento}

Existem duas classes de ressonâncias:

- Ressonâncias da forma, que são devido à forma do potencial. São ressonâncias devido ao acoplamento de um estado do continuo com um estado ligado que existe no potencial.

- Ressonâncias de Feshbach, que é uma ressonância multicanal devido à interação de dois ou mais estados. Seja $E_{n}>E_{\alpha}$ a energia de um estado quase ligado que está 
no enésimo estado ligado de um canal fechado $\beta$ com potencial sendo $V_{\beta \beta}(R)$. Um canal fechado é aquele onde $E_{\beta}>E$.

A interação de um canal fechado $\beta$ com um canal espalhado aberto $\alpha$ faz com que o estado quase ligado decaia para o canal $\alpha$ com uma largura de decaimento

$$
\Gamma_{n \alpha}=2 \pi\left|\left\langle\phi_{\beta}(n)\left|V_{\beta \alpha}\right| \phi_{\alpha}\left(E=E_{n}\right)\right\rangle\right|^{2}
$$

onde $V_{\beta \alpha}(R)$ é o termo de canal acoplado na matriz do potencial de interação. A função de onda do estado ligado está normalizada, $\left\langle\phi_{\beta}(n) \mid \phi_{\beta}(n)\right\rangle=1$, e a função de onda do estado espalhado $\phi_{\alpha}$ avaliada em $E=E_{n}$ está normalizada na energia $\left\langle\phi_{\alpha}(E) \mid \phi_{\alpha}\left(E^{\prime}\right)\right\rangle=$ $\delta\left(E-E^{\prime}\right)$. Devido que o sistema em ressonância pode decair para vários canais, assumimos que o canal de entrada é $\alpha$ e os canais de saída inelásticos são denotados com $\alpha^{\prime}$. Assim, a seção de choque que mede a ressonância entre os canais $\alpha$ e $\alpha^{\prime}$ é

$$
\sigma_{\alpha^{\prime} \alpha}=\frac{\pi}{k_{\alpha}^{2}} \frac{\Gamma_{n \alpha^{\prime}} \Gamma_{n \alpha}}{\left(E-\Delta_{n \alpha}\right)^{2}+\frac{1}{4} \Gamma_{n}^{2}}
$$

onde $\Gamma_{n}=\sum_{i} \Gamma_{n i}$ é largura de ressonância total somada sobre todos os canais $i=\alpha$ e $\alpha^{\prime}$. A dessintonia $\Delta_{n \alpha}=E_{n}-E_{\alpha}-s_{n \alpha}$ na energia limiar da ressonância pode incluir um termo de deslocamento ressonante devido à interação. Esta expressão geral se aplica para qualquer tipo de onda parcial.

\subsection{Colisões em uma armadilha magneto óptica na presença de um feixe laser}

Se levarmos em conta que o comprimento de onda de de Broglie $a_{\lambda}$ e o comprimento de espalhamento $a_{\alpha}$ são pequenos, comparados com as dimensões de uma armadilha, $a_{t}$, as colisões podem ser descritas pelos tratamentos dados anteriormente usando as condições de fronteira de ondas planas no espaço livre das equações 2.2.3 e 2.2.5.

Os primeiros trabalhos em colisões frias de átomos neutros foram direcionados para estudos de fotoassociação. Neste tipo de estudo, tratamos com um laser de frequência $\omega_{L}$, com o qual se induz diferentes tipos de processos de colisão na armadilha. Um átomo no primeiro estado excitado do potencial molecular irá interagir com um átomo no estado fundamental molecular na armadilha, mediante uma interação dipolo-dipolo de longo alcance $C_{3} / R_{3}$, onde dependendo do sinal do coeficiente $C_{3}$ podemos ter uma parte atrativa ou repulsiva. O coeficiente $C_{3}$ é, além disso, proporcional ao quadrado da transição atômica do momento dipolar, $d_{A}^{2}$. Comparado ao potencial do estado fundamental quase-molecular, do tipo de Van der Waals, este potencial é de longo alcance e pode ser excitado a grandes 
distâncias $R$. Assim, o potencial $C_{3} / R^{3}$ é da ordem da largura de linha natural da emissão atômica espontânea $\gamma_{A}$, quando $R$ é da ordem de $1 / \omega_{L}$. Se o laser $\omega_{L}$ é sintonizado para o vermelho da transição de aprisionamento - $3 S_{1 / 2}(F=2) \rightarrow 3 P_{3 / 2}\left(F^{\prime}=3\right)$ no caso do sódio - se consegue excitar estados do potencial molecular atrativo do par atômico e se permite assim a realização da espectroscopia de fotoassociação. Por outro lado, se $\omega_{L}$ é sintonizado ao azul da transição se consegue excitar estados moleculares repulsivos o qual dá lugar à chamada blindagem óptica (optical shielding em inglês). Se excitarmos muito perto da ressonância da transição de aprisionamento, excitaremos o par de átomos que estão muito afastados, de forma que eles podem decair por emissão espontânea antes da colisão ser completada.

Para os estudos destes processos, muitos modelos teóricos semiclássicos e quânticos tem sido desenvolvidos, assim como rigorosos tratamentos exatos (16, 19 23, 28 30). É comum o uso do modelo de campo quase-molecular, o qual inclui os estados do campo de radiação na descrição da colisão (28, 29, 31).

A principal modificação das equações acopladas 2.2 .2 é a inclusão da energia do fóton do campo de radiação no potencial e incluir o acoplamento óptico entre os estados: o potencial do estado excitado $V_{\beta \beta}(R)$ é substituído por $V_{\beta \beta}(R)-\hbar \omega$, onde $\hbar \omega$ é a energia do fóton que conecta o canal do estado fundamental $\alpha$ com potencial $V_{\alpha \alpha}(R)$ ao canal do estado excitado $\beta$. Assim os potenciais são $V_{\alpha \alpha}(R)$ e $V_{\beta \beta}(R)-\hbar \omega$. Os elementos de matriz entre os canais do campo molecular são dados por

$$
V_{\alpha \beta}(R)=\langle\beta|\mathbf{E} \cdot \mathbf{d}| \alpha\rangle=\sqrt{\frac{2 \pi I}{c}} d_{\alpha \beta}(R),
$$

onde $\mathbf{E}$ é campo elétrico, $I$ a intensidade do laser, $\mathbf{d}$ o operador dipolar, e $d_{\alpha \beta}(R)$ o elemento de matriz de transição molecular dipolar. Assim podemos ver o fóton como ressonante no ponto $R_{C}$, conhecido como ponto de Condon da transição, no qual as curvas dos potenciais se cruzam: $V_{\beta \beta}\left(R_{C}\right)-V_{\alpha \alpha}\left(R_{C}\right)=\hbar \omega$. Um ponto de Condon qualquer pode ser selecionado sintonizando adequadamente a frequência do laser $\omega_{L}$. A grandes distâncias $R$ se está muito perto dos pontos de retorno do movimento clássico no estado excitado do potencial. Em teorias semiclássicas a transição é considerada acontecendo em $R_{C}$. Em teorias quânticas a transição é não localizada, mas frequentemente é aproximada pelo modelo de Landau-Zener no cruzamento de curvas em $R_{C}$ (32).

\subsubsection{Espectroscopia de Fotoassociação}

Thorsheim e seus colaboradores propuseram a realização de uma espectroscopia de fotoassociação de alta resolução na época que a realização de armadilhas de átomos ainda 
era um tópico pouco explorado (1). Embora esta seja uma espectroscopia de estados livre-ligado pela qual um nível vibracional molecular de um canal $\beta$ de um estado molecular excitado de um dímero é formado pela excitação óptica de dois átomos nos seus estados fundamentais colidindo, a resolução é comparável ou superior a muitas das técnicas comuns de espectroscopia de estados ligados devido à estreita largura de energia $k_{B} T$ na distribuição térmica dos átomos no estado fundamental. O fenômeno de fotoassociação é bem descrito com tratamento de espalhamento ressonante (19, 29), onde o nível ligado molecular é uma ressonância de Feshbach opticamente acoplada. Este fenômeno será descrito mais em detalhe posteriormente.

\subsubsection{Blindagem Óptica}

A blindagem óptica acontece quando os átomos no MOT são exitadas por uma luz sintonizada para o azul da transição atômica, diferentemente dos processos espectroscópicos de fotoassociação, deste modo se excita um estado molecular repulsivo. Se a luz é suficientemente intensa, tal que cumpra a condição de adiabaticidade de Landau-Zener $A=2 \pi\left|V_{\beta \alpha}\left(R_{C}\right)\right|^{2} /\left(\hbar v_{C} d_{C}\right) \gg 1$ (32) , o movimento será adiabático no conjunto de potenciais diagonalizados. Aqui $v_{C}$ e $d_{C}$ são a velocidade e a diferença da inclinação nos potenciais no ponto de Condon, respectivamente. No limite adiabático, os átomos se aproximando no estado fundamental experimentarão uma força repulsiva perto do ponto de Condon quando eles se movem no potencial adiabático, e viram ao redor, tal que eles nunca penetram dentro de $R_{C}$. Já que $R_{C}$ pode ser bastante grande, os átomos serão blindados dos eventos de colisões inelásticas devido às interações acontecendo na região $R \ll R_{C}$. Aqui teremos uma pequena probabilidade, $e^{-A}$ no modelo de Landau-Zener, de passar a região de cruzamento e alcançar a região $R \ll R_{C}$. Já que se pode incrementar a intensidade do laser até $A$, deveria ser possível reduzir esta probabilidade de penetração e alcançar um alto grau de blindagem.

Infelizmente a blindagem não é tão efetiva como podia se esperar. A probabilidade de penetração satura com o incremento da intensidade do laser no lugar de um forte decaimento. A razão da saturação está relacionada com a existência de outras rotas existentes através da região onde há um cruzamento nas curvas para colisões tridimensionais. Uma rota é um caminho semiclássico nos potenciais por onde o par atômico se movimenta. Ambos teoria e experimento mostram que a blindagem é muito sensível à polarização da luz blindadora. A referência (33) dá uma formulação das equações acopladas 2.2 .2 para colisões frias em um campo de luz que prediz efeitos de saturação e polarização. A figura 2.3.1 mostra um gráfico de blindagem óptica tipica. 


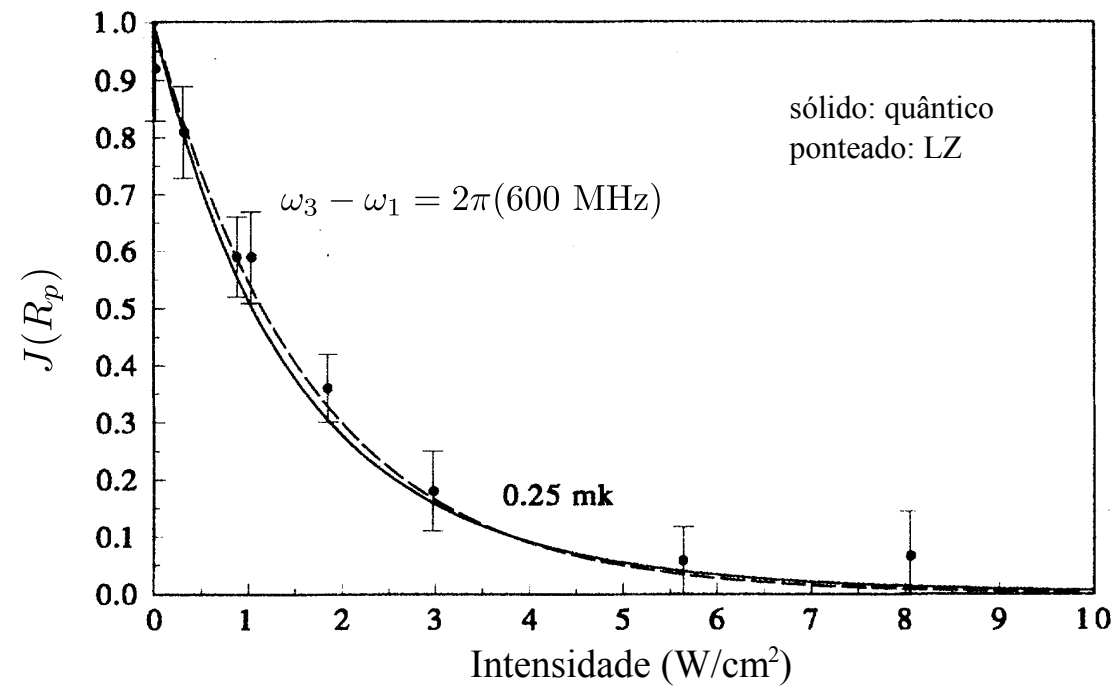

Figura 2.3.1 - Curva que mostra a blindagem óptica medida para moléculas $\mathrm{Na}_{2}$ (6). 


\section{Capítulo 3}

\section{A idéia das moléculas fotônicas de sódio e o uso da PAI para testes}

Uma molécula fotônica de sódio pode ser descrita como uma molécula fria não convencional produzida pela associação de dois átomos de sódio em uma armadilha magnetoóptica (MOT) na presença de campos laser intensos com dessintonias para o vermelho e azul da transição de ressonância. A fotoionização associativa (PAI, pela siglas em inglês de photoassociative ionization) tem sido um dos processos mais comuns para criar e detectar estados moleculares formados na presença de luz. A PAI pode envolver um ou dois fótons na formação dos estados moleculares e sua posterior ionização. A molécula fotônica tem como um passo prévio à sua formação um processo de PAI por dois fótons. Portanto será importante uma compreensão deste processo para uma adequada interpretação e análise da modificação dos potenciais os quais vão dar indícios da formação dos novos estados moleculares da molécula fotônica. De Paiva (34) tem feito os cálculos teóricos para determinar as frequências e intensidades dos campos de luz para os quais a molécula fotônica é produzida e detectada. Sendo fundamental conhecer os processos de átomos colidindo na presença de campos de luz, vamos discutir alguns casos que envolvem a presença de um e dois fótons.

\subsection{Fotoionização associativa por um só fóton}

Também conhecido como fotoionização associativa por uma só cor, envolve um processo de dois fótons com a mesma frequência, por este fato chama-se de PAI por uma só fóton. Se temos um laser com uma dessintonia para o vermelho da transição de ressonância atômica (chamado de laser de prova com uma frequência $\omega_{L}$ ), que pode ser varrido regularmente em um intervalo de frequências, incidindo em um MOT, vamos produzir moléculas fotoassociadas. Dependendo da frequência deste laser podemos excitar estados vibracionais do estado molecular simplesmente excitado desde o estado molecular funda- 


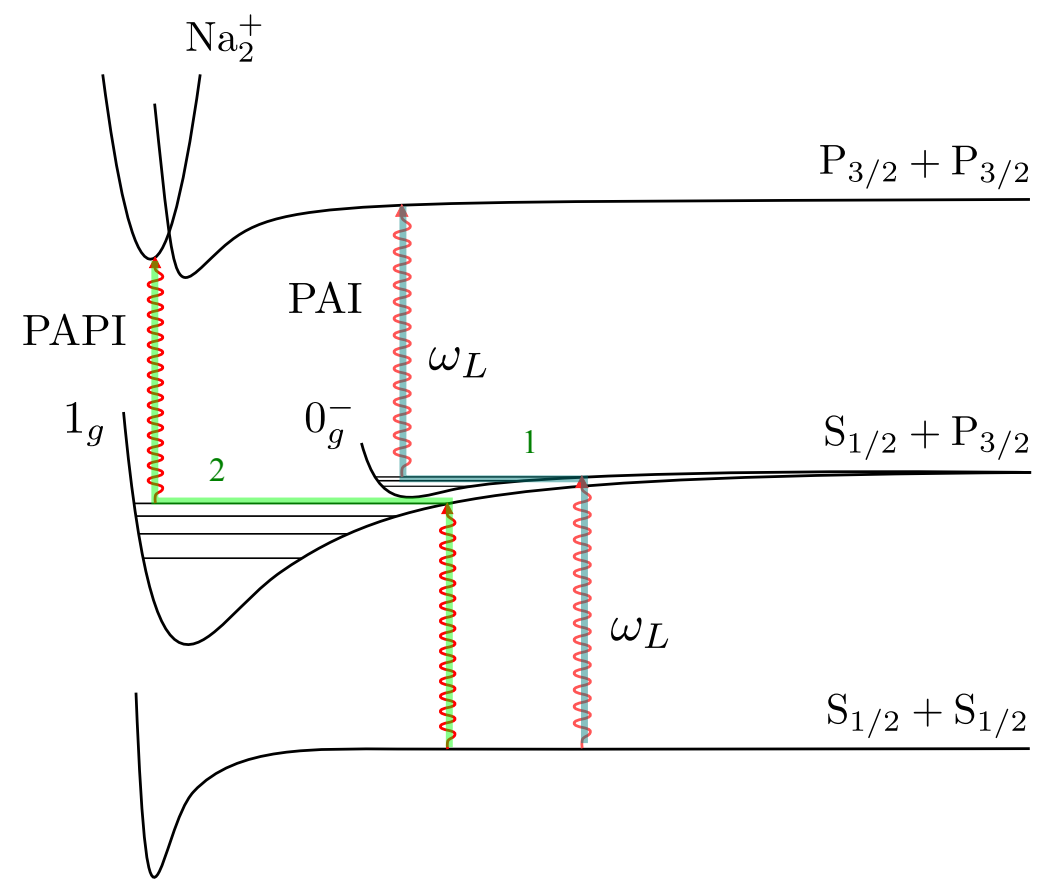

Figura 3.1.1 - Processo de dois passos para fotoionização por uma só cor. $\omega_{L}$ indica a frequência do laser que faz o processo de fotoassociação e que está presente nos dois passos.

mental. Chamamos este passo de primeiro passo de excitação, ou de associação. Um segundo passo acontece pelo fato da diferença de energias entre estados vibracionais do estado molecular simplesmente excitado e o estado molecular duplamente excitado ser ressonante com a energia do laser vermelho, responsável também pelo primeiro passo. Assim temos um processo de dois passos que pode ser monitorado mediante um decaimento na fluorescência, já que temos perdas de átomos na armadilha, ou mediante a contagem de íons como é comumente feito no caso do sódio. A Figura 3.1.1 esquematiza este processo.

O processo para átomos de sódio é sempre o mesmo no primeiro passo; aqui se fotoassociam dois átomos colidentes em um estado molecular ligado excitado pela absorção do fóton $\omega_{L}$. No segundo passo dois processos podem acontecer: pode acontecer fotoionização fotoassociativa (PAPI) a pequenas distâncias internucleares, na qual o fóton leva diretamente os átomos desde o estado molecular simplesmente excitado até o estado autoionizante; ou uma promoção para o estado molecular duplamente excitado que autoioniza a curtas distâncias internucleares, conhecida como PAI. Foi demonstrado que o segundo processo é dominante para excitações de longo alcance (35).

Um espectro de contagem de íons típico de fotoionização associativa por um só fóton para átomos de sódio nos primeiros $10 \mathrm{GHz}$ é mostrado na Figura 3.1.2. As estruturas ressonantes observadas no sinal de íons indicam a população de cada estado vibracional quando a frequência $\omega_{L}$ é varrida. As separações entre os picos dão informação sobre a separação energética entre os estados vibracionais do estado molecular simplesmente excitado. É importante levar em conta que as diversas estruturas não correspondem à 


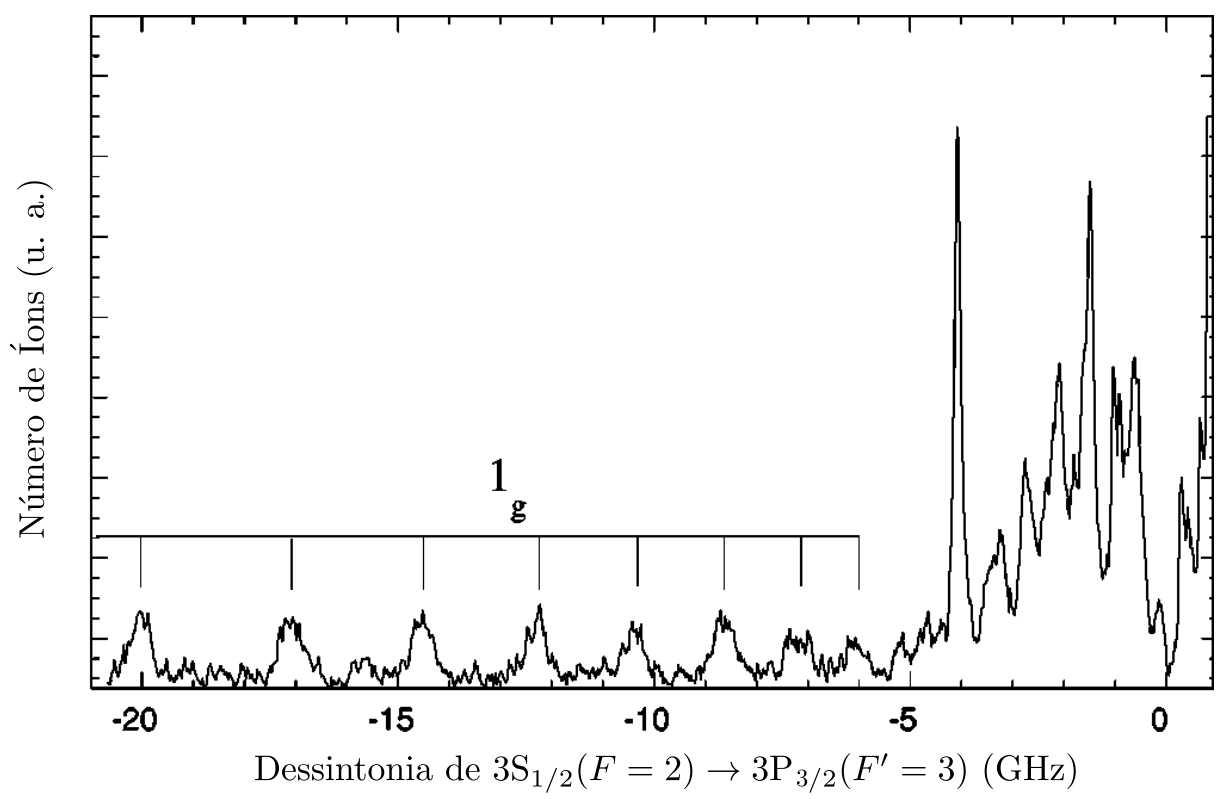

Figura 3.1.2 - Espectro típico de fotoionização associativa por um só fóton. Tomado da referencia (35).

presença de um só estado intermediário, mas sim a uma mistura destes, sendo que só alguns destes estados moleculares são puramente de longo alcance. A identificação dos picos com os correspondentes estados vibracionais se faz mais complicada pela presença de efeitos devidos à estrutura hiperfina.

Contudo, os estudos de fotoassociação com um só fóton tem a limitação que a probabilidade de acontecimento do segundo passo é muito pequena, visto que as ressonâncias entre os estados vibracionais dos potenciais moleculares simplesmente e duplamente excitados nem sempre correspondem à energia do fóton $\omega_{L}$.

\subsection{Fotoionização associativa por dois fótons}

Devido às limitações na fotoassociação por um só fóton, e para melhorar a resolução no sinal de espectroscopia de fotoassociação, uma modificação na técnica de fotoassociação foi proposta. Se adiciona um segundo fóton com uma energia maior que a diferença de energias entre as assíntotas dos estados moleculares fundamental e simplesmente excitado, ou dito de outra forma, o novo fóton tem uma dessintonia para o azul da frequência de ressonância da transição. Com a adição deste novo fóton se tem maior acesso aos estados do potencial molecular duplamente excitado, portanto a probabilidade do processo de ionização acontecer é aumentada, assim como também a aparição de novas estruturas que não são de acesso com um só fóton. A figura 3.2.1 esquematiza este processo.

O processo pode ser descrito como segue: dois átomos colidentes absorvem um fóton 


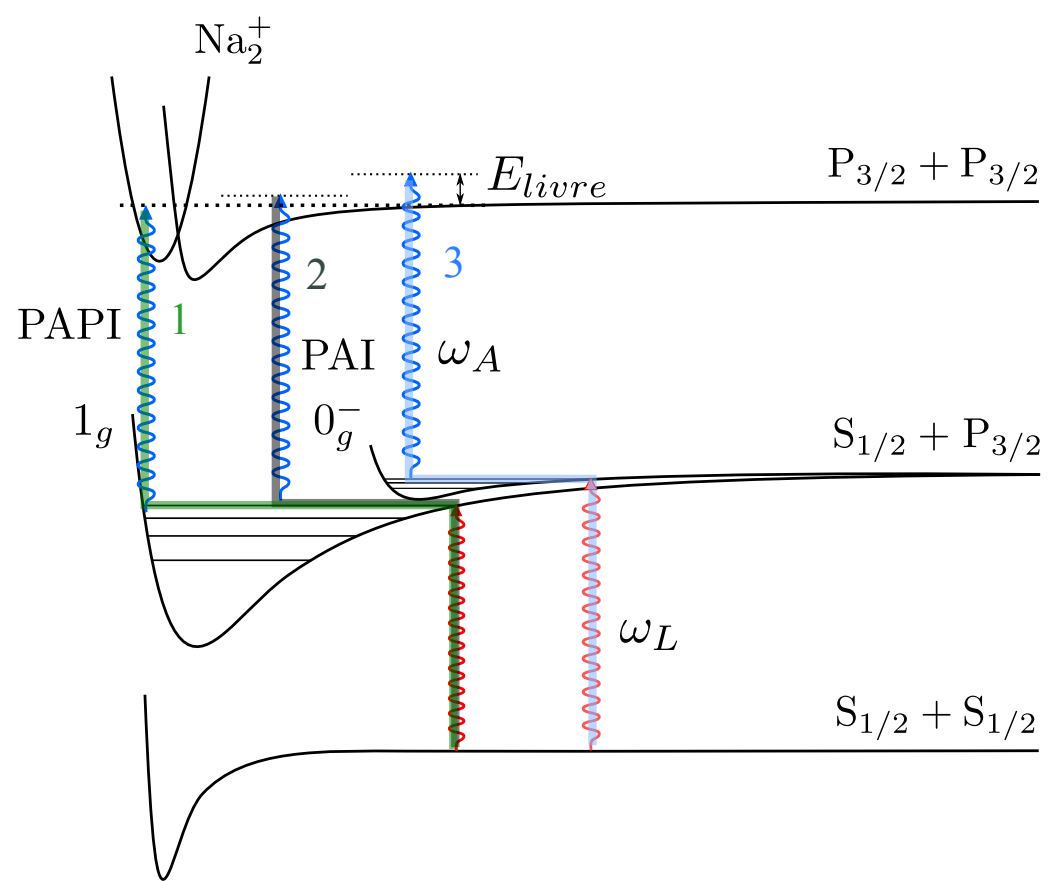

Figura 3.2.1 - Processo de dois passos para fotoionização associativa por dois fótons. Inicialmente o laser de prova de frequência $\omega_{L}$ leva o par atômico para um estado atrativo intermediário, ai este pode ser levado para o estado duplamente excitado por um fóton azul de frequência $\omega_{A}$ longas distancia interatômicas e sobreviver até cruzar com o estado ionizante (PAI); ou o par atômico pode ser excitado pelo fóton $\omega_{L}$ para o estado intermediário e ser ionizado diretamente a curtas distancias interatômicas (PAPI). Um processo onde o fóton $\omega_{A}$ leva o par atômico para o estado duplamente excitado a curtas distancias interatômicas pode também acontecer. 
vermelho para o vermelho da transição (o fóton de prova) de frequência $\omega_{L}$ para produzir uma molécula no estado eletrônico simplesmente excitado, que pode ser diretamente fotoionizado (PAPI) a pequenas distâncias internucleares ou promovida para um estado ionizante duplamente excitado pela absorção do segundo fóton $\omega_{A}$ (PAI). O laser vermelho é varrido para ter acesso aos estados que apareçam no intervalo de energias que correspondem à varredura; enquanto a frequência do laser azul permanece fixa. De forma geral, as dessintonias dos lasers azul $\Delta_{A}$ e de prova $\Delta_{L}$ com respeito à frequência de ressonância, devem cumprir a relação $\left|\Delta_{A}\right|>\left|\Delta_{L}\right|$.

\subsection{O estado repulsivo}

Quando adicionamos o fóton azul com frequência $\omega_{A}$, a energia deste pode ser ressonante com um estado molecular repulsivo, o que origina novas rotas no processo. O principal fenômeno que acontece é que os átomos são excitados pelo fóton azul e são levados para um estado molecular repulsivo onde não se formam estados ligados. Assim, o par atômico poderá se aproximar mais um pouco ainda até um certo ponto no potencial, a partir do qual eles serão repelidos. A Figura 3.3.1 mostra este processo acontecendo e ainda outro no qual se tem dois lasers azuis excitando o potencial repulsivo. Este laser adicional é que faz o processo de blindagem óptica, permitindo ao par atômico voltar para o estado molecular fundamental, e assim evita que o par atômico se aproxime até pequenas distâncias internucleares, onde acontecem as colisões inelásticas. Deste modo se suprimem as colisões inelásticas, e se "blinda" o sistema para não ter este tipo de fenômeno. O potencial repulsivo não só cria processos de supressão das colisões inelásticas e permite a aparição de novas rotas para os átomos, mas também sofre modificações quando campos intensos são aplicados. A modificação de um potencial repulsivo causada por fótons pode se traduzir em mudanças na contagem de íons quando realizamos experimentos de fotoionização associativa por dois fótons e variamos a intensidade do laser azul.

\subsection{A molécula fotônica}

A molécula fotônica, o objetivo mais amplo do qual faz parte este trabalho, pode ser observada na figura 3.4.1, a qual mostra esquematicamente o processo. Podemos descrever o processo como segue:

- 1 - Se tem um par atômico no estado molecular simplesmente excitado (o qual pode 


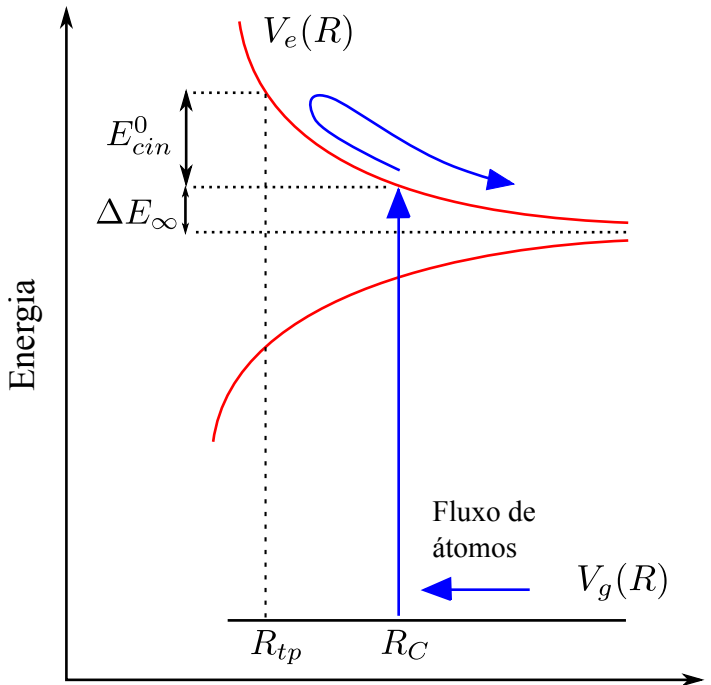

Distância

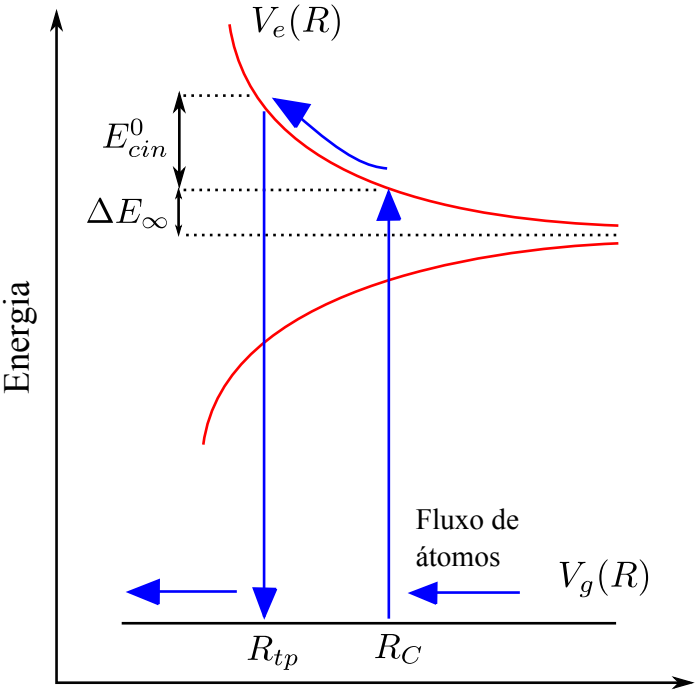

Distância

Figura 3.3.1 - Processos que acontecem pela presença do fóton azul: $V_{e}(R)$ é o potencial molecular excitado e $V_{g}(R)$ o estado molecular fundamental. $E_{\infty}=E_{D}$ é a energia de dissociação da molécula, $R_{t p}$ o ponto de retorno a partir do qual o par se repele e a separação entre eles aumenta. $E_{c i n}^{0}$ é a energia cinética efetiva adquirida pelo par de átomos colidindo, e que é usada para "subir" no potencial até a distância $R_{t p}$.

ter sido levado até ai por um fóton com uma dessintonia para o vermelho da transição atômica) se aproximando um do outro num potencial molecular simplesmente excitado atrativo.

- 2 - Um fóton com uma dessintonia para o vermelho da transição atômica (de frequência $\omega_{V}$ e que coneta o estado fundamental molecular com um estado atrativo do estado molecular simplesmente excitado num ponto de Condon $R_{V}$ ) leva o par atômico, no estado simplesmente excitado, para o estado molecular fundamental no ponto de Condon $R_{V}$.

- 3 - O par atômico estando no estado molecular fundamental se aproxima um do outro.

- 4 - A uma distância interatômica $R_{A}$, um fóton com uma dessintonia para o azul da transição atômica (de frequência $\omega_{A}$ e que coneta o estado molecular fundamental com um estado repulsivo conetado com a assintota do estado simplesmente excitado no ponto de Condon $R_{A}$ ); é leva o par atômico até o estado repulsivo (que esta conectado com a assíntota do estado simplesmente excitado).

- 5 - O par atômico irá se aproximar gastando sua energia cinética em subir o potencial repulsivo até um certo ponto, depois do qual começa se afastar passando novamente pelo ponto $R_{A}$ e será levado para o estado fundamental molecular pelo fóton azul, onde continua se separando até uma distância $R_{V}$, onde é levado agora pelo fóton 


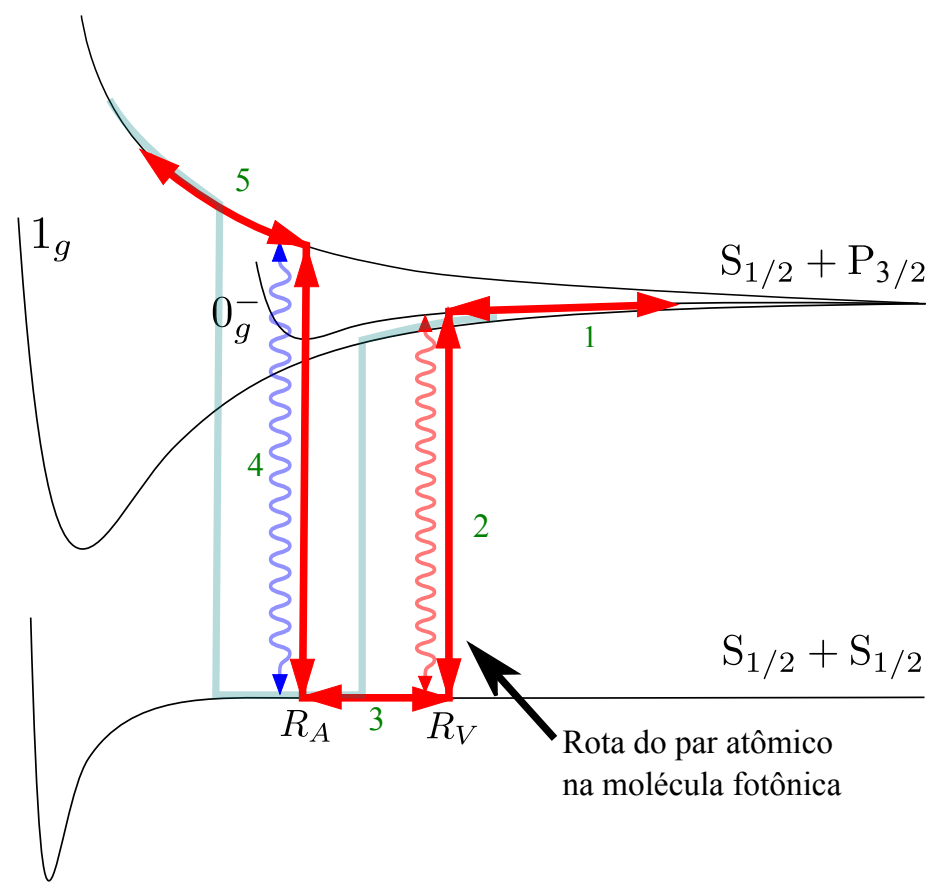

Figura 3.4.1 - Esquema da produção da molécula fotônica. O caminho seguido pelo par atômico pode ser observado.

vermelho para o estado atrativo simplesmente excitado, e ai afasta-se ainda um pouco mais. O par se separará até um certo ponto, onde poderá novamente repetir o ciclo.

Este processo se repete fazendo com que o par atômico oscile entre os potenciais fundamental e excitado. Um tratamento quântico mais em detalhe pode ser encontrado na teses de doutorado de R. R. de Paiva (34). É de se esperar que na formação de uma molécula fotônica, o espectro dela reflita a estrutura do novo potencial formado. Tanto o fóton azul, como o vermelho modificaram os potenciais moleculares envolvidos. Neste trabalho se investiga só a modificação que o laser azul induz nos potenciais. 


\section{Capítulo 4}

\section{Resfriamento e aprisionamento de átomos de sódio}

Neste capítulo descrevemos o sistema experimental utilizado na produção do MOT em nosso laboratório e o sistema de aquisição de dados, assim como os lasers que possibilitarão nossos estudos de fotoassociação. Este mesmo sistema, antes das melhorias e mudanças que serão relatadas, já foi usado, por exemplo, em experimentos de absorção cooperativa de dois fótons (36, 37), e em outros estudos ao longo de vários anos na divisão de colisões frias no Grupo de Óptica no IFSC. Em linhas gerais, o sistema é composto por um forno, duas bombas iônicas e uma bomba turbo; um desacelerador Zeeman, uma câmara para o MOT e todo o sistema óptico que tornaram possível a produção de nossa amostra de átomos frios para os estudos de fotoassociação. Como primeiro passo, esquentamos átomos no forno, que fluem até a câmara passando pelo desacelerador Zeeman, onde são freados por um feixe de desaceleração. Isto permite obter na câmara um gás de átomos de sódio com uma distribuição de velocidades adequada para serem aprisionados numa armadilha magneto-óptica mediante feixes laser e campos magnéticos. A seguir, descrevemos cada um dos elementos de importância, as novas implementações e as melhorias no nosso novo sistema de aprisionamento de átomos de sódio.

\subsection{Sistema experimental}

Para nossos estudos de fotoionização associativa, é necessário que a construção do MOT seja robusta, estável e com uma configuração em particular: que os átomos aprisionados estejam majoritariamente no estado fundamental hiperfino $F=1$. Nestes aspectos, é de suma importância a obtenção de um vácuo adequado no forno e na câmara da armadilha, assim como o controle da temperatura na qual são emitidos os átomos de sódio na saída do forno, pois isto vai determinar a distribuição de velocidades dos átomos, a temperatura na qual se possam aprisionar os átomos e o número de átomos disponíveis 
para serem aprisionados na câmara.

\subsubsection{Sistema de vácuo e produção de átomos}

Nosso sistema de vácuo é basicamente composto por uma bomba iônica, uma bomba turbo para o forno e uma bomba iônica na câmara, associadas a tubos, o que permite ter um bombeamento diferenciado entre essas duas regiões, como pode se ver também

na figura 4.3.1. É sabido que o tempo de vida da amostra na câmara é inversamente proporcional à pressão de fundo (38). No caso de nosso forno, uma pressão de $10^{-6}$ Torr é adequada para permitir que os átomos cheguem até a câmara, sendo que esta pressão é obtida pelo bombeamento de uma bomba iônica e uma bomba turbo. Já na câmara precisamos de uma pressão de $10^{-9}$ Torr, que é obtida mediante o bombeamento de uma bomba iônica. Este sistema nos permite aprisionar por volta de $5 \times 10^{9}$ átomos no MOT.

\subsubsection{Forno}

Uma das melhorias na montagem do experimento foi a implementação de um novo forno. Este forno baseia-se no forno anteriormente utilizado (36), contudo foram realizadas algumas modificações para suprir as novas necessidades e critérios para a realização do nosso experimento. A principal mudança está na implementação de novas resistências de alta temperatura e um sistema de aquecimento automatizado. A figura 4.1.1 mostra um esquema do novo forno. Basicamente, este forno permite um aquecimento mais rápido dos átomos de sódio, de modo que estes possam adquirir a distribuição de velocidades adequada com uma velocidade média de aproximadamente $850 \mathrm{~m} / \mathrm{s}$. O forno é constituído de três partes bem diferenciadas: o recipiente da amostra, o pescoço e o nozzle. O recipiente é aquecido aproximadamente a uma temperatura de $260{ }^{\circ} \mathrm{C}$, o pescoço em torno de $300{ }^{\circ} \mathrm{C}$ e o nozzle por volta de $360{ }^{\circ} \mathrm{C}$. Isto faz possível um aquecimento diferenciado, que somado ao bombeamento diferenciado da pressão no forno, permite se obter um fluxo de átomos com a distribuição de velocidades desejada. No recipiente, uma ampola com átomos de sódio em estado sólido é colocada para ser aquecida. O vapor produzido é ejetado na abertura circular da saída do forno, que conhecemos como nozzle. Uma janela perto do nozzle permite observar a fluorescência dos átomos em forma de um feixe brilhante, quando o feixe de desaceleração é adequadamente incidido nele. Um feixe com fluorescência intensa vai nos indicar, de um modo qualitativo, o quão boa é nossa distribuição de átomos saindo do forno. 


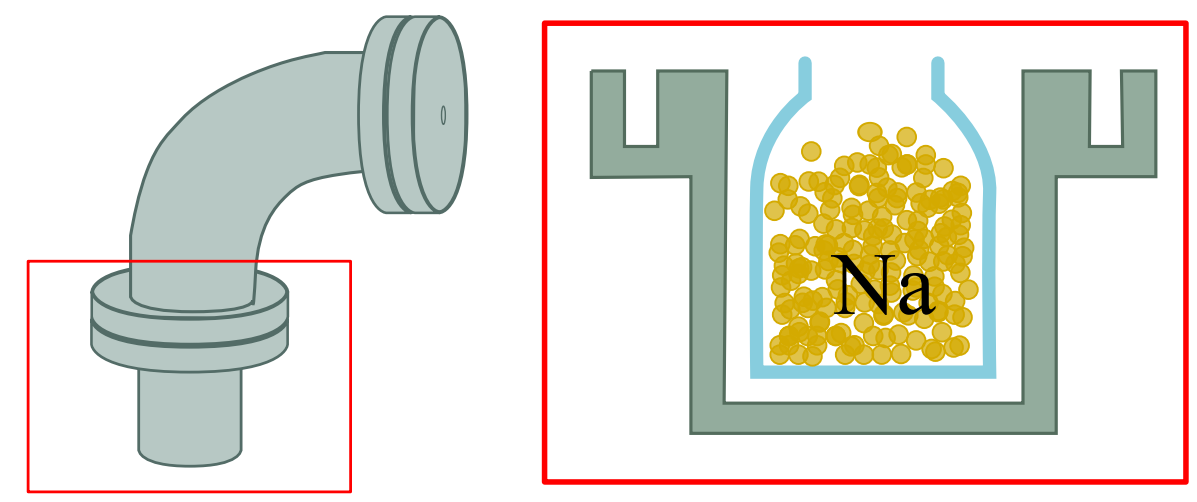

Figura 4.1.1 - Desenho do novo forno implementado. Para um melhor aquecimento resistências de alta temperatura foram usadas.

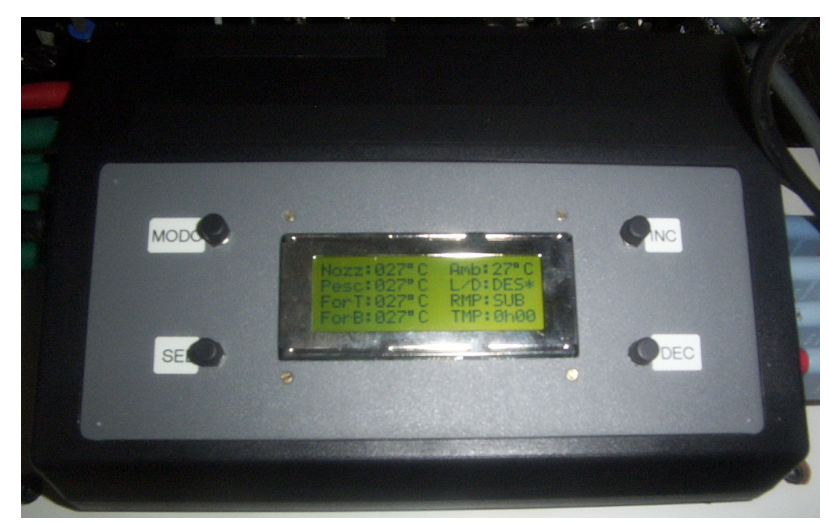

Figura 4.1.2 - Foto do dispositivo que permite o aquecimento automatizado e o monitoramento em tempo real das temperaturas para os átomos de sódio.

O sistema que permite o controle do aquecimento dos átomos substitui o aquecimento manual de cada parte do forno e permite a compactação e automatização num dispositivo eletrônico que é regulado dependendo das nossas necessidades experimentais. Além disto oferece um aquecimento mais homogêneo, rápido e seguro. O dispositivo usado foi desenvolvido e construído pelo Laboratório de Instrumentação Eletrônica (LIEPO) do Grupo de Óptica, e pode ser observado na figura 4.1.2.

\subsubsection{Câmara para o MOT}

Para ter acesso aos átomos de sódio na câmara, é necessário que a mesma tenha muitas janelas que permitam a passagem dos feixes que vão aprisionar os átomos, assim como os feixes de excitação e os sistemas de detecção normalmente usados para caracterizar o MOT. Para isso, temos uma câmara de aço inox com 16 janelas laterais e 2 verticais especialmente recobertas para a frequência dos lasers a serem usados. A câmara está conectada em uma janela com o desacelerador Zeeman, por outra janela com as bombas turbo e iônica, e por outra no contador de íons, o que deixa acesso às 15 janelas restantes. 
As duas janelas verticais e 4 laterais são usadas para a passagem dos feixes de aprisionamento. Duas janelas são usadas para a passagem contrapropagante do feixe de rebombeio. Uma delas, o outro extremo da janela conetada ao desacelerador Zeeman é usada para a passagem do feixe de desaceleração. Uma janela mais é usada para a passagem dos feixes que vão fazer fotoassociação, duas para os sistemas de detecção e uma para o sistema de imagem.

\subsubsection{Campos magnéticos}

Em um MOT convencional, são normalmente utilizados campos magnéticos em diferentes configurações espaciais. Isto devido ao fato dos átomos serem sensíveis à mudanças de intensidade de fluxos magnéticos, dependendo de sua estrutura particular. No caso dos átomos de sódio, o uso de um desacelerador Zeeman para a obtenção de átomos na câmara é amplamente usado por permitir a obtenção de uma quantidade maior de átomos na armadilha, e este também é nosso caso. Já na câmara, é necessário um gradiente de campo com uma variação particular, o que vai permitir, juntamente com os feixes laser, o aprisionamento dos átomos. Adicionalmente é conveniente o uso de bobinas de compensação na parte externa da câmara que permitam manipular a posição de nossa amostra.

\subsubsection{Desacelerador Zeeman}

Para diminuir a velocidade do feixe de átomos quentes saindo do forno, usamos a técnica de desaceleração compensada Zeeman. Proposta inicialmente por W. Phillips em meados da década de 80 (8), faz uso do efeito Zeeman para desacelerar os átomos. Os átomos saindo do forno são desacelerados por um feixe monocromático contrapropagante ao feixe atômico. O processo de desaceleração só é eficiente quando os átomos interagem com o feixe de desaceleração de forma ressonante à transição atômica ao longo de todo o caminho até a câmara.

A condição de ressonância se dá quando o deslocamento Doppler $\omega_{D}(z)=k \cdot v_{z}(z)$, que muda ao longo de todo o caminho de desaceleração, é compensado pelo efeito Zeeman. Esta técnica utiliza um solenóide com uma configuração particular, de tal forma que se gera um campo magnético inomogêneo ao longo do caminho de desaceleração. Os átomos que estão em ressonância com o feixe laser de desaceleração contrapropagante tem um deslocamento nas suas frequências de transição como resultado do efeito Zeeman. O deslocamento na transição atômica de resfriamento $F=2 \rightarrow F=3^{\prime}$ na presença de um 


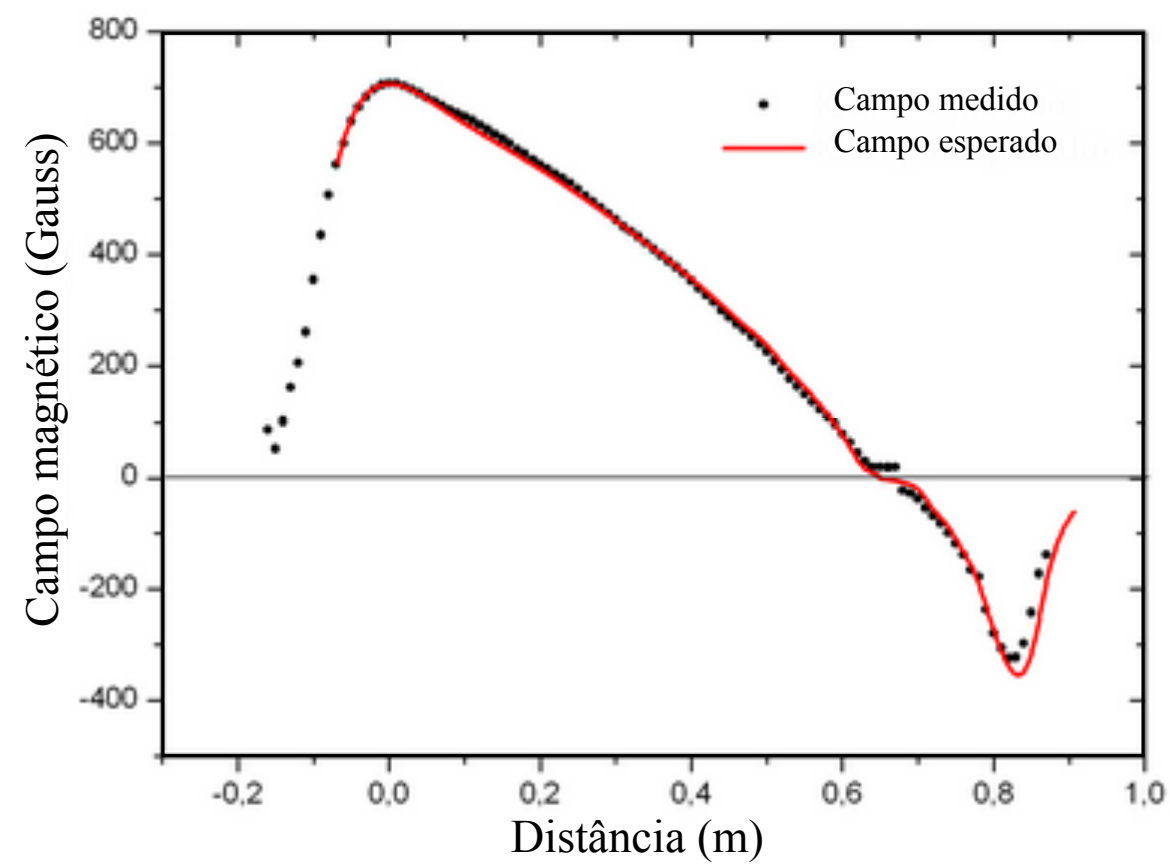

Figura 4.1.3 - Perfil do campo do desacelerador Zeeman usado em nosso experimento.

campo magnético é dado por

$$
\hbar \omega_{Z}(z)=\mu_{B} B(Z)
$$

sendo $\mu_{B}$ o magneton de Bohr. No caso do sódio temos que $\mu_{B} / \hbar=1.4 \mathrm{MHz} /$ Gauss. Nosso desacelerador Zeeman foi construído segundo o modelo proposto e desenvolvido por Naik (39) que é um desacelerador em configuração spin flip. O solenóide que produz o deslocamento Zeeman espacialmente dependente tem um comprimento total de aproximadamente $1 \mathrm{~m}$, com uma corrente circulando nele de aproximadamente $20 \mathrm{~A}$, gerando um campo total por volta de 706 Gauss. O desacelerador spin flip é constituído pela combinação em série de desaceleradores de campo decrescente e um desacelerador de campo crescente. Inicialmente, um campo decrescente serve para desacelerar os átomos. Posteriormente, os átomos entram numa região de campo crescente, onde são finalmente desacelerados. O campo crescente é menor em magnitude que o campo magnético decrescente. Com isto se consegue que o último trecho de desaceleração seja mais rápido. O campo gerado pelo desacelerador Zeeman usado no nosso experimento é mostrado na figura 4.1 .3 .

\subsubsection{Bobinas de aprisionamento magnético-óptico}

Duas bobinas circulares, dispostas em configuração anti-Helmhotz são necessárias para a criação de um campo magnético confinante no centro da câmara. Estas bobinas são conhecidas também como bobinas quadripolares devido à configuração espacial de campo 

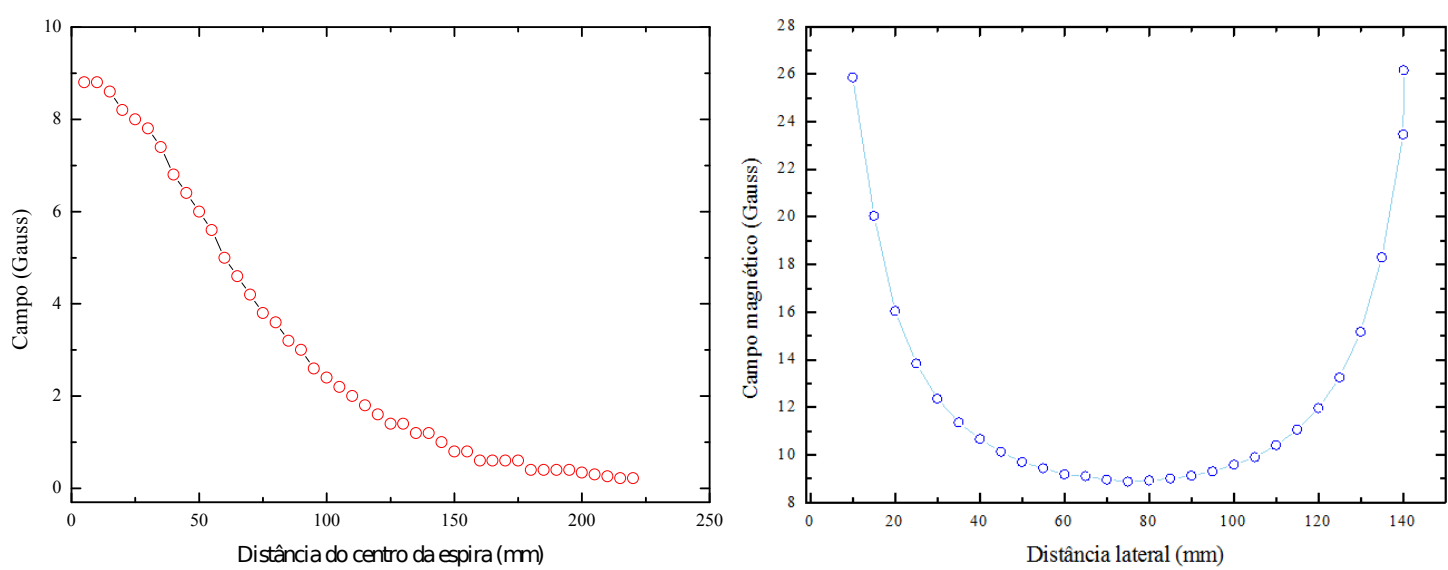

Figura 4.1.4 - Perfil de campo magnético de uma das bobinas de compensação para a câmara de aprisionamento.

magnético que geram. As bobinas são colocadas na parte exterior da câmara com o eixo central das bobinas coincidindo com os eixos $\pm z$ em cada caso. Desta forma se espera que o campo magnético no centro da câmara seja nulo e cresça linearmente conforme se afasta do centro da câmara. Adicionalmente, este campo cria um potencial atrativo para estados atômicos que tenham um $m_{F}>0$, e repulsivo para estados atômicos com $m_{F}<0$, tornando o aprisionamento dos átomos viável.

\subsubsection{Bobinas de compensação}

Uma das implementações deste novo sistema foram as bobinas de compensação. Dois pares de bobinas quadradas em configuração Helmholtz são colocadas no exterior da câmara, nos eixos $\pm x$ e $\pm y$. Um par de bobinas circulares é colocado exteriormente à câmara no eixo $\pm z$. O campo linear produzido por estas bobinas permite ter controle da posição do MOT controlando através da corrente que passa pelas bobinas. O perfil de campo magnético unidimensional das bobinas é apresentado na figura 4.1.4. Este conjunto de bobinas compensa os efeitos de campos magnéticos de fundo no experimento.

\subsection{Sistema de Resfriamento Laser}

A desaceleração e aprisionamento de átomos de sódio envolvem a utilização de várias frequências laser. Estas são obtidas mediante a utilização de moduladores acusto-ópticos (AOM, pelas siglas em inglês de acousto-optics modulator) e moduladores eletro-ópticos (EOM, pelas siglas em inglês de electro-optics modulator). A figura 4.2.1 é um diagrama 


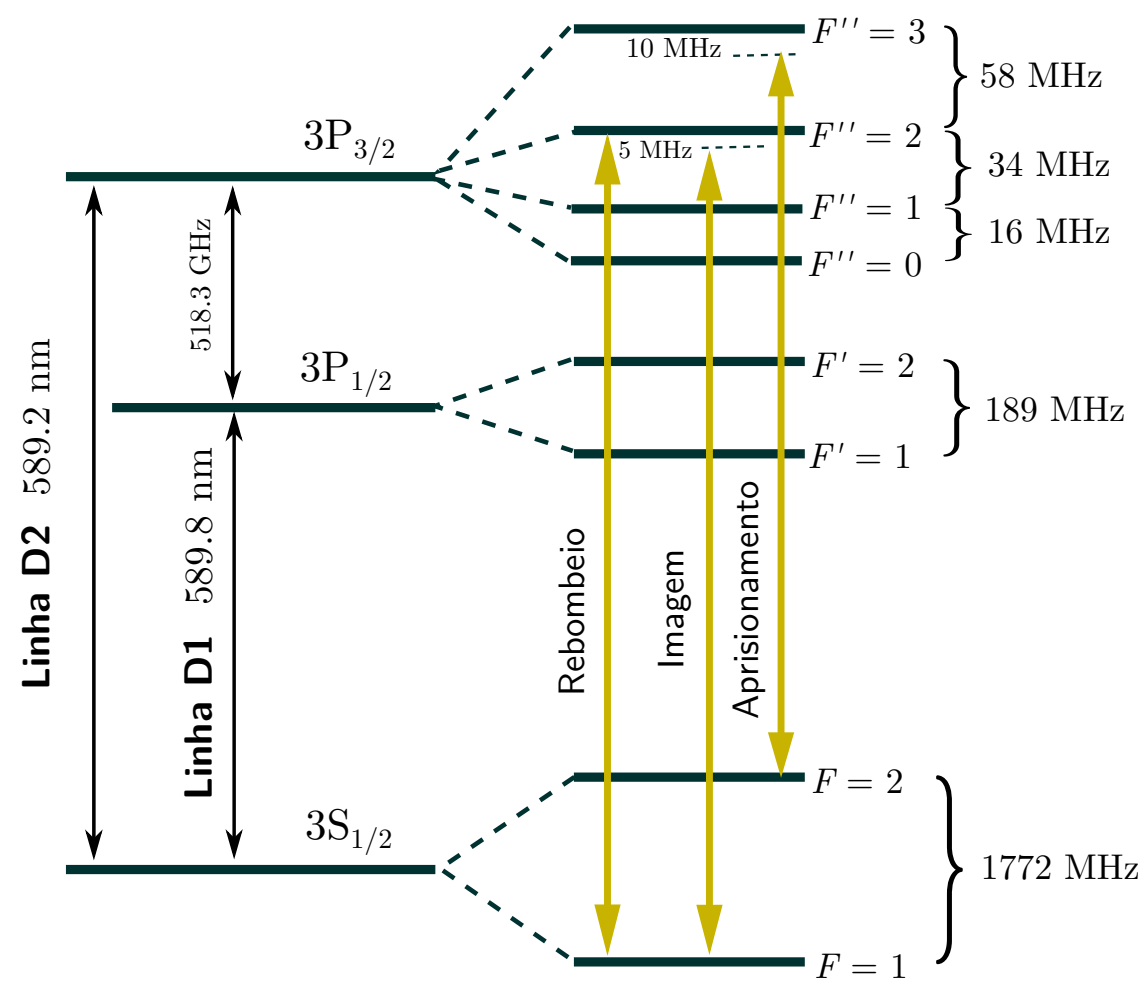

Figura 4.2.1 - Estrutura de níveis hiperfinos do átomo de sódio. Podem-se observar as transições correspondentes para o aprisionamento e o rebombeio.

mostrando os níveis de energia de interesse para o sódio. Todos os metais alcalinos tem uma estrutura hiperfina, o que torna possível a presença de dois subníveis no estado fundamental ${ }^{2} S_{1 / 2}$; os estados com $F=1$ e $F=2$. Um átomo de sódio no estado fundamental tem um só elétron de valência na configuração $3^{2} S_{1 / 2}$ com um spin nuclear $I=3 / 2$. O spin nuclear permite ter uma estrutura hiperfina com os dois níveis hiperfinos para o estado fundamental, $F=1$ e $F=2$, os quais estão separados por uma frequência de $1.71 \mathrm{GHz}$.

A linha de transição conhecida como $D 2$ (transições $3^{2} S_{1 / 2} \rightarrow 3^{2} P_{3 / 2}$ ) tem uma frequência de uns $589.15 \mathrm{~nm}$. No átomo de sódio, a transição $F=2 \rightarrow F=3^{\prime}$ da linha D2 mostra um momento dipolar grande, e por isso é mais adequado para o resfriamento do átomo. Para um processo de resfriamento, é requerida uma transição cíclica, depois da qual os átomos de sódio voltam para o estado fundamental depois de espalhar um fóton. Esta transição é a $F=2 \rightarrow F=3^{\prime}$ da linha $D 2$. Além disso, temos um efeito adicional a ser considerado: os átomos podem fazer uma transição indesejada do estado $F=2^{\prime}$ para o estado $F=1$. Com o intuito de recuperar estes átomos no processo de resfriamento, um feixe de rebombeio, sintonizado nesta transição, é utilizado. Assim, os átomos de sódio podem alcançar baixíssimas temperaturas ao serem aprisionados.

Em nosso sistema, geramos estas frequências a partir de um laser de estado sólido, implementado recentemente, e que dá mais estabilidade e uma melhor performance na obtenção do MOT. 


\subsubsection{Laser de estado Sólido}

A maioria de átomos alcalinos metálicos usados em experimentos de resfriamento possuem transições atômicas em frequências que são obtidas mediante laser de diodo. O $\mathrm{Rb}$, o Cs e o K são exemplos claros. No caso do Na a linha de transição, conhecida como a linha $D 2$ em $589 \mathrm{~nm}$, precisa tipicamente de um laser de corante para atingir a frequência de transição. Anteriormente se fazia uso de laser de corante para a realização dos MOT em nosso laboratório. Contudo a performance que um destes lasers oferece está sujeita ao alinhamento interno e concentração de corante, o que ocasiona mudanças nas caraterísticas do feixe laser com o tempo. Recentemente, lasers comerciais de estado sólido apareceram no mercado, permitindo gerar a frequência necessária para o resfriamento de sódio. São dois os princípios que permitem a geração da luz em $589 \mathrm{~nm}$; amplificação e geração do segundo harmônico. O sistema que gera o laser em $589 \mathrm{~nm}$ possui um amplificador óptico que mantém a polarização e que amplifica um sinal proveniente de um laser de diodo de $1178 \mathrm{~nm}$ com um subsequente dobramento de frequência do sinal amplificado num módulo Gerador de Segundo Harmônico (SHG). O módulo consiste em um Amplificador Visível Raman por Fibra e um módulo de bombeamento laser por fibra. A luz bombeada do módulo de bombeamento é guiada ao amplificador mediante uma fibra óptica mantenedora de polarização. O módulo de bombeamento também monitora o sinal do amplificador Raman por fibra. Isto permite a estabilização da potência de saída do SHG e a estabilização da temperatura do cristal no SHG. A temperatura ótima pode ser ligeiramente diferente para diferentes correntes no laser de diodo. No final do processo de geração, podemos obter na melhor das performances uma potência de 1,5 W aproximadamente na saída do laser de luz em 589 nm.

Um destes lasers é usado no nosso atual sistema para a geração das frequências com o uso adicional de moduladores acusto-ópticos; o que permite a produção do MOT, além de produzir a frequência adequada para o sistema de imagem de absorção. Na figura 4.2.2 pode se ver o laser de estado sólido utilizado no experimento.

\subsubsection{Lasers de Corante}

Além do laser de estado sólido que gera as frequências necessárias para a obtenção do nosso MOT, precisamos de frequências adicionais para nossos estudos de fotoionização associativa. Estas frequências são obtidas através da utilização de lasers de corante. 


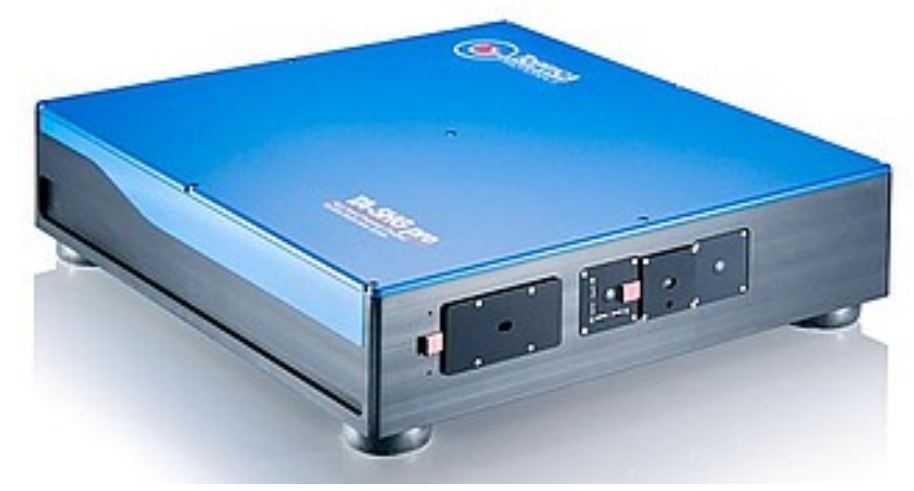

Figura 4.2.2 - Laser de estado sólido utilizado na produção do MOT.
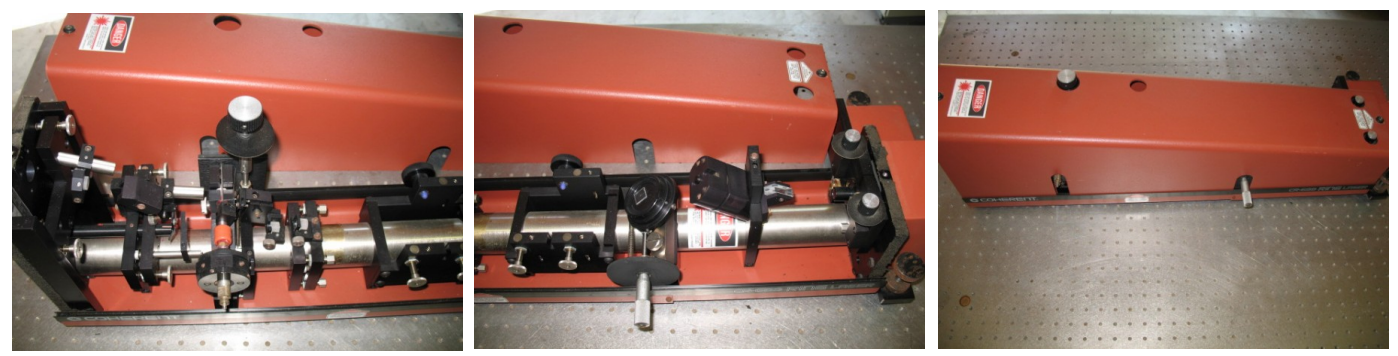

Figura 4.2.3 - Um dos lasers de corante Coherent ${ }^{\circledR}$ 699, utilizado nos nossos experimentos.

Três lasers de corante são usados para este fim: dois laser de corante Coherent ${ }^{\circ}$ 699, e um Coherent® 899. Cada laser opera sendo bombeado por um laser de estado sólido Coherent ${ }^{\circledR}$ Verdi a uma potência de 10 W. Em média, a potência destes lasers de corante é em torno de $1 \mathrm{~W}$. Um destes lasers de corante é mostrado na figura 4.2.3.

\subsection{Produção do MOT de Sódio}

A técnica mais comum para aprisionar átomos neutros, é a chamada armadilha magneto-óptica (MOT). Uma armadilha magneto óptica usa um arranjo de feixes lasers e campos magnéticos para desacelerar ou "resfriar" átomos neutros até temperaturas em torno do zero absoluto (da ordem de $\mu \mathrm{K}$ ).

Consiste basicamente de três pares de feixes laser contrapropagantes distribuídos nos eixos $x, y$ e $z$; com polarizações circularmente opostas e sintonizados um pouco abaixo da frequência de ressonância, além de um gradiente de campo magnético gerado por bobinas na configuração anti-Helmholtz. Devido à transferência de momento entre átomos e fótons, ocorre o resfriamento dos átomos. Sem o gradiente de campo magnético temos assim o que é conhecido por melaço óptico (40), contudo os átomos não permanecem aprisionados. Em um MOT, além dos seis feixes laser, se tem o gradiente de campo 


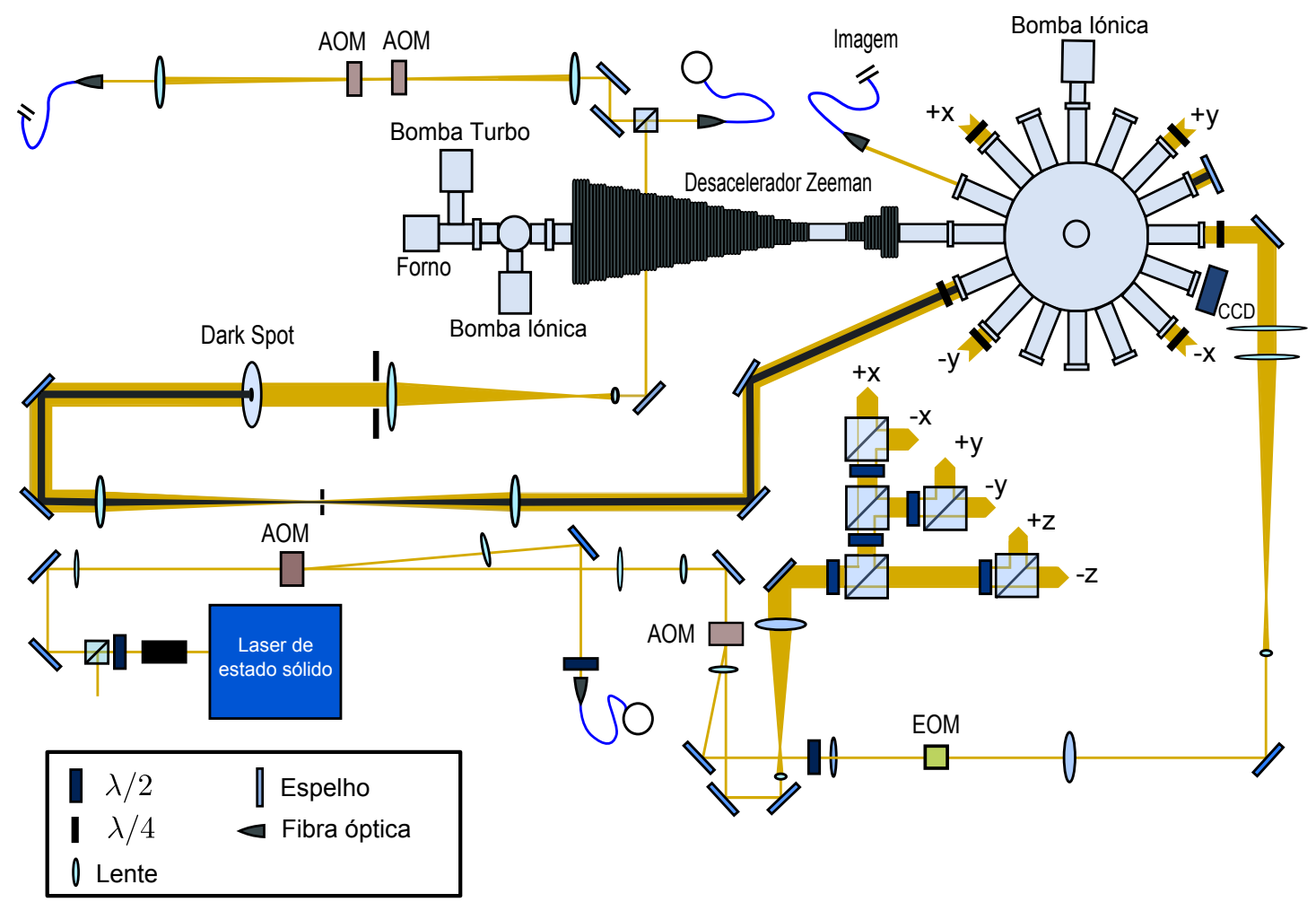

Figura 4.3.1 - Sistema experimental utilizado nesta dissertação para a produção de átomos de sódio frios numa armadilha magneto-óptica.

magnético, que devido ao efeito Zeeman, "abre" os níveis de energia do átomo de acordo com a posição, visto que trata-se de um gradiente de campo. As polarizações circularmente opostas dos pares de feixes e o gradiente de campo magnético fazem com que ocorra uma seleção espacial dos feixes dos quais o átomo pode absorver fótons, surgindo assim uma força semelhante a uma força de mola, que mantém os átomos no centro da armadilha.

O sistema experimental para a produção de nosso MOT é mostrado esquematicamente na figura 4.3.1. Um laser de estado sólido é usado para gerar as frequências necessárias para o feixe de aprisionamento, rebombeio e desaceleração. Adicionalmente produz a frequência para o sistema de imagem. Tipicamente a potência de saída deste laser está acima de $1 \mathrm{~W}$, sendo a performance utilizada em nossos experimentos de $1.15 \mathrm{~W}$ de luz linearmente polarizada. A luz após sair do laser passa através de um isolador óptico para evitar efeitos de retroalimentação no laser, visto que estes efeitos podem diminuir o seu desempenho. Em seguida, a luz passa através de um sistema polarizador-cubo onde uma fração da luz vai para um sistema de absorção saturada para estabilização do laser, e a outra é utilizada para a produção do MOT. A passagem por um AOM gera as frequências necessárias para o feixe de rebombeio e um feixe que passa por outro AOM para gerar as frequências para o feixe de aprisionamento e desaceleração. O feixe de desaceleração é adicionalmente modulado num EOM que vai produzir os sidebands em $1.71 \mathrm{GHz}$. As duas primeiras ordens de sidebands são separadas por $1.71 \mathrm{GHz}$ e levam aproximadamente 30 \% da potência de entrada cada uma. Elas são usadas para manipular as transições de 
esfriamento e rebombeio de $F=2 \rightarrow F=3^{\prime}$ e $F=1 \rightarrow F=2^{\prime}$, respectivamente. Depois de passar pelo EOM o feixe laser é expandido usando um telescópio. Posteriormente este feixe é focalizado numa distância de $2.9 \mathrm{~m}$, e passa através do desacelerador Zeeman até chegar ao nozzle, que ejeta os átomos para a câmara.

A primeira parte do feixe que é usada para o feixe de rebombeio é acoplada numa fibra óptica de alta potência que mantém a polarização. O feixe saindo da fibra passa também através de um sistema polarizador-cubo, já que a partir deste feixe vamos gerar a frequência adequada para o feixe de baixa intensidade que irá fazer parte de nosso sistema de imagem por absorção. O feixe que será usado inteiramente para rebombeio, passa através de um sistema de lentes que o expande e o leva para a câmara onde ele entrará por uma janela própria. Este feixe de rebombeio é retrorefletido por um espelho no outro lado da câmara.

A outra parte deste feixe, irá gerar o feixe de aprisionamento. Este feixe passa através de um sistema polarizador-cubo para controlar adequadamente as potências. $\mathrm{O}$ sistema divide dois feixes, um produzindo o feixe de aprisionamento na direção $\pm z$ e o outro que irá passar num sistema semelhante para produzir os feixes nas direções $\pm x$ e $\pm y$. Posteriormente cada um destes feixes passa por um sistema similar para ter controle da potência de cada eixo de aprisionamento.

\subsubsection{MOT em configuração Dark Spot}

O Dark MOT ou MOT Dark Spot foi proposto e desenvolvido no MIT por Ketterle (41). No Grupo de Óptica foram anteriormente estudados MOT's com esta configuração especial (42).

Numa armadilha comum (armadilha brilhante ou Bright MOT), os átomos estão majoritariamente (99\%) no estado hiperfino excitado $F=2$. Nesta configuração a densidade está limitada devido aos processos de colisão entre os estados fundamental e excitados, na qual parte da energia de excitação é transformada em energia cinética, o que permite aos átomos escaparem da armadilha. Num Dark MOT, um spot é colocado no meio do feixe de rebombeio, com a consequência que o volume central da armadilha fica livre de luz de rebombeio. Assim a maioria dos átomos aprisionados (cerca de 99\%) são ópticamente bombeados para o nível hiperfino fundamental $F=1$, onde eles não interagem com a luz de aprisionamento, já que esta tem um leve deslocamento para o vermelho da ressonância atômica. Desta forma não há átomos no estado excitado para participar dos processos de colisão que levam a perdas na armadilha. Como resultado direto disto, a densidade dos átomos no Dark MOT é maior do que aquela em uma armadilha comum. Em resumo, um Dark MOT permite inverter o panorama que se tinha dos átomos na 


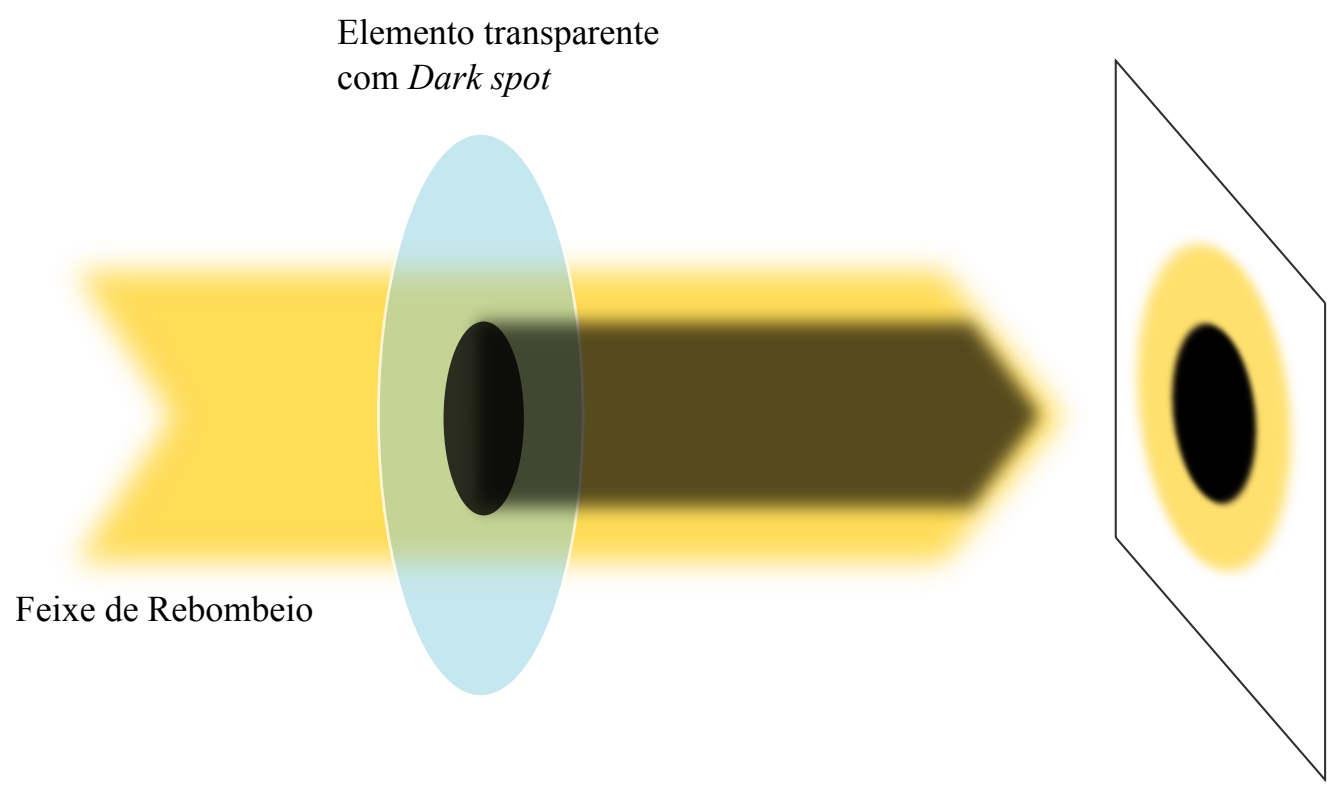

Figura 4.3.2 - Sistema de produção do Dark MOT.

armadilha, passando estes a estarem em grande parte no estado fundamental hiperfino $F=1$, e diminuindo as perdas na armadilha por colisões.

Experimentalmente, a adição do dark spot no feixe de rebombeio, não é suficiente para obter um Dark MOT robusto. Isto porque existiam efeitos de borda no dark spot, que levam a ter um feixe de rebombeio entrando na câmara com o centro não suficientemente escuro. Como resultado disto, uma fração dos átomos no centro da armadilha sentia a luz de rebombeio e assim passava a estar no estado hiperfino excitado $F=2$, além de ocasionar perdas por processos de colisão. Para superar este problema uma imagem virtual do dark spot foi usada. Isto se conseguiu simplesmente focalizando e depois colimando o feixe de rebombeio com dark spot. No foco, uma íris foi colocada e ajustada para permitir passar só a parte central do feixe, filtrando assim os raios desviados por efeitos de difração nas bordas. Com este método conseguimos um dark spot totalmente escuro. A figura 4.3.2 mostra o esquema usado. Para ver o aumento de densidade na amostra, procedemos a verificar o espectro de absorção de nosso Dark MOT. Uma densidade de aproximadamente $5 \times 10^{11}$ átomos $/ \mathrm{cm}^{3}$ foi atingida. É importante destacar que esta configuração de MOT é de vital importância para os nossos experimentos, pois ela permite a aparição de estados moleculares ainda pouco estudados nos nossos experimentos de fotionização associativa.

\subsection{Sistema de controle e aquisição de Dados}

O sistema de controle e adquisição de dados foi desenvolvido especialmente para o nosso experimento. É um sistema que permite a aquisição em tempo real de parâmetros 


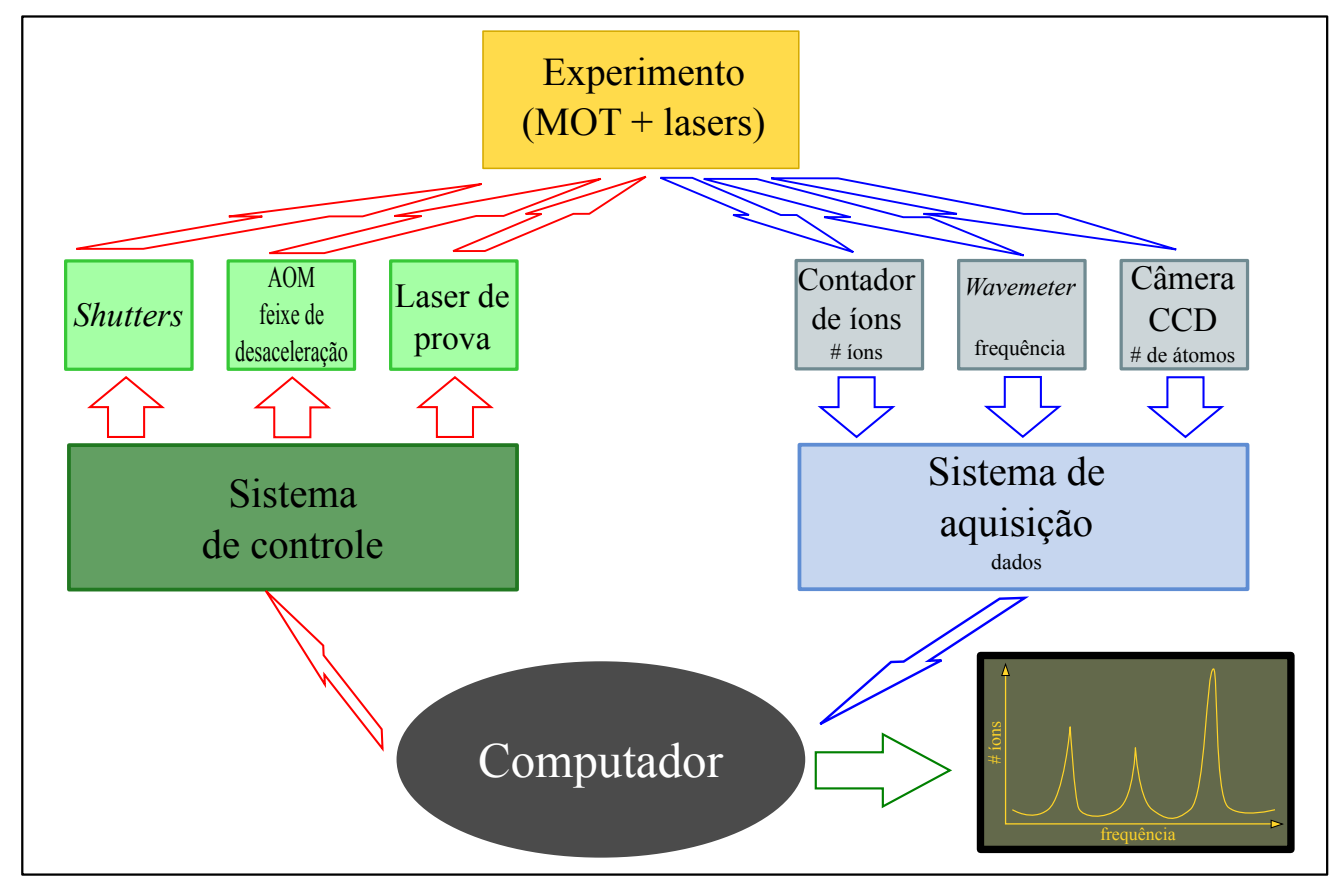

Figura 4.4.1 - Diagrama do sistema de controle e aquisição implementado para os nossos experimentos.

como o número de átomos, o número de íons e o controle da sequência temporal de medição, controle dos moduladores e lasers, entre outros, por meio de uma placa de adquisição da National Instruments® (NI-DAQmx) e a interface computadorizada comercial Labview®. A figura 4.4.1 mostra um diagrama do sistema de controle e aquisição e a figura 4.4 .2 mostra uma captura na tela do programa desenvolvido em Labview® para o controle e aquisição em nossos experimentos. 


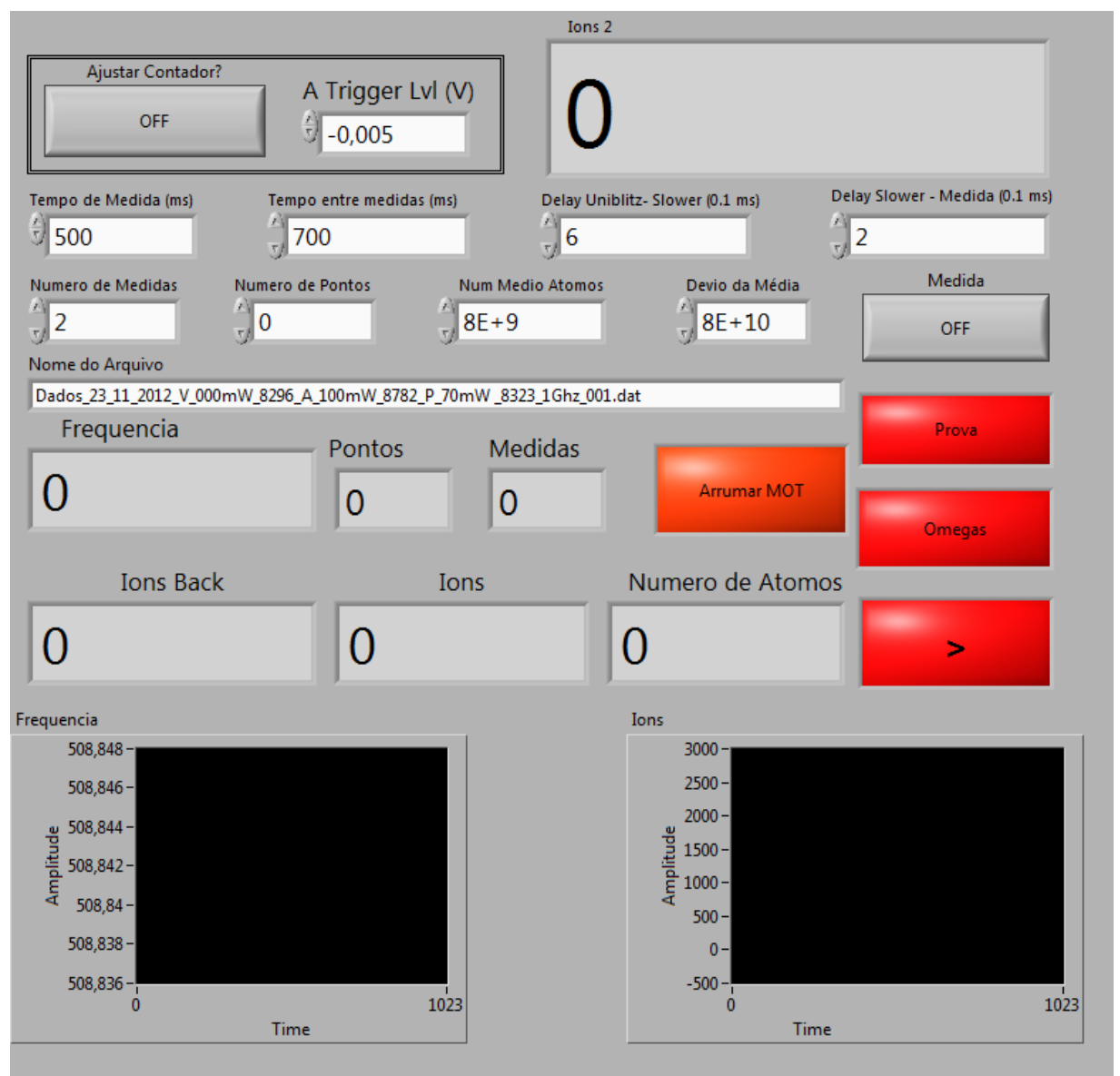

Figura 4.4.2 - Captura na tela do programa desenvolvido em Labview® para o monitoramento e aquisição de dados no experimento. 


\section{Capítulo 5}

\section{Indícios da formação da molécula fotônica com a modificação dos potenciais}

Neste capítulo iremos analisar a viabilidade experimental para a produção das moléculas fotônicas. Veremos como a presença dos fótons envolvidos no processo altera os potenciais através da fotoionização associativa. Por isso é de grande importância entender o que acontece nos estados intermediários $0_{g}^{-}$e $1_{g}$ quando são modificados pela presença dos fótons. O que esperamos na formação da molécula fotônica é que os níveis vibracionais de uma molécula fotoassociada com potenciais intermediários mudem energeticamente na presença dos lasers. Isto se verá refletido no desvio das estruturas de um possível espectro de fotoionização associativa. Neste contexto, se poderia esperar que em um espectro completo de fotoionização associativa as séries vibracionais envolvidas tenham uma mudança significativa, mas se poderia esperar também que os efeitos sejam mínimos, ou diferentes para cada série vibracional dependendo das potências e dessintonias dos lasers envolvidos. Uma medição deste tipo poderia não dar uma clara evidência da formação da molécula fotônica. Como alternativa pudemos fazer uma medição indireta da formação da molécula fotônica variando a potência do laser e centrando o estudo nos níveis vibracionais nos quais temos uma mudança significativa, com o intuito de verificar a dependência do efeito em relação à variação das intensidades dos lasers. Também pode-se fazer estudos mudando as dessintonias dos lasers vermelho e azul com respeito à transição de ressonância. Um estudo mais completo e detalhado que apresenta resultados experimentais e simulações numéricas acerca da molécula fotônica pode ser encontrado na tese de doutorado de de Paiva (34); sendo que aqui apresentaremos apenas alguns indicativos para a formação da molécula fotônica. A seguir, será descrito o sistema experimental para a produção das moléculas fotônicas de sódio e uma análise qualitativa de como a presença dos fótons modificam os potenciais intermediários de longo alcance no sódio. Além disto, as perspectivas que se tem para a molécula fotônica de sódio também serão discutidas. 


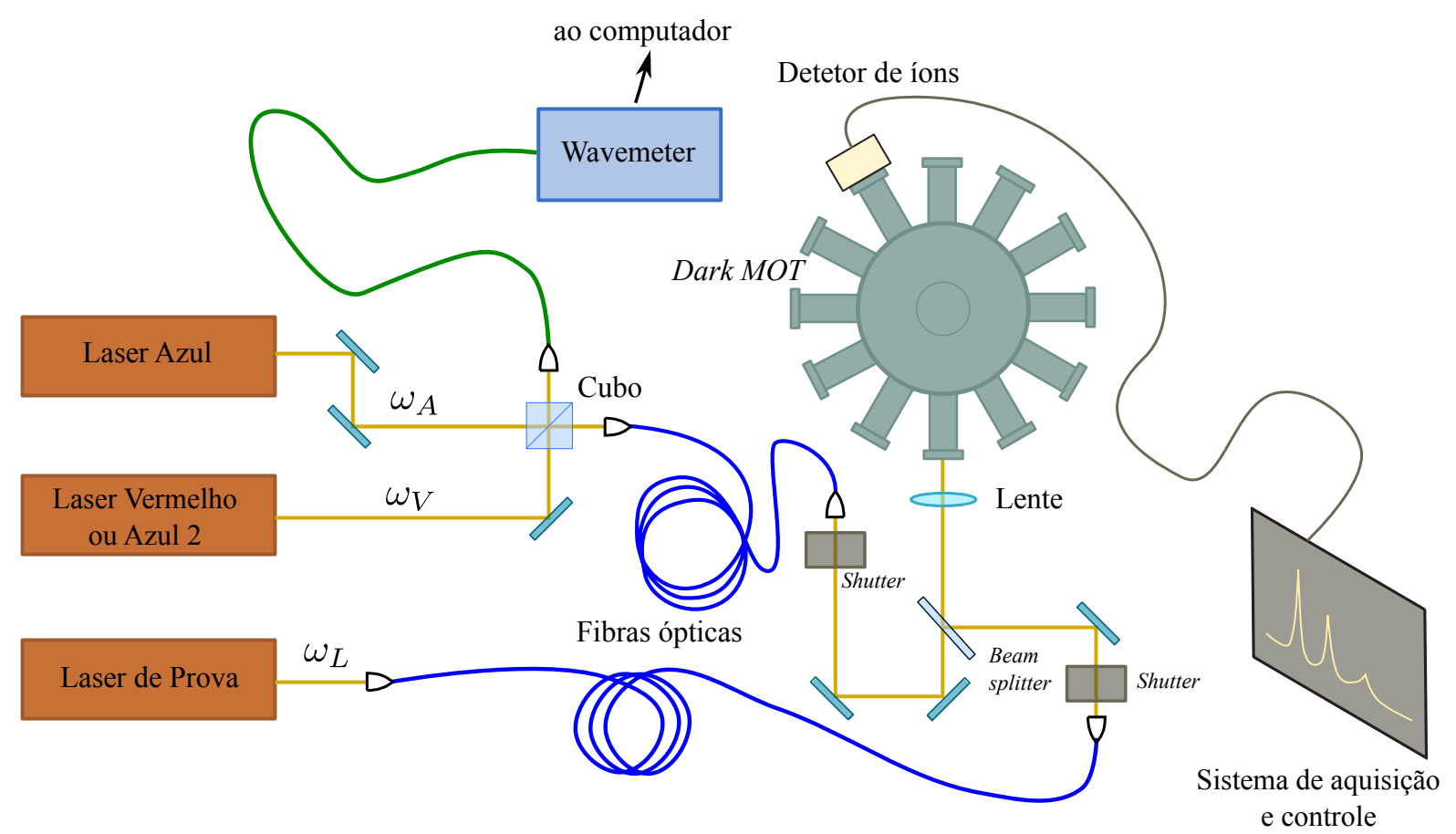

Figura 5.1.1 - Esquema experimental para a produção das moléculas fotônicas.

\subsection{Descrição do sistema experimental para a produ- ção das moléculas fotônicas de sódio}

Este sistema experimental é basicamente o mesmo que foi usado para os estudos de fotoionização associativa por dois fótons na região de 0 até -30 GHz e para a blindagem óptica, que serão apresentados nos capítulos posteriores desta dissertação. Para a produção da molécula se desenvolveu um sistema experimental compacto e otimizado para aprisionar átomos de sódio. No capítulo 4 foi apresentado este sistema experimental para a produção de um MOT de sódio na configuração de Dark MOT. Para produzir as moléculas fotônicas utiliza-se este sistema de aprisionamento, com a adição de três lasers:

- Um laser com uma dessintonia para o vermelho da transição de aprisionamento, que será varrido regularmente na frequência. Este laser é sintonizado com uma frequência de $\omega_{L}$ e é chamado de laser de prova.

- Um laser com uma dessintonia para o azul da transição de aprisionamento, que será mantida fixa. Este é chamado de laser azul e tem uma frequência $\omega_{A}$.

- Um último laser com uma dessintonia para o vermelho da transição de aprisionamento, também mantido fixo e é chamado de laser vermelho, sendo que a sua frequência é aqui denominada como $\omega_{V}$.

Os dois primeiros lasers realizam o processo comumente chamado de fotoionização 
associativa por dois fótons, que já foi apresentado no capítulo 3. O terceiro laser é que induz as maiores mudanças nas medidas, e se espera que o seu efeito combinado com o laser azul modifique os potenciais intermediários de longo alcance, dando origem as moléculas fotônicas.

Para a realização do experimento implementaram-se três lasers distintos para obter os lasers azul, vermelho e de prova. Utilizamos três lasers do fabricante Coherent ${ }^{\circledR}$, sendo dois deles do modelo 699, e um 899. O laser de prova passa por uma fibra óptica que mantém a polarização e a sua saída é levada por espelhos, que oferecem controle dos graus de liberdade espaciais, até a janela da câmara onde estão aprisionados os átomos de sódio. De forma análoga ao laser de prova, os outros dois lasers passam por uma fibra óptica que mantém a polarização, com a diferença que ambos passam pela mesma fibra. O feixe saindo da fibra é levado também por meio de espelhos até a câmara. Os três feixes são combinados por um beam splitter para assim passar pela mesma janela da câmara. Antes de entrarem na câmara, estes feixes são focalizados com uma lente de $25 \mathrm{~cm}$, para ter um maior número de fótons incidindo nos átomos. Este sistema experimental pode ser observado na figura 5.1.1.

Já com o MOT operando, precisamos alinhar os feixes para nos assegurar que incidam da melhor maneira possível no MOT. Isto se consegue colocando individualmente cada laser na frequência de aprisionamento e fazendo incidir um de cada vez no MOT. Quando o MOT é destruído completamente, podemos dizer que temos o feixe incidindo na maior área possível. Isto é monitorado por uma câmera CCD, que permite ver em tempo real a dinâmica deste processo. Uma vez que cada feixe está alinhado, se procede à realização de um ajuste fino. Com o contador de íons operando, sendo monitorado pela interface Labview ${ }^{\circledR}$, podemos ver em um computador a contagem de íons em tempo real. O processo de alinhamento é o seguinte:

1. Apenas com o feixe azul incidindo no MOT modificamos os graus de liberdade espaciais (espelhos), até obter a melhor contagem de íons.

2. Liberamos o feixe de prova e modificamos os graus de liberdade dele até obter a melhor contagem de íons. Isto com o feixe azul incidindo no MOT durante toda esta etapa do procedimento.

3. Ainda com o feixe azul e o feixe de prova incidindo no MOT, liberamos o feixe vermelho. Novamente movemos o mesmo espelho que havia sido movido no alinhamento do feixe azul (já que ambos feixes saem da mesma fibra, tem o mesmo trajeto espacial) até melhorar a contagem de íons.

Uma vez com os feixes alinhados, implementamos a sequência temporal de medida para poder realizar o experimento de produção e detecção de moléculas fotônicas. A sequência temporal de quatro passos implementada é a seguinte: 


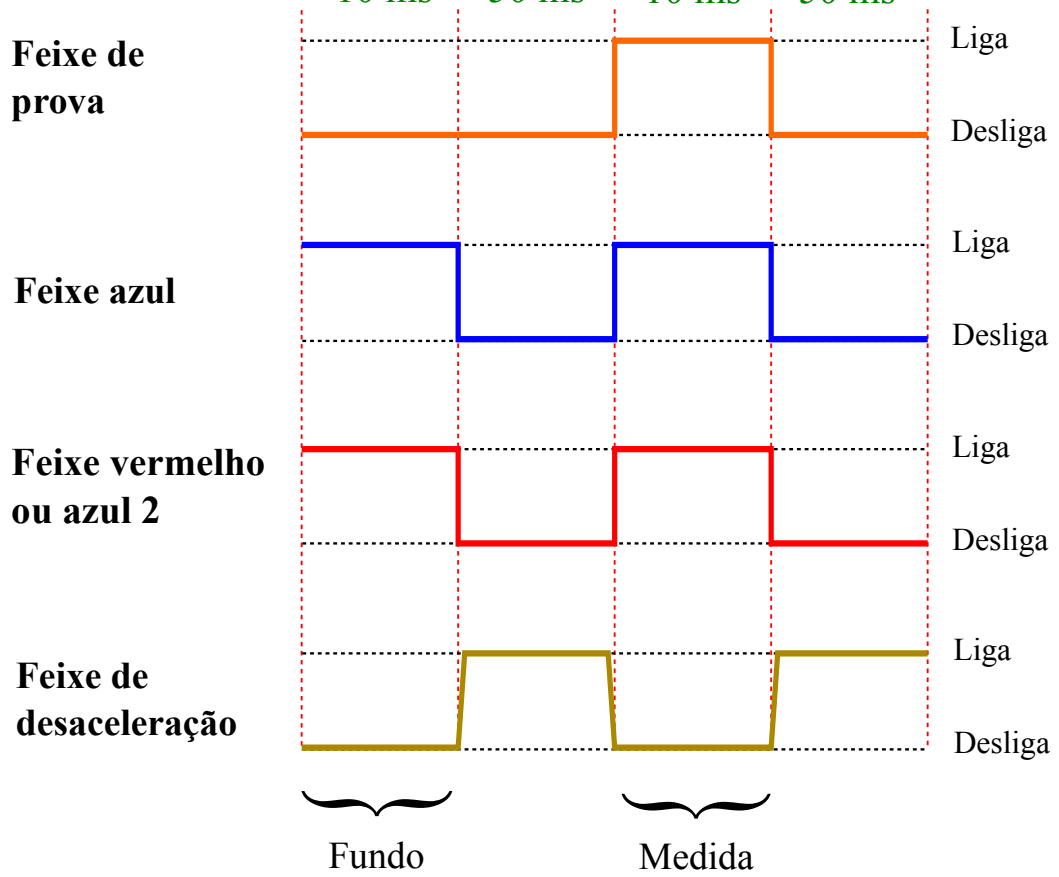

Figura 5.1.2 - Esquema da sequência temporal implementada para a produção das moléculas fotônicas e controlada pela interface comercial Labview®. "Fundo" indica a contagem de íons que será tomada como contagem de fundo, e "Medida" a contagem total. A diferença desta contagem dá o número de íons produzidos efetivos para o espectro de fotoassociação.

- Passo 1: Se desliga o feixe de desaceleração e se ligam os feixes azul e vermelho por um intervalo de tempo. A contagem de íons deste intervalo é realizada.

- Passo 2: Se desligam os feixes azul e vermelho e se liga o feixe de desaceleração por um intervalo de tempo para poder recuperar a amostra de átomos frios. Nenhuma medida é realizada neste intervalo.

- Passo 3: Se desliga novamente o feixe de desaceleração e se ligam os feixes azul, vermelho e de prova pelo mesmo intervalo de tempo do Passo 1. É realizada a contagem de íons.

- Passo 4: Se desligam os feixes azul, vermelho e de prova e volta-se a ligar o feixe de desaceleração deixando o sistema pronto para começar uma nova medida. Nenhuma medida é feita neste intervalo.

A figura 5.1 .2 mostra a sequência temporal para o experimento. Toda a sequência temporal foi controlada pela interface comercial Labview®, assim como por shutters do fabricante Uniblitzer®. A automatização do laser de prova é feita também mediante a interface Labview ${ }^{\circledR}$. Para obter e monitorar as frequências necessárias para as dessintonias dos laser fazemos uso de um wavemeter (equipamento que mede comprimento de onda de uma luz) do fabricante High Finesse®, o qual também nos permite obter a frequência 
do laser de prova em cada medida (com uma resolução de $30 \mathrm{MHz}$ ), novamente com o programa de controle e aquisição Labview®. Desta forma se tem uma medida da frequência do laser de prova em tempo real, com precisão e automatizada. A contagem de íons é realizada com um contador de íons já usado para outros experimentos no mesmo sistema (37). A contagem de íons é dada da relação:

$$
\text { íons }(\text { sinal })=\text { íons }(\text { medida }) \text {-íons (fundo) }
$$

As medidas podem ser feitas variando as potências e frequências dos diferentes lasers, assim como os intervalos de tempo na sequência temporal.

\subsection{Indícios da produção das moléculas fotônicas nos potenciais}

Sabe-se que o campo do laser de prova induz processos de fotoassociação, permitindo a formação de estados moleculares simplesmente excitados. Também se sabe que o fóton do laser azul cria efeitos de supressão óptica das colisões inelásticas e abre novas rotas para os átomos. Quando temos ambos os fótons, vamos ter os dois processos, além do segundo passo na fotoassociação, causado majoritariamente pelo laser azul, e desta maneira teremos uma competição de processos. Dependendo da dessintonia de cada laser $\Delta_{A}$ e $\Delta_{L}\left(\Delta_{A}\right.$ para o laser azul e $\Delta_{L}$ para o laser de prova, com respeito à frequência de ressonância), podemos excitar diferentes níveis vibracionais dos estados simplesmente excitados, assim como também excitar o potencial repulsivo em diferentes pontos de Condon (). A adição do fóton vermelho vai provocar uma pequena contribuição nos processos de fotoionização associativa por dois fótons, mas esta vai ser fixa, e pode ser desconsiderada quando a tomamos como uma contagem de fundo. O efeito combinado do laser azul e este laser vermelho será o que modificará os potenciais intermediários.

\subsubsection{O modelo do oscilador harmônico e anarmônico}

O nosso principal interesse é entender como podemos pôr em evidência que um potencial intermediário tem sido modificado. Um potencial molecular para uma molécula de $\mathrm{Na}_{2}$ tem níveis vibracionais, os quais obedecem uma lei de escala dependendo de se este se conecta com as assíntotas dos estados fundamental, simplesmente excitado ou duplamente excitado. Quando fótons se acoplam com átomos colidindo numa armadilha, 


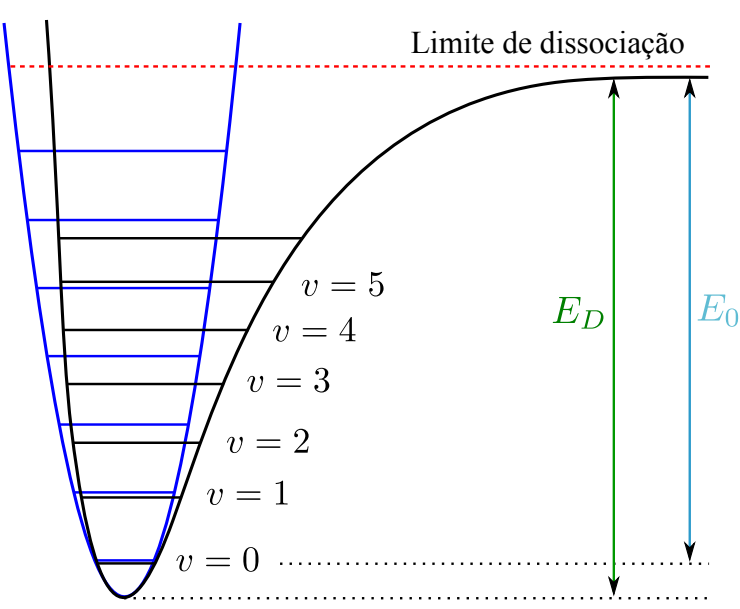

a)

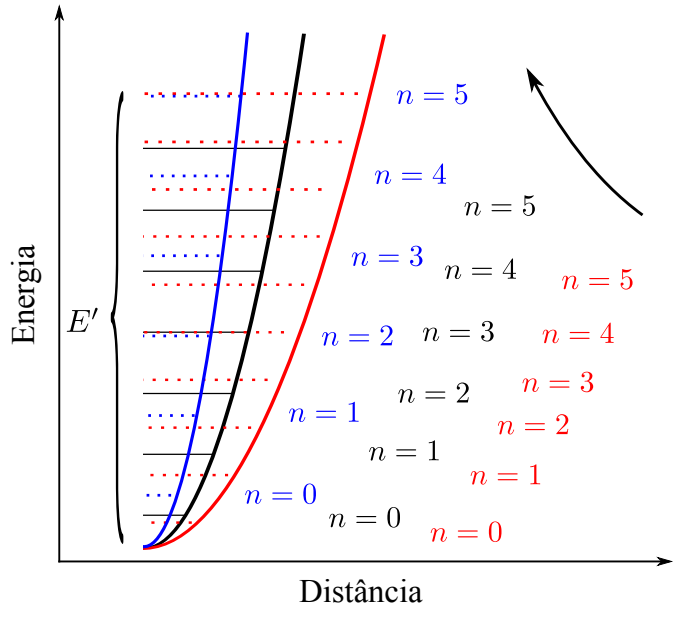

b)

Figura 5.2.1 - a) Potencial molecular aproximado por um oscilador harmônico. Podese ver que os níveis com menor $v$ são melhor aproximados. b) O gráfico mostra que quanto maior a largura do potencial do oscilador harmônico, mais níveis de energia podem ser admitidos para o mesmo intervalo de energia. Assim os deslocamentos nas energias dos mesmos $n$ para diferentes osciladores se fazem maiores conforme $n$ aumenta.

estes devem modificar de alguma forma os potenciais moleculares. Para entender como os potenciais podem ser modificados podemos analisar um potencial molecular e estender a análise para outros potenciais.

Podemos imaginar que quando um dos potenciais intermediários de longo alcance foi modificado pela presença de um laser vermelho, teremos um deslocamento efetivo das energia dos seus níveis vibracionais. Por exemplo, imaginando que um potencial hipotético fosse modificado pela presença dos fótons azul e vermelho, poderíamos fazer uma estimativa qualitativa de como as energias dos níveis vibracionais vão se modificar usando o modelo de um oscilador harmônico, um oscilador anarmônico ou um potencial de Morse (). Por simplicidade usaremos o oscilador harmônico para discutir as mudanças nas energias dos seus níveis, já que um análogo é também verdade para o oscilador anarmônico. A figura 5.2.1 a mostra como pode ser aproximado um potencial molecular por um oscilador harmônico. Agora podemos analisar algumas possíveis mudanças no potencial.

Se analisarmos um oscilador harmônico, vemos que se este é alongado da sua forma original, os níveis energéticos serão vistos deslocados para menores energias. Além disso, a diferença energética entre dois níveis também será menor. Deste modo, o potencial admite mais níveis energéticos no mesmo intervalo de energia. Considerando que os potenciais têm o mesmo vértice (como se mostra na figura 5.2.1 b) os níveis terão um deslocamento energético para o vermelho quando o potencial é alongado. Similarmente, quando o potencial é mais estreito e com o mesmo vértice, se tem um deslocamento para o azul nas energias para os níveis, e a separação entre níveis aumenta. Podemos ver também que os deslocamentos entre o mesmo nível para diferentes osciladores aumentam conforme 
aumenta o número quântico do nível. Por outro lado, se os vértices dos potenciais são deslocados verticalmente, mas mantendo a mesma forma do potencial, temos que todos os níveis se deslocarão de seus originais na mesma proporção. Se quisermos considerar efeitos combinados temos um panorama mais complexo, mas que está sujeito às mesmas regras.

Uma melhor aproximação do comportamento para potenciais moleculares realísticos pode ser feita usando o modelo do oscilador anarmônico. Neste caso, os níveis de energia estão dados por:

$$
E_{v}=\left(v+\frac{1}{2}\right) v_{e}-\left(v+\frac{1}{2}\right)^{2} v_{e} \alpha+\left(v+\frac{1}{2}\right)^{3} v_{e} \beta+\text { termos superiores }
$$

onde o primeiro termo corresponde ao oscilador harmônico e

$$
v_{e}=\frac{1}{2 \pi c} \sqrt{\frac{k}{\mu}}
$$

onde $\mu$ é a massa reduzida do sistema e $k$ é a constante de mola, $v_{e}$ é chamada de constante vibracional.

O mesmo raciocínio do oscilador harmônico serve com respeito às modificações nestes potenciais. Portanto os nossos argumentos para o oscilador harmônico são também válidos neste sistema. Com isto, podemos fazer uma análise qualitativa nos potenciais moleculares mais realísticos, como é o caso dos potenciais intermediários de uma molécula de $\mathrm{Na}_{2}$.

\subsubsection{Modificação nos potenciais moleculares realísticos}

No caso dos potenciais realísticos, como os que irão se tratar na formação da molécula fotônica, uma aproximação por um potencial anarmônico seria mais precisa. No oscilador anarmônico os níveis com maior $n$ têm uma variação menor com um alongamento do potencial, mas suas energias são deslocadas para a mesma direção em energia, ou seja são diminuídas ou aumentadas, que para $n$ menores. A partir de agora, usaremos os argumentos para osciladores harmônicos, pois são válidos também para osciladores anarmônicos. São diversos os casos que podemos considerar em um potencial realístico como os que apresentam a molécula formada por colisão de dois átomos frios de sódio. Vamos tratar aqui os casos nos quais os potenciais mantêm a sua forma perto do limite de dissociação, e vamos só considerar pequenas mudanças no potencial.

- Um destes casos pode ser quando o potencial fica menos profundo, mantendo uma forma proporcional ao potencial original. Aqui, fazendo uma analogia com o caso 


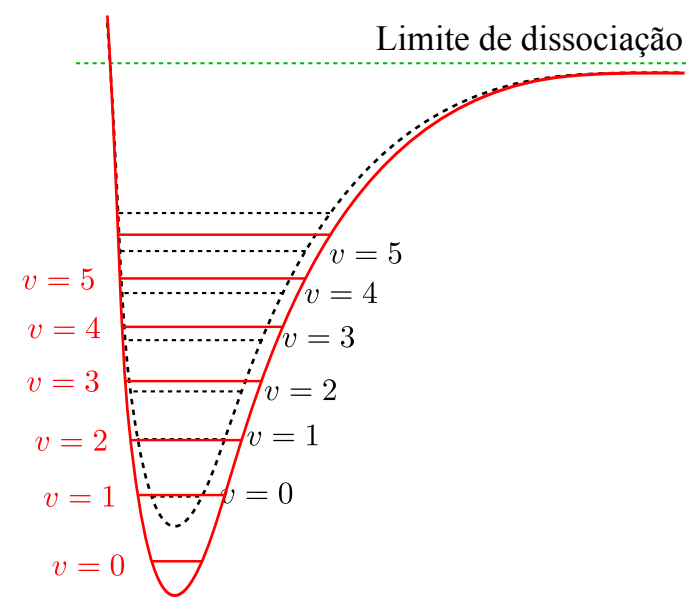

a)

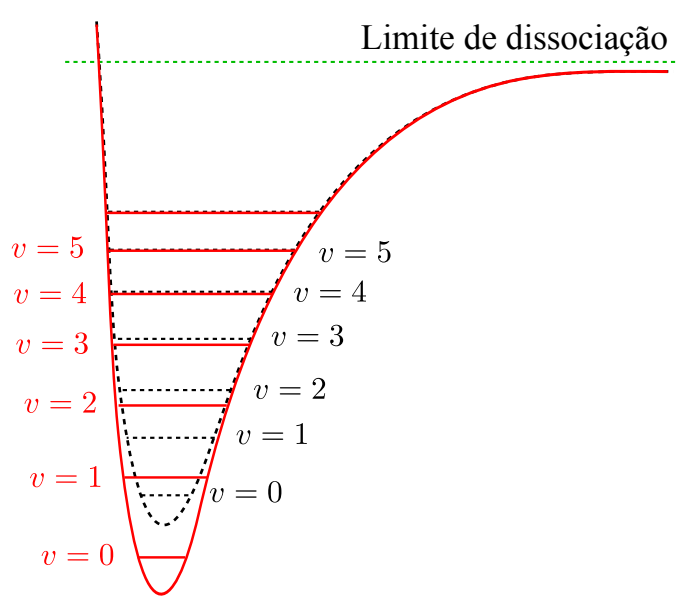

b)

Figura 5.2.2 - Deslocamento dos níveis vibracionais de um potencial molecular para a) um potencial mais profundo que mantém uma forma proporcional ao potencial original, e b) um potencial mais profundo, mas que é apenas modificado no fundo. O potencial original é dado pelas linhas pontoadas.

do oscilador harmônico, temos que a diferença de energia dos níveis vibracionais do potencial com respeito ao limite de dissociação são reduzidos. Assim os níveis tem um deslocamento efetivo para o azul, sendo os níveis com $v$ menores os de maior deslocamento. O mesmo argumento pode ser usado no caso de um potencial que se faz mais profundo mantendo uma forma proporcional com o potencial original. Neste caso, os deslocamentos dos níveis vibracionais em relação ao limite de dissociação serão para menores energias (para o vermelho) como na figura $5.2 .2 a$.

- Se temos que o potencial diminui a sua profundidade, mas que a maior parte do potencial mantém a sua forma original vamos ter que para grandes $v$, os níveis serão os mesmos. Fazendo o raciocínio com osciladores harmônicos, temos que o novo potencial pode ser aproximado por um oscilador harmônico mais longo, e assim os deslocamentos de energia dos níveis vibracionais com respeito ao limite de dissociação vão ser modificados só para os primeiros $v$, os níveis vibracionais no fundo do potencial. Aqui temos também deslocamento para o azul das energias dos níveis vibracionais. Um análogo acontece se a profundidade do poço aumenta 5.2 .2 $b$ ). Neste caso temos um deslocamento para o vermelho dos primeiros $v$.

- Quando o potencial é só modificado na sua região intermediária, ou seja, a profundidade é sempre a mesma, mas a curva do potencial nas regiões intermediárias é modificada, temos que os níveis vibracionais de maior e de menor $v$ quase não serão alterados energeticamente. Dependendo de como for a modificação sofrida pelo potencial, só os estados vibracionais intermediários serão modificados. No caso 


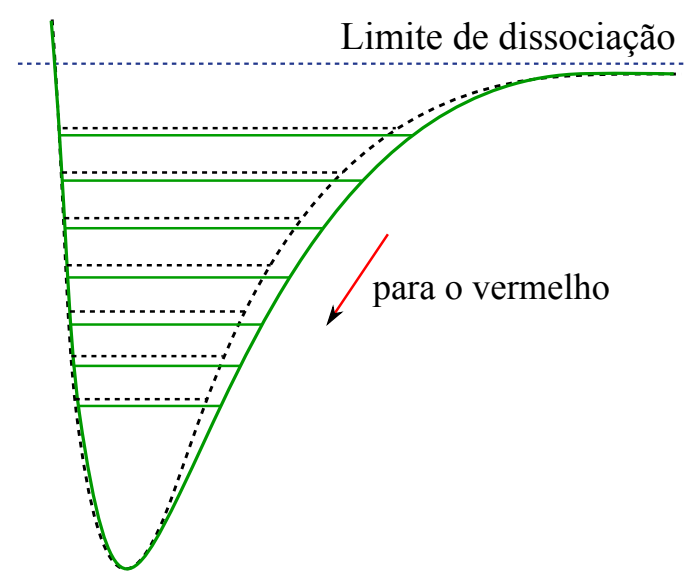

a)

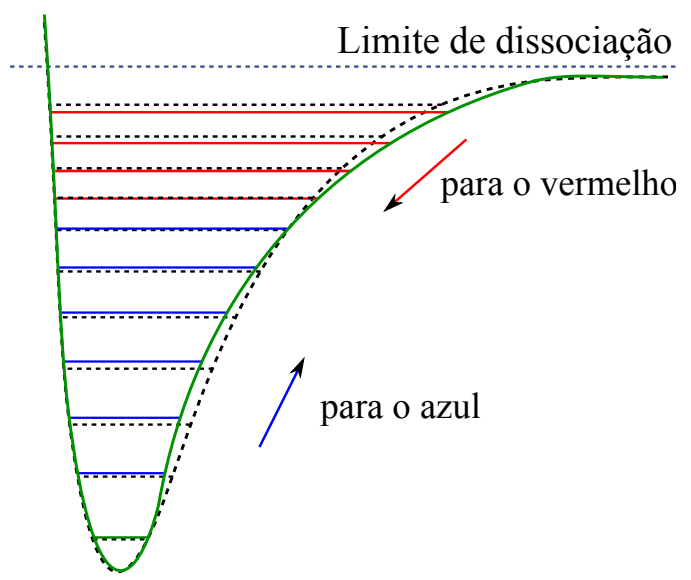

b)

Figura 5.2.3 - Deslocamento dos níveis intermediários quando a) o potencial é modificado na sua região intermediária se deslocando para um só lado, e b) quando existem dois tipos de deslocamentos.

de um alongamento na região intermediária no potencial, podemos pensar os níveis vibracionais intermediários como tendo um deslocamento para o vermelho (figura 5.2.3 a). Caso contrário, se o potencial ficar mais estreito nesta região, teremos um deslocamento para o azul. Se tivermos um efeito combinado, poderíamos ter ambos, deslocamentos para o azul e para o vermelho, dependendo da forma do novo potencial (figura $5.2 .3 \mathrm{~b}$ ).

\subsection{Como associar as mudanças em potenciais realís- ticos com uma molécula fotônica de sódio}

Como podemos ver nas distintas figuras dos potenciais modificados, temos que os pontos de Condon dos níveis vibracionais serão modificados quando o potencial é modificado. Isto repercute no tamanho dos picos de um possível espectro de fotoassociação para a molécula. Portanto, além de deslocamentos energéticos dos picos, poderíamos ter também modificação no tamanho dos picos, ou seja, um aumento na contagem de íons para certos estados vibracionais. No entanto, isto é difícil de quantificar quando as mudanças no potencial são mínimas.

Assim, a maior evidência da formação do potencial que dará origem às moléculas fotônicas que podemos esperar são os deslocamentos dos picos correspondentes aos estados vibracionais intermediários, já que são os que vão ser afetados pelo laser vermelho e azul no nosso experimento. Se colocarmos o laser vermelho ressonante com um nível vibracional particular $v$, temos que seus primeiros vizinhos $v+1$ e $v-1$ serão os mais afetados. Se 
variarmos a intensidade do laser vermelho podemos esperar intensificar o efeito. Só uma análise detalhada do espectro de fotoassociação de uma molécula fotônica vai nos dar informação total dos níveis afetados. No entanto, o deslocamento energético num nível e nos seus primeiros vizinhos é suficiente para ter um indicativo que o potencial molecular foi modificado.

Desta forma, mostramos que os fótons vão induzir modificações nos potenciais intermediários, o que evidencia a possibilidade da formação das moléculas fotônicas. Os indícios que podem mostrar isso são deslocamentos dos picos num espectro de fotoionização associativa ao variar as potenciais dos lasers envolvidos, assim como possíveis variações na contagem de íons.

Nos capítulos seguintes fazemos estudos preliminares no sentido de analisar a viabilidade da produção da molécula fotônica, identificando as séries vibracionais que aparecem no espectro de fotoionização associativa na região de 0 até -30 GHz, que se espera sejam os estados de longo alcance $0_{g}^{-}$e $1_{g}$ majoritariamente. Posteriormente o estudo da blindagem óptica dos picos que foram encontrados para serem modificados pela presença dos campos intensos é feito. O estudo em detalhe dos efeitos do laser vermelho, lamentavelmente, escapam do escopo deste trabalho. 


\section{Capítulo 6}

\section{Estudo dos estados ligados de longo alcance: 0 até $-30 \mathrm{GHz}$}

Os estados de longo alcance aparecem nas colisões de átomos frios como sendo dominantes. Quando dois átomos se aproximam um do outro, eles interagem e assim sentem uma força que pode ser descrita por um potencial de interação. Esta interação é dominada por diferentes efeitos, dependendo da distância entre os núcleos dos átomos. Se eles estão muito separados as funções de onda radiais deles não se sobrepõem, e assim, a interação é causada quase exclusivamente pela força de Coulomb, que é de longo alcance. Quando eles se aproximam um do outro, a interação vem a ser dominada pela sobreposição das suas funções de onda radiais.

Neste capítulo serão abordados alguns conceitos usados para descrever um potencial de interação de longo alcance. A discussão é restrita para moléculas diatômicas, pois são estas as que se produzem no MOT de sódio. Primeiro descreveremos brevemente as interações de curto alcance entre dois átomos, para posteriormente descrever os potenciais de longo alcance. As regras de seleção para transições entre estados de diferentes potenciais moleculares são dadas. Em seguida são apresentados os nossos resultados experimentais de fotoionização associativa por dois fótons na região de 0 até -30 GHz e uma identificação dos estados de longo alcance envolvidos.

\subsection{Interações de curto alcance}

Caso $a$ ) de Hund (43)

Para a região das pequenas distâncias internucleares, as funções de onda radiais dos átomos envolvidos se sobrepõem e a energia de acoplamento do momento angular eletrônico com o eixo internuclear (o eixo que une os dois núcleos) da molécula excede a energia de acoplamento spin-órbita entre os elétrons. Para esta região pode se usar o caso a) 


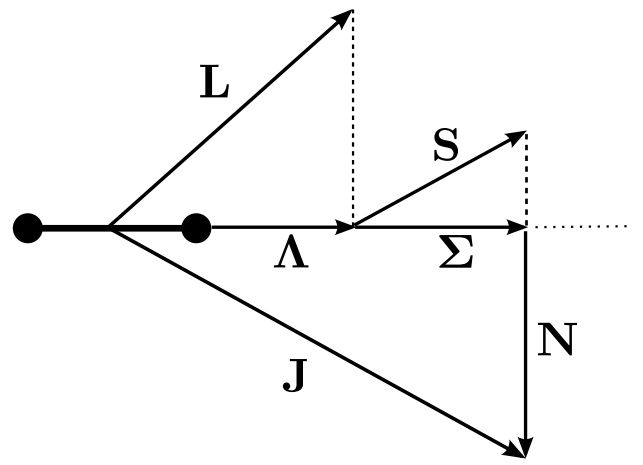

a)

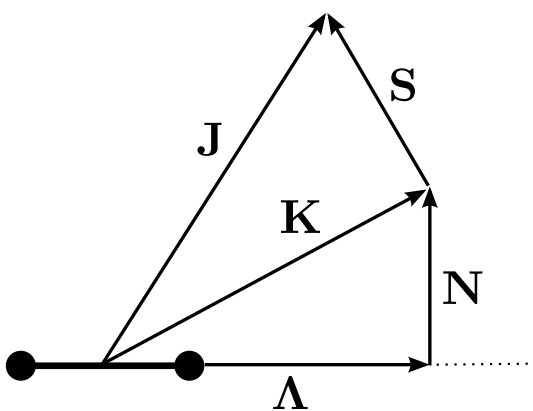

b)

Figura 6.1.1 - Esquemas vetoriais para os casos a) e b) de Hund. a) A energia de interação é maior que a energia de acoplamento spin-órbita, assim $\mathbf{L}$ e $\mathbf{S}$ podem ser projetados no eixo internuclear. Junto com o momento angular $\mathbf{N}$ se acoplam para formar o momento angular $\mathbf{J}$. b) $\boldsymbol{\Lambda}$ se acopla com $\mathbf{N}$ para gerar o momento angular $\mathbf{K}$. Este por sua vez se acopla com $\mathbf{S}$ para gerar $\mathbf{J}$, o momento angular total.

de Hund (43). O acoplamento do momento angular orbital eletrônico com o eixo internuclear é mais forte que o acoplamento spin-órbita, e assim o momento angular orbital dos elétrons se soma ao momento angular orbital resultante $\mathbf{L}$ que gira ao redor do eixo internuclear. A projeção de $\mathbf{L}$ neste eixo produz o número quântico $\boldsymbol{\Lambda}$ que pode tomar os valores $\Lambda=0,1,2, \ldots L$. Estes estados são denotados como $\Sigma, \Pi, \Delta, \Phi, \ldots$ em cada caso. O momento intrínseco total dos elétron soma para dar um valor $S$. Se $\Lambda \neq 0$ existe um campo magnético na molécula ao longo do eixo internuclear e o spin pode girar ao redor deste eixo. Um número quântico denotado como $\Sigma^{\prime}$ é dado pela projeção de $\mathbf{S}$ no eixo internuclear e pode tomar os valores $\Sigma^{\prime}=-S,=S+1, \ldots, S-1, S$. Deste modo cada spin $\mathbf{S}$ terá $2 S+1$ diferentes subestados com diferentes energias. Em uma molécula, o spin eletrônico $\Sigma^{\prime}$ e o momento angular orbital $\Lambda$ geram um momento angular total do elétron $\Omega=\left|\Sigma^{\prime}+\Lambda\right|$ e cada estado é classificado pelo seu número quântico como ${ }^{2 S+1} \Lambda_{\Lambda+\Sigma^{\prime}}^{ \pm}$, onde \pm denota a paridade de acordo com a reflexão em qualquer plano contendo o eixo internuclear. Uma molécula com $\Lambda=0$ não tem momento magnético ao longo do eixo molecular e a projeção do spin $\Sigma^{\prime}$ no eixo fica sem definição. No entanto, ainda se define a multiplicidade de estados como sendo $2 S+1$. Se tem também que a molécula pode girar ao redor de um eixo perpendicular ao eixo internuclear com um momento angular $\mathbf{N}$. O momento angular $\mathbf{J}$ da molécula é definido como a soma vetorial $\boldsymbol{\Omega}+\mathbf{N}$. Devido ao fato de $\mathbf{N}$ ser perpendicular ao eixo molecular (e da mesma forma com $\Omega$ ), $J$ pode só tomar valores iguais ou maiores que $\Omega$, isto é, $J=\Omega, \Omega+1, \Omega+2, \ldots$. A energia rotacional da molécula pode ser expressa por $E_{\text {rot }}=B_{\text {rot }}(v)\left[J(J+1)-\Omega^{2}\right]$ com uma constante rotacional $B_{\text {rot }}(v)$ que tem o mesmo valor para todos os estados rotacionais dentro de um estado vibracional $v$. 


\section{Caso b) de Hund (43)}

A energia total dos estados $\Sigma^{\prime}(\Lambda=0)$ é calculada em termos do caso $\left.b\right)$ de Hund, que é usado para um fraco acoplamento do spin com o eixo internuclear, já que estes estados não têm campo magnético originado pelo momento angular orbital dos elétrons. Por isso se tem que $\boldsymbol{\Lambda}$ e $\mathbf{N}$ se acoplam em um momento angular $\mathbf{K}$ com valores $K=\Lambda, \Lambda+1, \ldots$ Agora o momento angular total $\mathbf{J}$ vem do acoplamento dos momentos $\mathbf{S}$ e $\mathbf{K}$. Neste caso, se pode escrever a energia rotacional $E_{\text {rot }}=B_{\text {rot }} K(K+1)$ com $B_{\text {rot }}$ constante.

Para os estados $\Sigma^{\prime}, N$ é igual a $K$, e $J$ é definido como $J=(K+S),(K+S-$ $1), \ldots,|K-S|$, podendo ser escrito analogamente como $J=(N+S),(N+S-1), \ldots,|N-S|$. No caso dos dímeros alcalinos o spin $S$ pode ter valores 0 ou 1 resultando nos estados ${ }^{1} \Sigma$ ou ${ }^{3} \Sigma$ respectivamente. Para o estado ${ }^{1} \Sigma, J=N$ e a energia rotacional é determinada somente pela rotação da molécula ao redor do eixo internuclear. Para ${ }^{3} \Sigma$, $J$ pode tomar valores de $N$ ou $N \pm 1$, e um nível de energia rotacional com certa energia correspondente a um $N$ pode ser compensada para vários valores diferentes do momento angular total $J$.

\subsection{Interações de longo alcance}

\section{Caso $c$ ) de Hund (43)}

A grandes distâncias, o acoplamento spin-órbita é maior que o acoplamento do momento angular orbital com o eixo internuclear. Aqui é preciso usar o caso $c$ ) de Hund, onde o momento angular $\mathbf{L}$ e o spin $\mathbf{S}$ se acoplam para dar um momento angular total dos elétrons J. Para este caso temos que nem $\Lambda$ nem $\Sigma^{\prime}$ são bons números quânticos e unicamente a projeção do momento angular total $\Omega$ do elétron é conservada. Aqui denotamos os estados como $\Omega_{\mathrm{u}, \mathrm{g}}^{ \pm}$, onde $\Omega$ é a projeção de $\mathbf{J}$ no eixo internuclear e \pm e $\mathrm{u}, \mathrm{g}$ denotam a simetria com o plano e o comportamento da função de onda devido a uma troca dos núcleos, respectivamente. A energia rotacional $E_{\text {rot }}=B_{\text {rot }} N(N+1)$ é dada também por $E_{\text {rot }}=B_{\text {rot }}\left[J(J+1)-\Omega^{2}\right]$ como no caso $\left.a\right)$ de Hund. Quando os átomos estão muito afastados, a parte do potencial de interação de longo alcance é dominada unicamente pela força de Coulomb. Neste caso, podemos expandir o potencial de interação em uma série de potências:

$$
V(R)=E_{D}-\sum_{n} \frac{C_{n}}{R^{n}}
$$


Tabela 6.1 - Cada coeficiente identifica uma contribuição diferente no potencial devido a uma interação diferente entre os átomos. Os * servem para indicar que os termos multipolares são induzidos.

\begin{tabular}{c|c}
\hline Coeficiente de interação & Interação que carateriza \\
\hline \hline$C_{1}$ & íon-íon \\
\hline$C_{2}$ & íon-dipolo \\
\hline$C_{3}$ & dipolo-dipolo \\
\hline$C_{4}$ & íon-dipolo* \\
\hline$C_{5}$ & dipolo-quadrupolo \\
\hline$C_{6}$ & dipolo*-dipolo* \\
\hline$C_{7}$ & quadrupolo-quadrupolo \\
\hline$C_{8}$ & dipolo*-quadrupolo* \\
\hline$C_{9}$ & quadrupolo-octopolo \\
\hline$C_{10}$ & quadrupolo*-quadrupolo* \\
\hline
\end{tabular}

sendo $E_{D}$ a energia de dissociação e $R$ a distância internuclear. Os coeficientes $C_{n}$ são calculados da teoria de perturbação, pela expansão multipolar (44). Os coeficientes $C_{1}$, $C_{2}$ e $C_{4}$ caraterizam as interações íon-íon, íon-dipolo e a interação de um íon com um dipolo induzido, respectivamente. Estes coeficientes são diferentes de zero unicamente quando tratamos com partículas que tem uma carga efetiva. Portanto podemos desconsiderar estes termos daqui para frente pois tratamos exclusivamente com átomos neutros. Os coeficientes com números ímpares $n \geq 3$ correspondem a forças intermoleculares ressonantes. Os termos com $n$ par 6, 8 e 10 são comumente chamados de termos dissociativos. A Tabela 6.1 mostra as contribuições que cada um destes termos oferece para o potencial de interação total.

Como dois átomos alcalinos nos seus estados fundamentais não têm momentos elétricos permanentes, todos os termos com $n$ ímpar são zero. O principal termo na expansão da equação 6.2.1 é o termo de van der Waals, um termo de interação de dipolos induzidos pelas flutuações no vácuo. $\mathrm{O}$ valor de $C_{6}$ pode ser obtido tratando dois átomos colidindo como um sistema de dois níveis, consistindo de um estado fundamental $\left|g_{i}\right\rangle$ e um estado excitado $\left|e_{i}\right\rangle$ e a frequência de transição entre os estados sendo $\omega_{i}=2 \pi c / \lambda_{i}$ (com $i=A, B$, as etiquetas para cada átomo). Neste caso a teoria de perturbações produz (3)

$$
C_{6} \simeq-\frac{4 d_{A}^{2} d_{B}^{2}}{\hbar\left(\omega_{A}+\omega_{B}\right)}
$$

para $C_{6}$ no estado fundamental, onde $d_{i}=\left\langle g_{i}|e \mathbf{r}| e_{i}\right\rangle$ é o momento dipolar dos átomos. Desta forma o potencial $C_{6} / R^{6}$ é sempre atrativo. 
O coeficiente $C_{3}$ de um potencial molecular excitado descrito pela interação ressonante dipolo-dipolo pode ser escrito como

$$
C_{3} \simeq \pm 2\left\langle g_{A}|e \mathbf{r}| e_{B}\right\rangle^{2}
$$

Esta equação mostra uma diferença entre os potenciais dos estados fundamental e excitado: no estado fundamental todas as curvas são atrativas, enquanto que no estado excitado, que é caraterizado pelas interações dipolo-dipolo, temos que a metade das curvas pertencem a potenciais repulsivos, os quais não aceitam estados moleculares ligados.

Cohen e Schneider (45) realizaram cálculos teóricos para uma derivação semi-empírica a fim de calcular os potenciais do caso $c$ ) de Hund com a teoria de perturbação a partir do caso a) de Hund, produzindo os potenciais

$$
\begin{aligned}
0_{g} & =\left(\begin{array}{cc}
V\left({ }^{3} \Pi\right)-\frac{A^{S O}}{2} & \frac{A^{S O}}{\sqrt{2}} \\
-\frac{A^{S O}}{\sqrt{2}} & V\left({ }^{3} \Sigma^{+}\right)
\end{array}\right) \\
0_{u} & =\left(\begin{array}{cc}
V\left({ }^{3} \Pi\right)-\frac{A^{S O}}{2} & -\frac{A^{S O}}{\sqrt{2}} \\
-\frac{A^{S O}}{\sqrt{2}} & V\left({ }^{1} \Sigma^{+}\right)
\end{array}\right) \\
1_{g} & =\left(\begin{array}{ccc}
V\left({ }^{3} \Pi\right) & -\frac{A^{S O}}{2} & -\frac{A^{S O}}{\sqrt{2}} \\
-\frac{A^{S O}}{2} & V\left({ }^{1} \Pi\right) & \frac{A^{S O}}{2} \\
-\frac{A^{S O}}{2} & \frac{A^{S O}}{2} & V\left({ }^{3} \Sigma^{+}\right)
\end{array}\right)
\end{aligned}
$$

onde $A^{S O}$ é o desdobramento na estrutura fina. O potencial $0_{g}^{-}$é uma mistura dos potenciais tripleto, enquanto que $0_{u}^{+}$e $1_{g}$ têm caraterísticas de singleto e tripleto.

\subsection{Regras de seleção para potenciais moleculares}

Para o caso da formação das moléculas, se tem certas regras para as transições eletrônicas dipolares. O número quântico do momento angular total não pode ser mudado mais do que uma unidade por vez $\left(\Delta J=0, \pm 1\right.$, com a restrição $\left.J=0 \leftrightarrow J^{\prime}=0\right)$. Desta forma, as transições entre singleto e tripleto não são permitidas. As mais importantes regras de seleção são resumidas na Tabela 6.2. 
Tabela 6.2 - Regras de seleção para a formação de estados moleculares (transições eletrônicas dipolares).

\begin{tabular}{c|c}
\hline & Regra de seleção \\
\hline \hline Simetria & $+\leftrightarrow-,+\leftrightarrow+,-\leftrightarrow-$ \\
\hline Paridade & $g \leftrightarrow u, g \leftrightarrow g, u \leftrightarrow u$ \\
\hline Momento angular orbital & $\Delta \Lambda=0, \pm 1$ \\
\hline Spin eletrônico $S$ & $\Delta S=0$ \\
\hline Projeção do spin eletrônico & $\Delta \Sigma^{\prime}=0$ \\
\hline Momento angular eletrônico total & $\Delta \Omega=0, \pm 1$ \\
\hline Momento angular total & Se $\Delta \Omega=0 \Rightarrow \Omega=0$ mais do que $\Delta J \neq 0$ \\
\hline
\end{tabular}
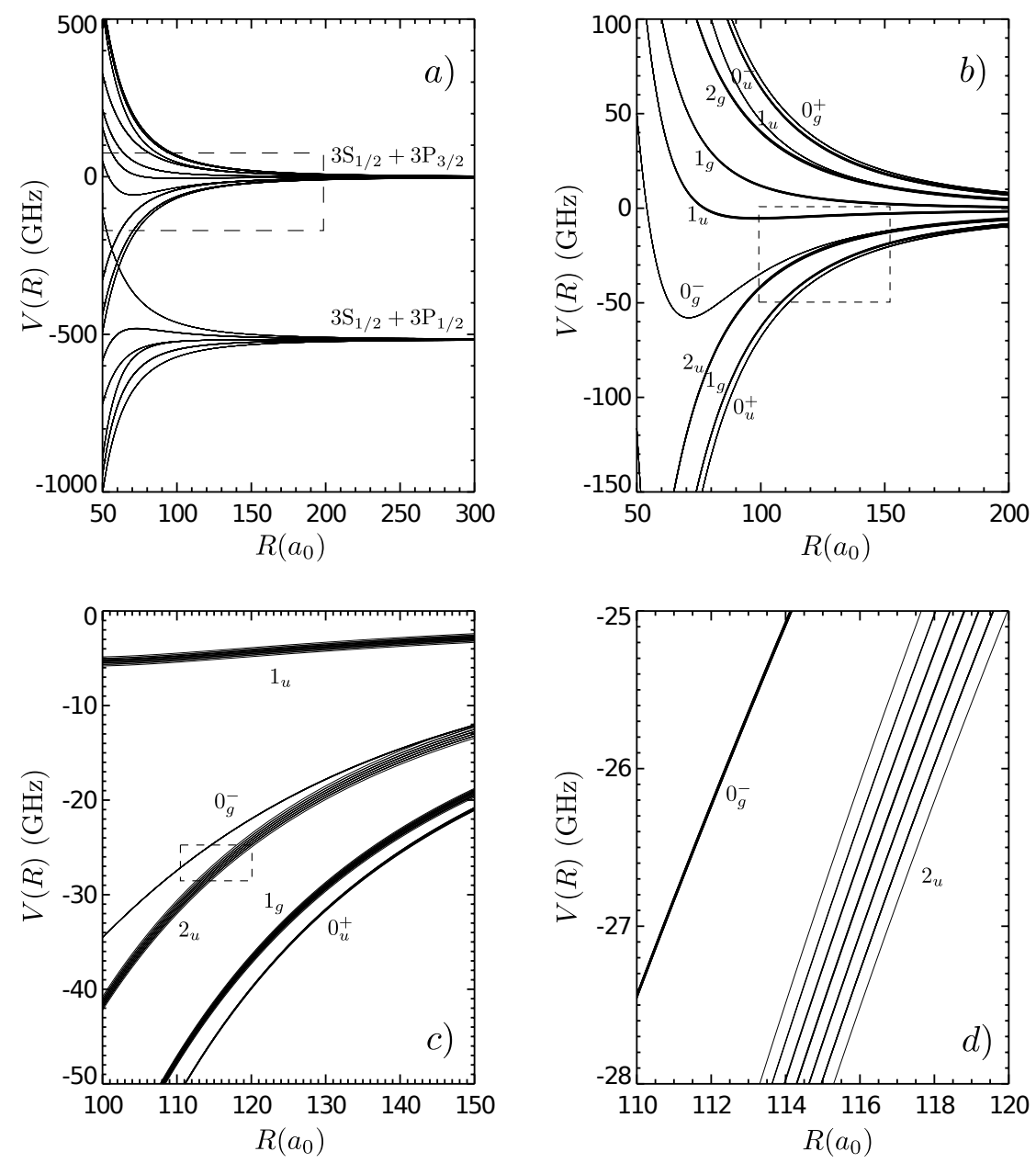

Figura 6.3.1 - Curvas potenciais para o caso c) de Hund para o $\mathrm{Na}_{2}$. a) Vista dos estados moleculares da molécula de $\mathrm{Na}_{2}$ conetados com as assíntotas $3^{2} S_{1 / 2}+3^{2} P_{1 / 2}$ e $3^{2} S_{1 / 2}+3^{2} P_{3 / 2}$, com diferença entre elas de 515,52 GHz. b) Estados moleculares conetados com a assíntota $3^{2} S_{1 / 2}+3^{2} P_{3 / 2}$. c) Aqui se podem apreciar os estados atrativos de interesse neste trabalho. d) A figura mostra a estrutura hiperfina para o estado $2_{u}$. 


\subsection{Estados moleculares intermediários de longo al- cance no sódio}

Para o sódio, os estados moleculares de longo alcance já foram amplamente estudados em anos passados (46, 47). As duas séries vibracionais reconhecidas na maioria dos espetros de fotoionização associativa por um e dois fótons são os estados simplesmente excitados $0_{g}^{-}$e $1_{g}$. Ambos estão conectados assintoticamente com o limite de dissociação $3^{2} S_{1 / 2}+3^{2} P_{3 / 2}$. Estes potenciais são atrativos para grandes distâncias de separação internuclear $R$. Desta forma os únicos potenciais confinados que podem contribuir são $0_{u}^{+}, 0_{g}^{-}, 1_{g}, 1_{u}$, e $2_{u}$, já que só estes estados são atrativos e estão conectados à assíntota $3^{2} S_{1 / 2}+3^{2} P_{3 / 2}$. Devido às regras de seleção devemos excluir dos estados o $2_{u}$, visto que não podemos excitar desde um estado fundamental $\Sigma^{\prime}$ para o estado $2_{u}$. A figura 6.3.1 mostra os diferentes potenciais que aparecem devido ao caso $c$ ) de Hund para átomos de sódio, considerando inclusive a estrutura hiperfina. Se tem também que a profundidade do estado $1_{u}$ é de apenas aproximadamente $5.4 \mathrm{GHz}$. Portanto, o espectro dele em um possível espectro de fotoionização associativa se veria sobreposto com os correspondentes aos estados $0_{g}^{-}$e $1_{g}$, que têm maior população e, portanto, maiores picos nessa região do espectro. Se deve levar em conta também o fato que a estrutura hiperfina causa um alargamento nos picos do espectro de fotoionização associativa, que é da ordem de 0.1 $\mathrm{GHz}$ para as estruturas do estado $0_{g}^{-}, 0.3 \mathrm{GHz}$ para o $0_{g}^{+}$e $1 \mathrm{GHz}$ para o mais profundo estado $1_{g}$. Lett verificou que os picos dos espectros de fotoionização associativa mostram efeitos da estrutura hiperfina (9, 48).

\subsubsection{O estado $1_{g}$}

Este é um estado profundo que apresenta muitos níveis vibracionais (mais de 100), entre os estados atrativos do estado intermediário simplesmente excitado, que se conecta com a assíntota $3^{2} S_{1 / 2}+3^{2} P_{3 / 2}$ para a molécula de $\mathrm{Na}_{2}$. Os níveis vibracionais deste estado tem uma maior presença para dessintonias maiores que $5 \mathrm{GHz}$ com respeito ao limite de dissociação, como é mostrado por Amelink e Lett (35, 48) para experimentos com uma só cor. No entanto, para experimentos com duas cores, uma melhor identificação das estruturas é mais complicada devido à maior presença de picos pertencendo ao estado $0_{g}^{-}$. 


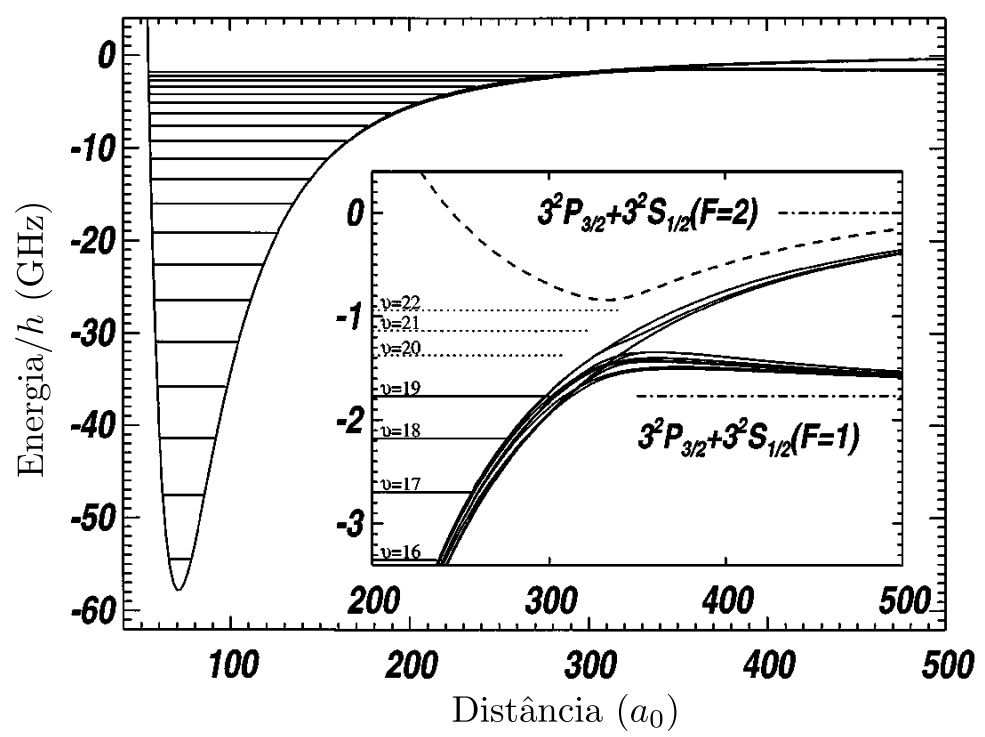

Figura 6.4.1 - Estado ligados calculados por Molenaar (49) para o estado $0_{g}^{-}$em átomos de sódio. O inset mostra os estados mais próximos do limite de dissociação. Pode se observar também que a maioria dos estados $0_{g}^{-}$ estão conectados a $3^{2} S_{1 / 2}\left(F_{g}=1\right)+3^{2} P_{3 / 2}$; só três estados estão conectados a $3^{2} S_{1 / 2}\left(F_{g}=2\right)+3^{2} P_{3 / 2}$.

\subsubsection{O estado $0_{g}^{-}$}

O estado $0_{g}^{-}$é um estado atrativo puramente de longo alcance. Foi demonstrado em anos anteriores que o estado $0_{g}^{-}$é o maior responsável pela estrutura que aparece nos primeiros $5 \mathrm{GHz}$ dos espectro de ionização (35). A profundidade do estado $0_{g}^{-}$é de aproximadamente uns $58 \mathrm{GHz}$ com respeito ao limite de dissociação. A figura 6.4.1 mostra uma simulação feita por Molenaar (49) para os estados deste potencial. A presença deste potencial permite o processo de fotoionização associativa, no qual um fóton leva o par desde um nível vibracional deste estado para o estado duplamente excitado, o qual permitirá posteriormente o par ser autoionizado. Para este potencial, este processo é exclusivo, devido ao fato que não existem transições verticais desde um nível vibracional deste estado para o estado autoionizante, já que a parte atrativa deste potencial existe só a longas distancias interatômicas, não permitindo deste modo, a ionização direta desde este estado.

\subsubsection{O estado $1_{u}$}

O estado $1_{u}$ é um estado pouco profundo, quase raso, puramente de longo alcance, que está conectado assimptoticamente com $3^{2} S_{1 / 2}+3^{2} P_{3 / 2}$. Amelink demonstrou (50) 


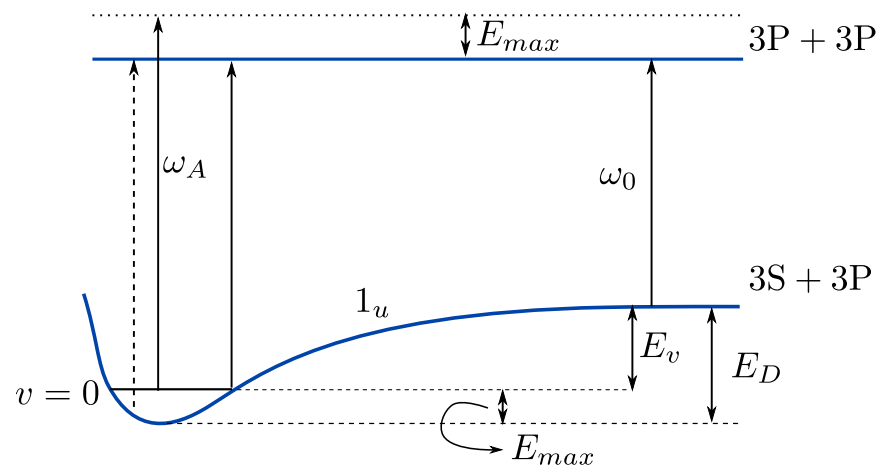

Figura 6.4.2 - Esquema mostrando o processo pelo qual se justifica a ausência do estado $1_{u}$ dos espectros de fotoionização associativa.

que o estado vibracional mais baixo para este potencial, o estado $v=0$ tem só $4.6 \mathrm{GHz}$ de profundidade. Mediante argumentos semiclássicos se pode justificar a ausência das estruturas deste potencial na maioria dos espectros de fotoionização associativa por um e dois fótons para grandes dessintonias dos lasers de excitação. Amelink justifica que os estados do potencial $1_{u}$ não são ionizados em experimentos de uma e duas cores com as típicas dessintonias usadas. Os argumentos são os que seguem: temos que no caso do nível $v=0$ do $1_{u}$ temos que $E_{\max } / h=-4.6-(-5.4)=0.8 \mathrm{GHz}$. Usando o princípio de FranckCondon sabemos que a energia cinética não pode ser mudada pela absorção de um fóton. Assim, os fótons absorvidos no segundo passo do processo têm que cumprir com a relação $0 \leq E_{\text {excesso }} \leq E_{\text {max }}$, onde $E_{\text {excesso }}=\hbar \omega_{L}+\hbar \omega_{A}-2 \hbar \omega_{0}$, com $\omega_{0}$ a frequência de ressonância entre as assíntotas dos estados simplesmente excitado e o duplamente excitado, como mostra a figura 6.4.2. Desta forma, se cumpre que $\omega_{0}+E_{v} / \hbar<\omega_{A}<\omega_{0}+E_{D} / \hbar$, o estado $v=0$ não será ionizado em um segundo passo. A única possibilidade disto acontecer é ter que as dessintonias das frequências dos lasers $\Delta_{L}<4.6$ e $\Delta_{A}<5.4$. A maioria de experimentos de fotoionização associativa se realiza com dessintonias dos lasers sendo maiores do que as energias destes estados, devido à limitação que impõem as frequências cut-off para este tipo de processo (6). No entanto, com as dessintonias propostas para ver as estruturas do potencial $1_{u}$, estas estariam sobrepostas com as estruturas dos outros potenciais.

\subsubsection{Outros Estados}

Se observamos a figura 6.3.1, podemos apreciar que os estados $0_{g}^{-}, 1_{g}$ e $1_{u}$ não são os únicos estados moleculares atrativos que podemos considerar. Anteriormente temos descartado a presença do estado $2_{u}$, pois transições desde o estado fundamental até este estado são proibidas. Assim temos que o único estado a considerar além dos já discutidos é o estado $0_{u}^{+}$. As estruturas correspondentes a este estado não têm sido detectadas em 
experimentos de fotoionização associativa, ou em todo caso, não têm sido identificadas de maneira explícita como tal.

Temos também que os espectros de fotoionização associativa muitas vezes carregam consigo as estruturas pertencentes aos estados moleculares duplamente excitados como foi estudado por Amelink (51). Nestes estados, o termo de interação dominante deve ser a interação quadrupolo-quadrupolo $C_{5} / R^{5}$. Se demostrou além disto, que os estados que majoritariamente predominam na promoção dos íons desde os estados simplesmente excitados são os estados de simetria atrativa $0_{u}^{-}$e $1_{u}$.

\subsection{Resultados experimentais: espectro de fotoioni- zação associativa por dois fótons para a região de 0 até $-30 \mathrm{GHz}$}

Levamos em consideração experimentos de fotoionização associativa por dois fótons para átomos de sódio em um Dark MOT, com dois feixes laser obtidos de lasers de corante Coherent® 699 e 899. O MOT é operado a uma frequência de aprisionamento de 508.84801 $\mathrm{GHz}$, proveniente de um laser de estado sólido como foi descrito no capítulo 4 . Com a implementação do Dark Spot é esperado que mais de $90 \%$ dos átomos estejam no estado fundamental hiperfino $F_{g}=1$.

O esquema experimental para a obtenção de átomos de sódio resfriados e aprisionados é o mesmo daquele mostrado no capítulo 4. Para a realização do experimento de fotoionização associativa por dois fótons adicionamos os dois lasers de excitação. Um destes, ao qual daqui em adiante chamaremos de laser de prova, é varrido desde a frequência de aprisionamento, com dessintonias no vermelho, até os $-30 \mathrm{GHz}$ de dessintonia. Por outro lado temos o laser com dessintonia para o azul da transição de aprisionamento, que será chamado daqui para frente de laser azul, o qual tem uma dessintonia $+30 \mathrm{GHz}$ e é mantido fixo em potência e em frequência. Eles são focalizados por uma lente de 25 cm na entrada da câmara com o que se consegue uma área de incidência no MOT de $3,4 \times 10^{-3} \mathrm{~mm}^{2}$. Ambos os lasers entram pela mesma janela da câmera do MOT, com perfis de intensidade da mesma ordem, ao incidir no MOT como mostra a figura 6.5.1.

Estes lasers foram incididos com o MOT da mesma forma que foi descrito o alinhamento para as moléculas fotônicas no capítulo 5. Para uma melhor resolução do espectro de fotoionização associativa foi implementada uma sequência temporal, a qual é mostrada na figura 6.5.2. A sequência temporal foi controlada mediante shutters do fabricante Uniblitzer®, que permitem uma melhor sincronia na sequência. A sequência basicamente é constituída de 4 passos: 


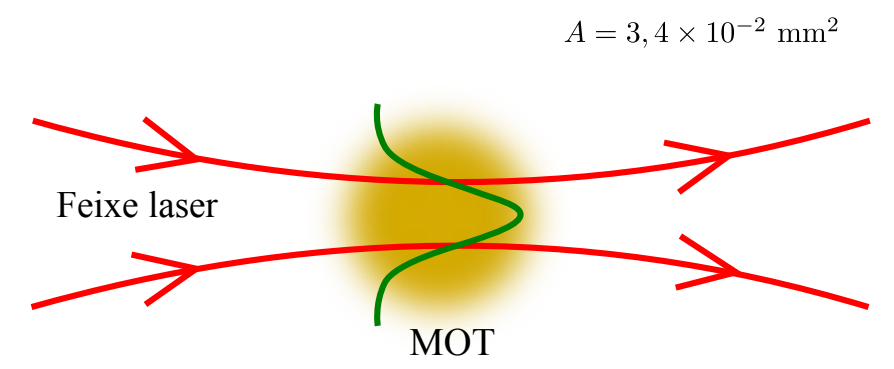

Figura 6.5.1 - Interação do MOT com um feixe gaussiano do laser. $A$ é a área com a qual o feixe gaussiano incide no MOT.

- Passo 1: Se desliga o feixe de desaceleração e se liga o feixe azul por um intervalo de tempo. A contagem de íons deste intervalo é realizada.

- Passo 2: Se desliga o feixe azul e se liga o feixe de desaceleração por um intervalo de tempo para poder recuperar a amostra de átomos frios. Nenhuma medida é realizada neste intervalo.

- Passo 3: Se desliga novamente o feixe de desaceleração e se ligam os feixes azul e de prova pelo mesmo intervalo de tempo do Passo 1. É realizada a contagem de íons.

- Passo 4: Se desligam os feixes azul e de prova e volta-se a ligar o feixe de desaceleração, deixando pronto o sistema para começar uma nova medida. Nenhuma medida é feita neste intervalo.

A contagem de íons é dada pela equação 5.1.1. Todo o sistema da sequência temporal, assim como o sistema de operação dos lasers, é controlado e monitorado pela interface comercial Labview ${ }^{\circledR}$. Como o laser de prova é varrido desde a frequência de ressonância até chegar aos -30 GHz de dessintonia, é preciso mudar uniformemente os intervalos de medida. Isto se consegue colocando o laser de corante em modo de operação externo e controlando por meio da interface Labview ${ }^{\circledR}$, que também monitora qualquer desvio nos intervalos da frequência. É importante destacar que todo o sistema de automatização e monitoramento implementado neste experimento foi desenvolvido por R. R. de Paiva (34).

Para a contagem de íons, utilizamos um contador de íon, que está implementado dentro da câmara de aprisionamento. Do mesmo jeito, temos usado um fotodetetor para monitorar a fluorescência dos átomos e assim o número de átomos aprisionados em um sistema de imagem. Maiores detalhes destes sistemas podem ser encontrados na dissertação de mestrado de E. Pedrozo-Peñafiel (36). A seguir discutiremos os resultados produzidos por este experimento. 


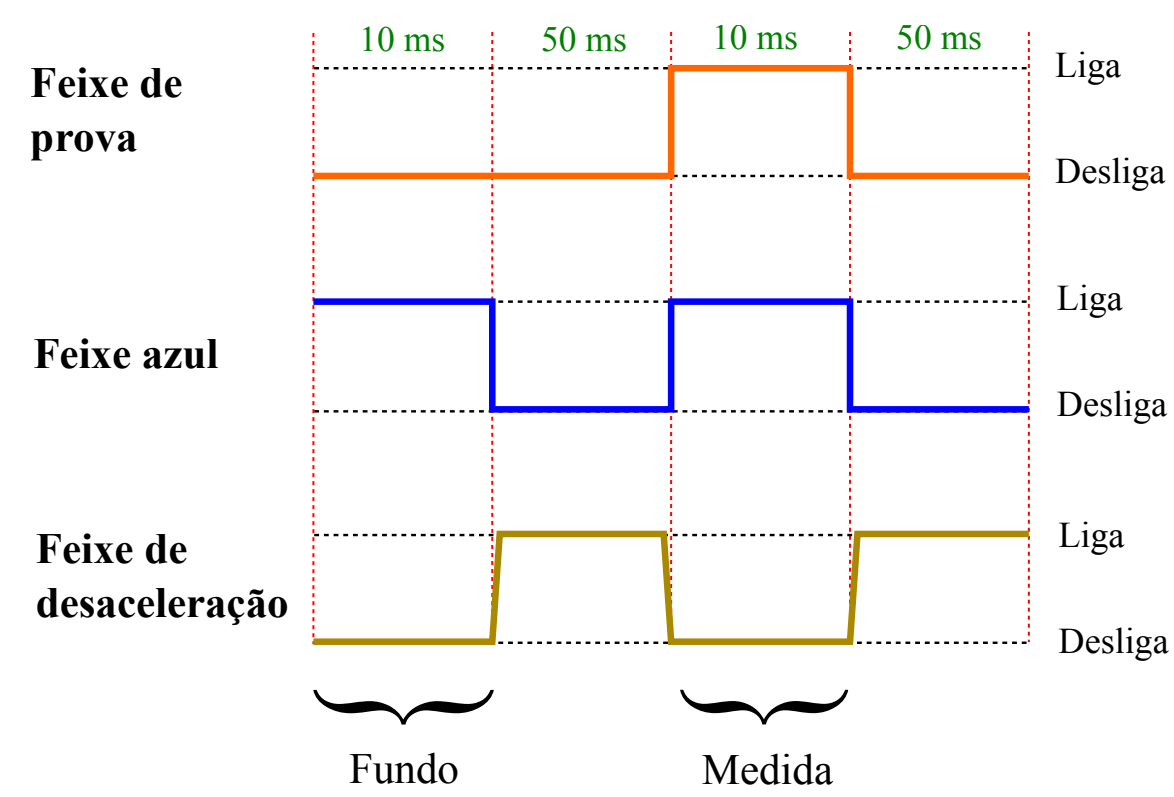

Figura 6.5.2 - Esquema da sequência temporal implementada neste experimento e controlada pelo programa de controle e aquisição Labview®.

\subsubsection{Espectro na região de 0 até $-30 \mathrm{GHz}$.}

Foi visto em estudos anteriores, que os estados dominantes nos espectros de fotoionização associativa são o $0_{g}^{-}$e o $1_{g}$. Lett (48) fez experimentos de fotoionização associativa por uma e duas cores e identificou as séries vibracionais, como correspondentes a $0_{g}^{-}$e o $1_{g}$ efetivamente. Em muitos experimentos de fotoionização associativa por um e dois fótons, são identificadas as séries vibracionais como sendo as séries pertencentes a $0_{g}^{-}$e $1_{g}$, mas, é sabido que não são as únicas presentes. Em um espectro amplo, como o que obtivemos, podemos fazer uma identificação mais completa, além disto, podemos estudar series vibracionais de estados que não aparecem em espectros de fotoionização associativa no qual tem se usado um MOT convencional (conhecido como Bright MOT). A vantagem do Dark MOT, é precisamente que ele permite a aparição de estados que estão ausentes quando ambos os átomos que colidem estão nos seus estados fundamentais hiperfinos $F=2$, como acontece em um Bright MOT. Assim, a estrutura convencional além dos 5 primeiros $\mathrm{GHz}$, onde se espera que tenha a presença majoritária dos níveis vibracionais do estado $0_{g}^{-}$, agora pode ter picos pertencendo a estados não convencionais neste tipo de espectro. Estas novas estruturas tornam-se interessantes, pois mostram que dependendo da configuração do sistema, se pode ter acesso a diferentes níveis moleculares. São estas novas estruturas que podem ser protagonistas na formação de um estado molecular que envolve fótons, como é a molécula fotônica. É por isto que uma identificação destas estruturas mediante uma lei de escala vai ser de importância para saber com que tipo de estados moleculares estamos trabalhando.

As figuras mostram dois espectros obtidos para fotoionização associativa por duas 


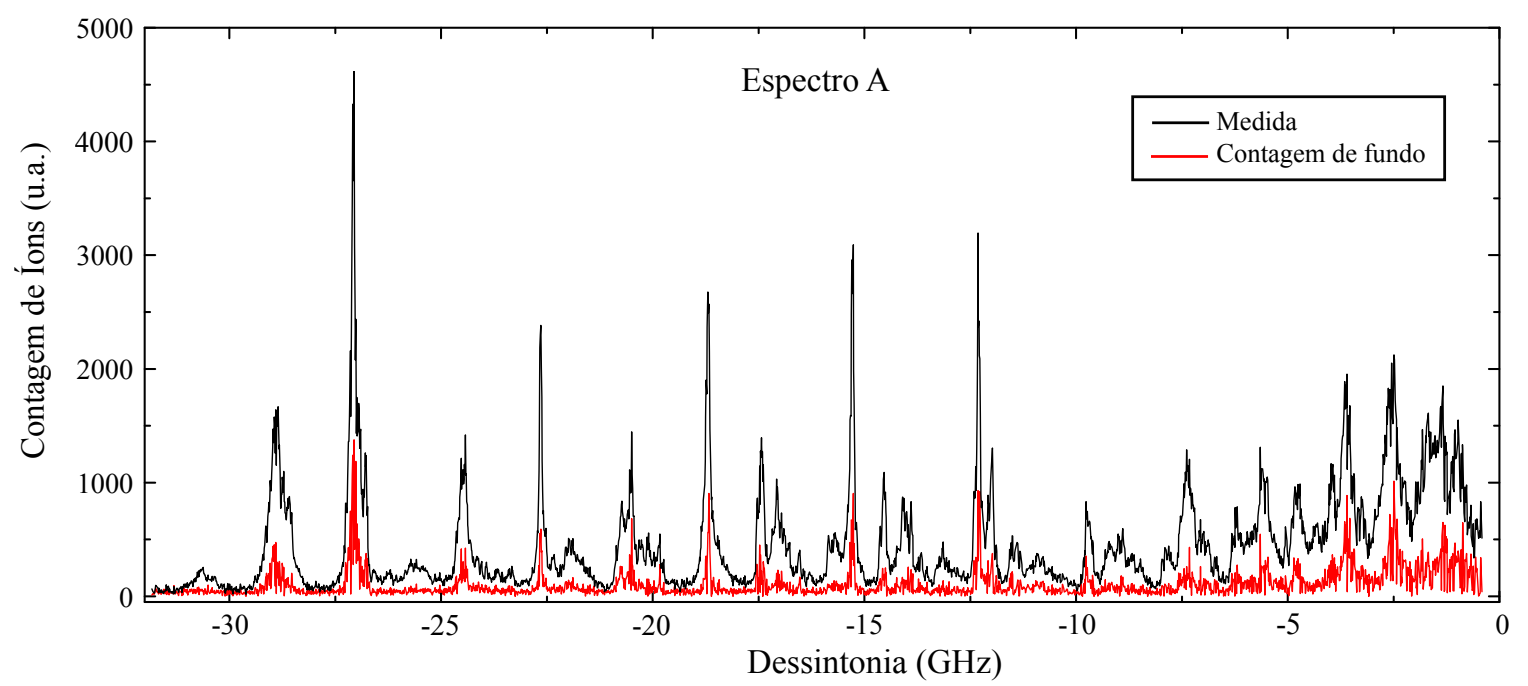

Figura 6.5.3 - Espectro de Espectro $A$ onde se mostra as contagens de fundo e de medida.

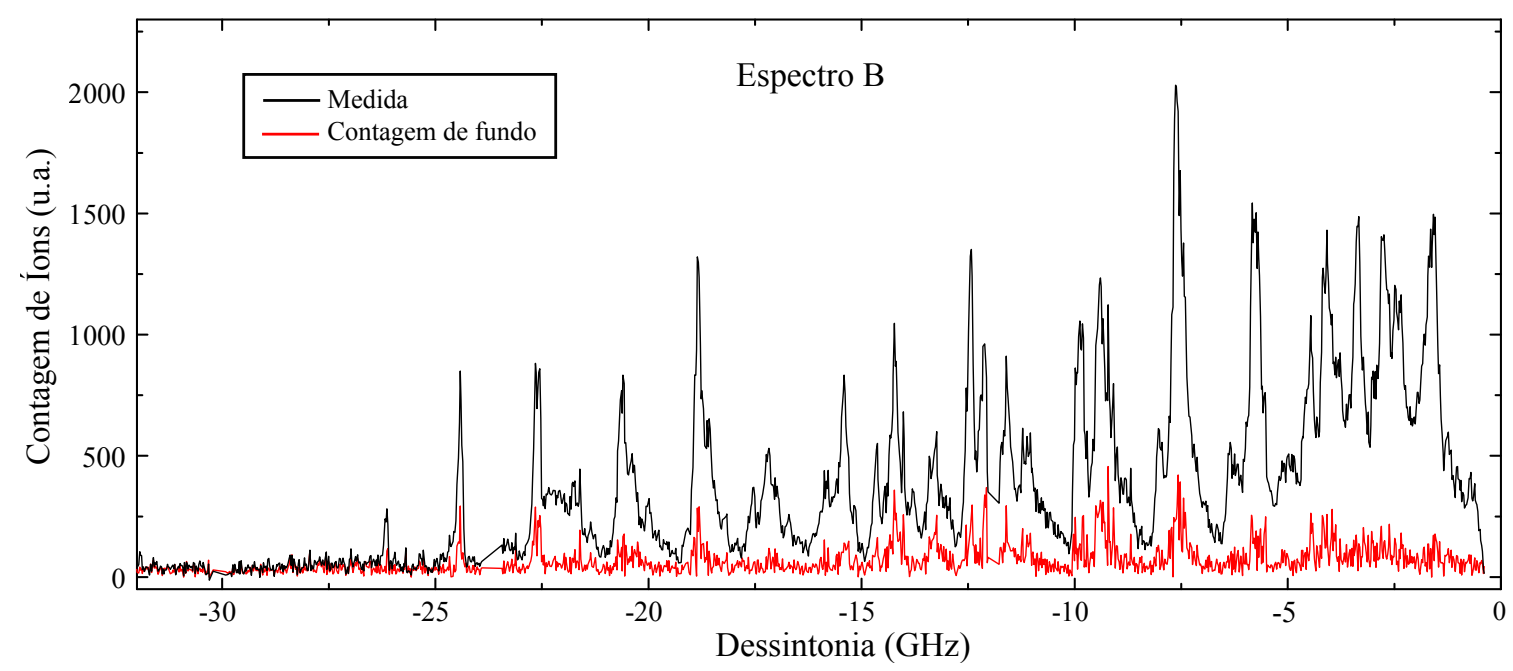

Figura 6.5.4 - Espectro de Espectro $B$ onde se mostra as contagens de fundo e de medida. 


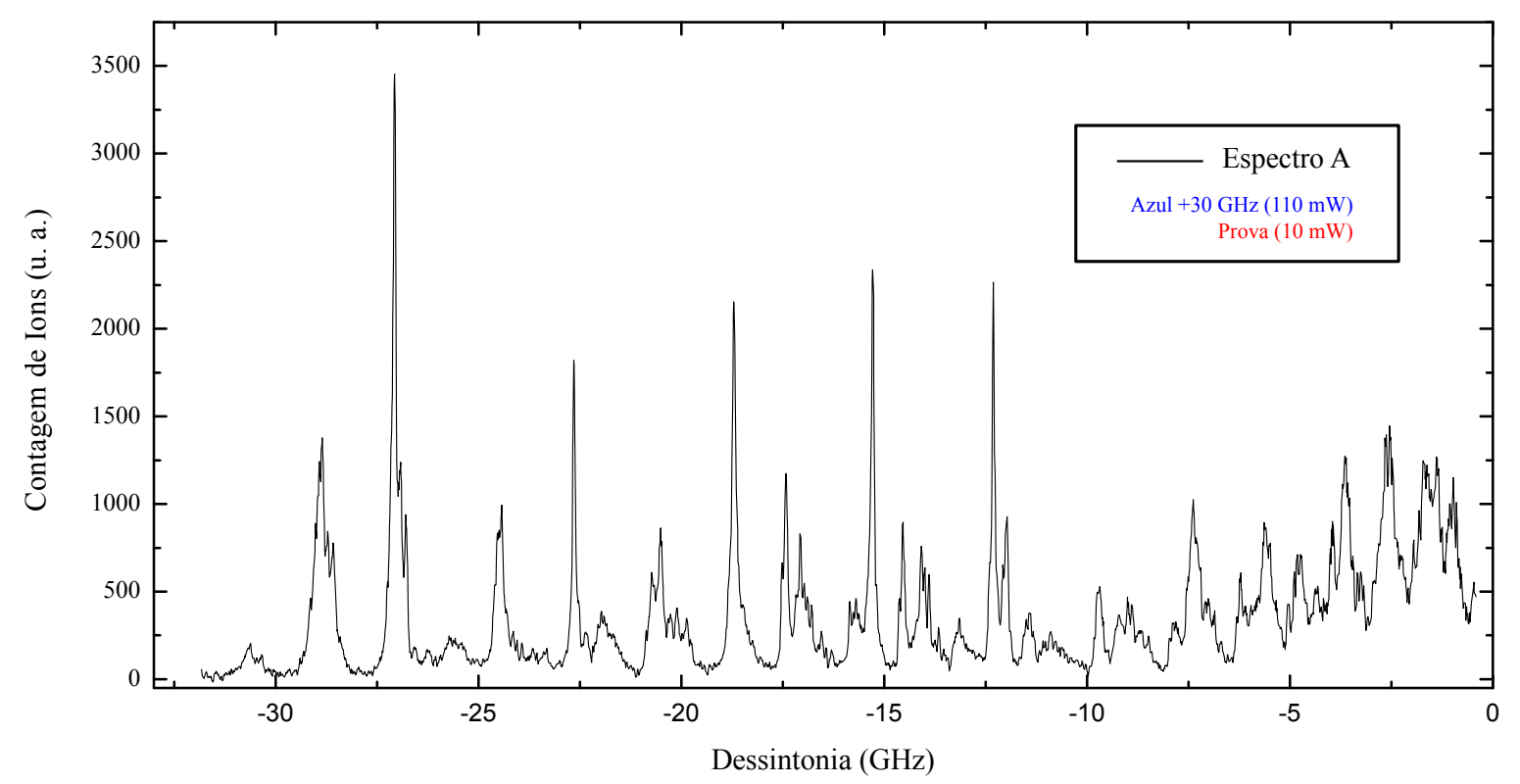

Figura 6.5.5 - Espectro de fotoionização associativa por dois fótons para átomos de sódio na região de 0 até $-30 \mathrm{GHz}$. Se pode ver que as estruturas na região de -10 até $-30 \mathrm{GHz}$ estão melhor resolvidas.

cores em um Dark MOT onde podem ser observado a contagem de fundo e a contagem total de íons. Já as figuras 6.5.5 e 6.5.6 mostram a contagem neta de íons produzidos na medida. Denominamos esses espectros "A" e "B", respectivamente. O espectro "A" foi obtido varrendo o laser de prova desde 0 até $-32 \mathrm{GHz}$ com uma potência de $10 \mathrm{~mW}$ e um laser azul com uma dessintonia da frequência de ressonância de $+30 \mathrm{GHz}$ e uma potência de $110 \mathrm{~mW}$. Já para o espectro "B" utilizamos uma potência para o laser de prova de $4 \mathrm{~mW}$ com a mesma varredura que para o espectro "A" e um laser azul com uma potência de $173 \mathrm{~mW}$ e sendo a dessintonia igualmente de $+30 \mathrm{GHz}$. No espectro "A" destacam-se os picos na região dos -10 até -30 GHz, enquanto que para o espectro do espectro "B", pode-se notar que os picos na região de 0 até -10 GHz são mais evidentes, o que vai possibilitar uma melhor identificação nessa região.

Em um experimento de PAI por dois fótons, a influência do segundo passo (no qual o laser com dessintonia para o azul de frequência $\omega_{A}$ ioniza o par atômico) no espectro se pode ver refletida nas alturas relativas dos picos dos estados, sendo este efeito mais evidente no estado puramente de longo alcance $0_{g}^{-}$. Isto ressalta a importância do segundo passo no espectro de fotoionização associativa. Amelink demonstra que a altura dos picos dos estado $0_{g}^{-}$está relacionada com o segundo passo devido às estruturas do estado duplamente excitado, já que o estado $0_{g}^{-}$é quem geralmente faz exclusivamente fotoionização associativa (35). Ele apresenta um modelo que justifica o raciocínio. Anteriormente, demonstrou que os estados $1_{u}$ e $0_{u}^{-}$do estado duplamente excitado dominam as rotas do processo de fotoionização associativa para átomos de sódio. Se assume que os momentos dipolares para transições do estado fundamental ao estado simplesmente excitado $0_{g}^{-}$independem do número quântico vibracional. Também, se assume que os 


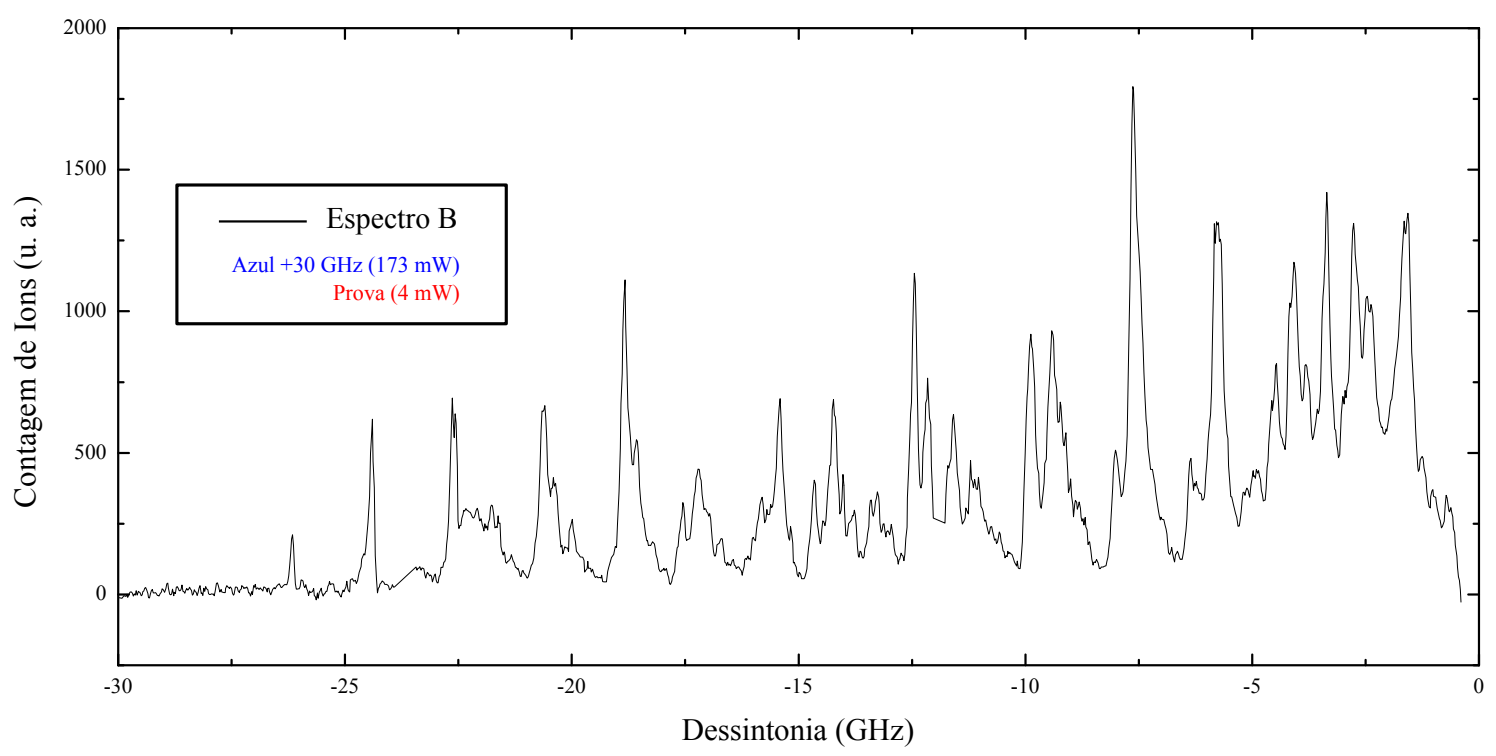

Figura 6.5.6 - Espectro de fotoionização associativa por dois fótons para átomos de sódio na região de 0 até $-30 \mathrm{GHz}$. As estruturas na região de 0 até -10 $\mathrm{GHz}$ estão neste espectro, mais claras. Nota-se que a partir dos $26 \mathrm{GHz}$ não se tem mais picos do que aqueles encontrados no espectro "A".

momentos dipolares para transições de qualquer nível vibracional do estado $0_{g}^{-}$para os estados $1_{u}$ e $0_{u}^{-}$dependem da simetria do estado duplamente excitado, mas não do excesso de energia. Assim, devemos levar em conta que as estruturas correspondentes ao estado $0_{g}^{-}$vão depender do segundo passo que é realizado pelo laser azul.

Para poder identificar as estruturas presentes nos nossos espectros de fotoionização associativa por dois fótons, fizemos um ajuste lorentziano dos espectros "A" e "B". Os ajustes por lorentzianas feitos para os espectros "A" $\mathrm{e}$ "B" podem ser observados nas figuras 6.5.7 e 6.5.8 respectivamente. Etiquetamos nestes espectros as frequências nas quais acontecem as ressonâncias mais destacadas, das quais identificaremos as séries vibracionais com o método proposto por Stwalley a mais de 30 anos (5). Estes espectros devem conter majoritariamente a presença dos estados $0_{g}^{-}$e $1_{g}$, segundo trabalhos de PAI por dois fótons feitos por outros grupos de pesquisa no mundo (6). Os primeiros $5 \mathrm{GHz}$ de forma geral são mais ricos em estruturas e se tem demonstrado que correspondem a uma majoritária presença do estado $0_{g}^{-}(35)$.

Muitos trabalhos têm feito similares identificações das séries vibracionais presentes nos espectros de fotoionização associativa (48, 51), e estão inspiradas no trabalho original de Stwalley. Lett (48) fez uma identificação parecida nos primeiros $100 \mathrm{GHz}$ do espectro para fotoionização associativa por um fóton. Bagnato (6) também fez uma identificação similar para um espectro de duas cores em átomos de sódio para os primeiros $3 \mathrm{GHz}$. Novamente, Amelink (51), usando o mesmo método com a lei de escala correspondente para os estados duplamente excitados, identificou as séries rotovibracionais para um espectro de fotoionização associativa para os estados duplamente excitados da molécula de $\mathrm{Na}_{2}$. A grande diferença do nosso trabalho consiste em estarmos trabalhando com um Dark 


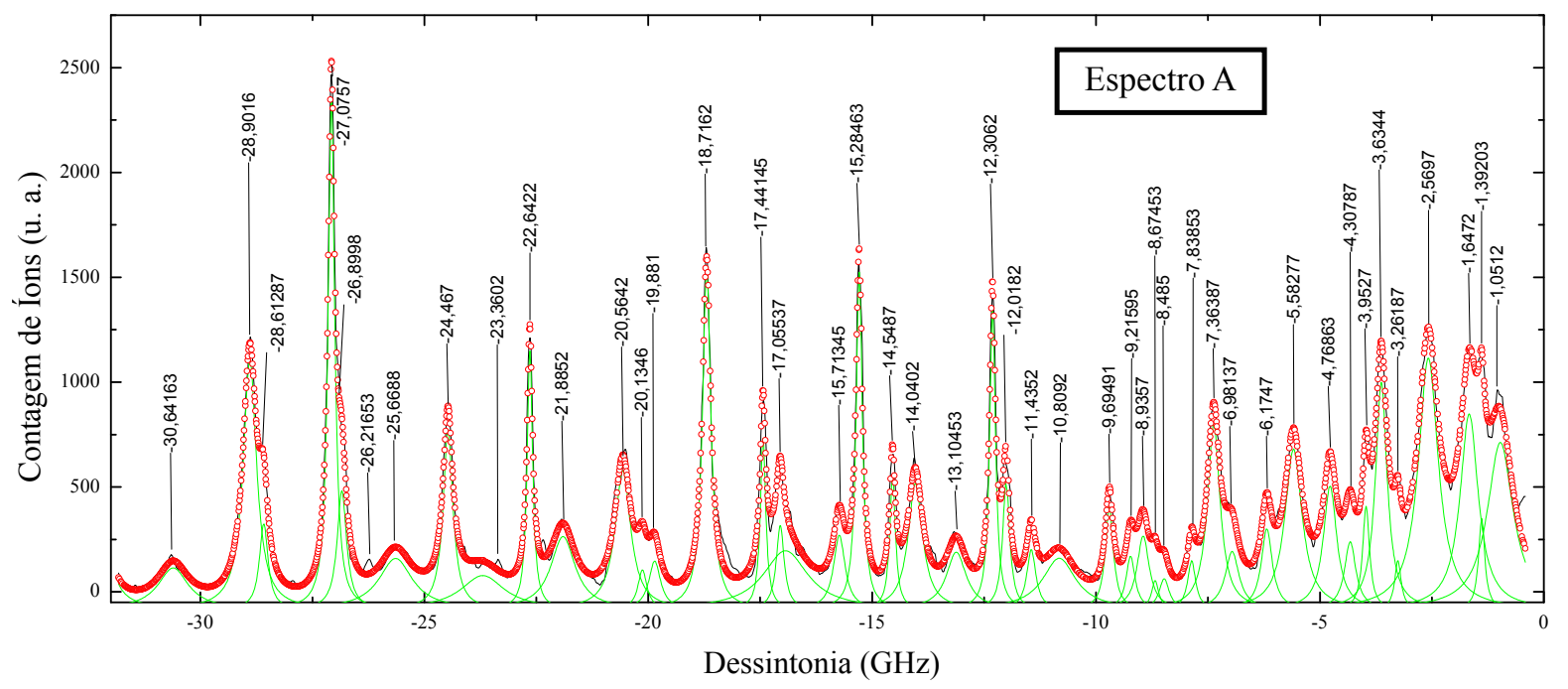

Figura 6.5.7 - Ajuste por lorentzianas do espectro de fotoionização associativa obtido na figura 6.5.5. O nosso ajuste reproduz quase todas as estruturas presentes no gráfico original com a exceção de uma situada em -26,216 GHz. As curvas de cor verde são os picos individuais ajustados por lorentzianas que serviram para reproduzir cada série vibracional presente no espectro.

MOT, em que o MOT tem majoritariamente as chamadas colisões $1+1$, e assim temos os átomos do estado fundamental no estado hiperfino $F=1$. Deste modo, podemos observar as estruturas que consideram alguns estados vibracionais que um MOT convencional não consideraria devido às majoritárias colisões de átomos no estado hiperfino $F=2$, chamadas de colisões $2+2$ (42).

Como vimos no capítulo 2, a energia dos níveis vibracionais estando mais próximas do limite de dissociação no potencial simplesmente excitado podem ser aproximados por $C_{3} / R^{3}$ e obedece à relação semiclássica (5):

$$
v_{D}-v=a_{3} \epsilon_{v}^{1 / 6}
$$

onde

$$
\begin{gathered}
a_{3}=\frac{2(2 \mu \pi)^{1 / 2}}{h} \frac{\Gamma\left(\frac{5}{6}\right)}{\Gamma\left(\frac{4}{3}\right)} C_{3}^{1 / 3} \\
\epsilon_{v}=E_{D}-E_{v=0}
\end{gathered}
$$

Estas equações nos dizem como que uma série vibracional se comporta em relação a potencia $1 / 6$ da dessintonia. A equação 6.5.1 dá uma relação linear e vai nos permitir fazer uma identificação dos níveis vibracionais pertencentes a uma serie vibracional em particular. Aqui $a_{3}$ é uma constante de proporcionalidade que pode ser calculada com teoria de perturbação independente do tempo, e que contém a constante $C_{3}$.

Descartamos anteriormente a presença das séries vibracionais correspondentes ao 


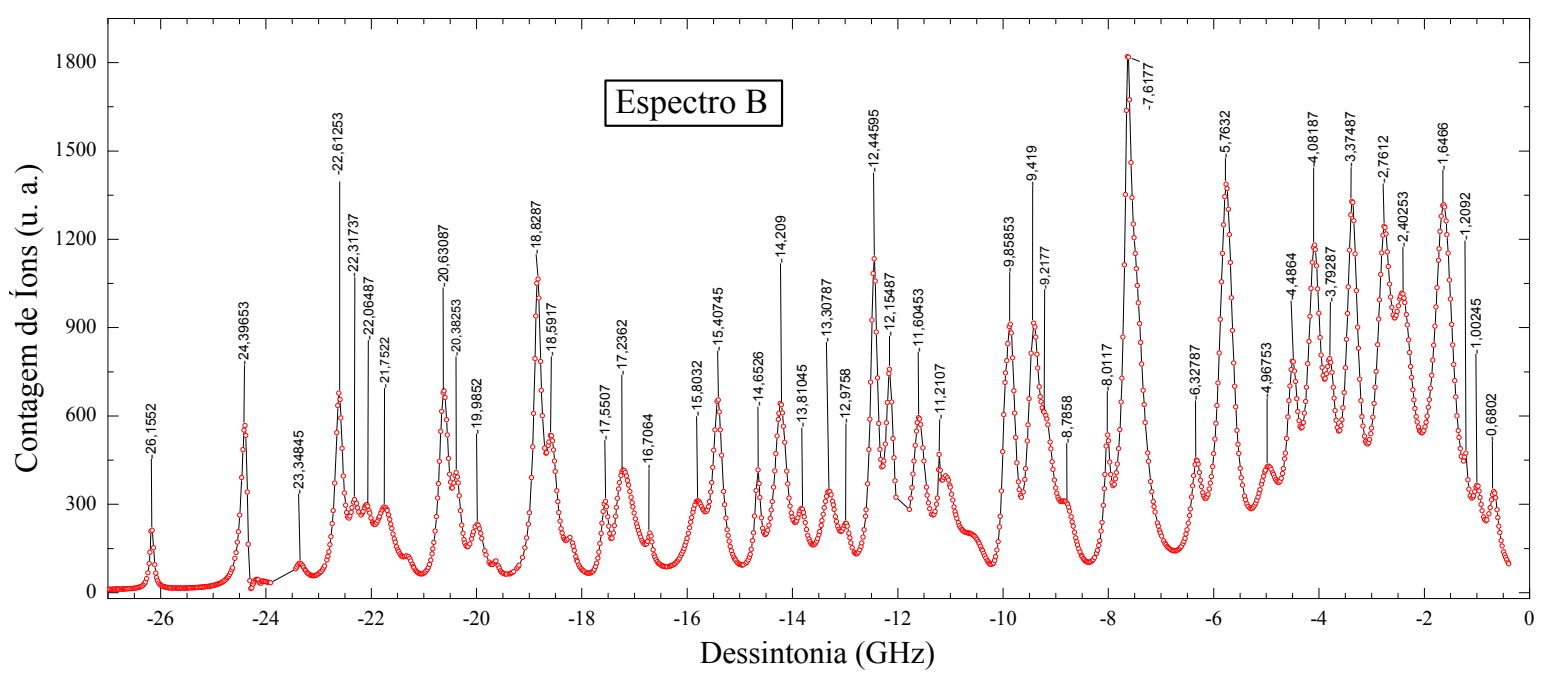

Figura 6.5.8 - Ajuste por lorentzianas do espectro de fotoionização associativa obtido da figura 6.5.6, o espectro "B". Este ajuste reproduz todas as estruturas presentes no gráfico original. Os picos têm sido etiquetados para um reconhecimento posterior das séries vibracionais presentes.

estado $1_{u}$, devido as dessintonias dos nossos lasers de excitação, visto que as estruturas que procuramos devem ser quase exclusivamente próprias dos estados $0_{g}^{-}$e $1_{g}$. No entanto, a relação dada pela equação 6.5.1 não leva em conta os efeitos que a estrutura hiperfina induz nos potenciais de longo alcance. Uma melhor identificação das séries vibracionais deveria levar em conta estes efeitos. Bagnato e Lett discutiram e analisaram a estrutura hiperfina real para uma molécula fotoassociada de sódio e seus efeitos num processo de fotoionização associativa (9, 48).

Para proceder à identificação dos picos podemos plotar as nossas estruturas como dependentes da dessintonia elevada a 1/6 como manda a lei de escala para estados moleculares intermediários. Com isto temos novos espectros que vão permitir uma melhor identificação das séries vibracionais presentes. Com a ajuda de um programa computacional puderam ser identificadas três series existentes em todo o espectro para ambos espectros "A" e "B". As figuras 6.5.9 e 6.5.10 mostram o espectro elevado a $1 / 6$ para os espectros "A" e "B", respectivamente. Para ambos os casos pode se ver que têm sido etiquetadas as series vibracionais correspondentes aos estados $0_{g}^{-}, 1_{g}$ e outro estado mais que obedece a mesma lei de escala.

Para uma melhor identificação temos tomado o espectro "A" e sua reprodução por lorentzianas. Tomando os valores correspondentes às frequências onde acontecem os picos para uma série em particular e elevando esta a 6, para recuperar a posição em frequência dos picos originais, podemos identificar cada lorentziana na figura 6.5.7. Agora tomando cada pico ajustado por uma lorentziana podemos reproduzir cada série vibracional presente no nosso espectro. Isto pode ser apreciado na figura 6.5.11, onde têm se isolado as séries para os estados $0_{g}^{-}, 1_{g}$ e o outro estado presente identificado como $0_{u}^{+}$. Para poder identificar picos residuais no nosso espectro, subtraímos cada série do espectro 
Espectro A

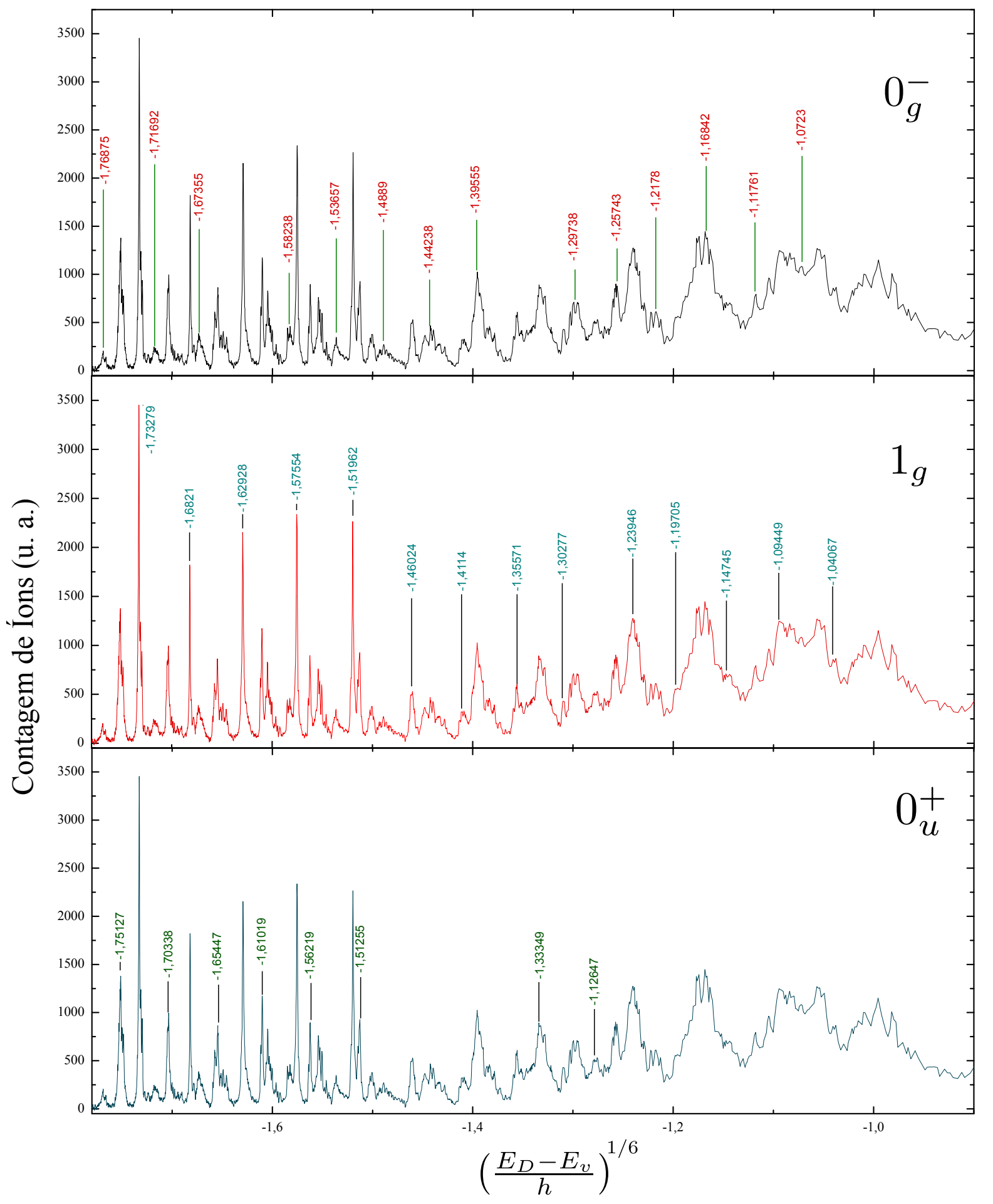

Figura 6.5.9 - Espectro das energias dos picos do espectro "A" elevadas ao exponente $1 / 6$. Os picos regularmente espaçados correspondem a uma determinada série vibracional identificada. Temos etiquetado os valores das dessintonias a $1 / 6$ para poder comprovar a lei de escala. 


\section{Espectro B}

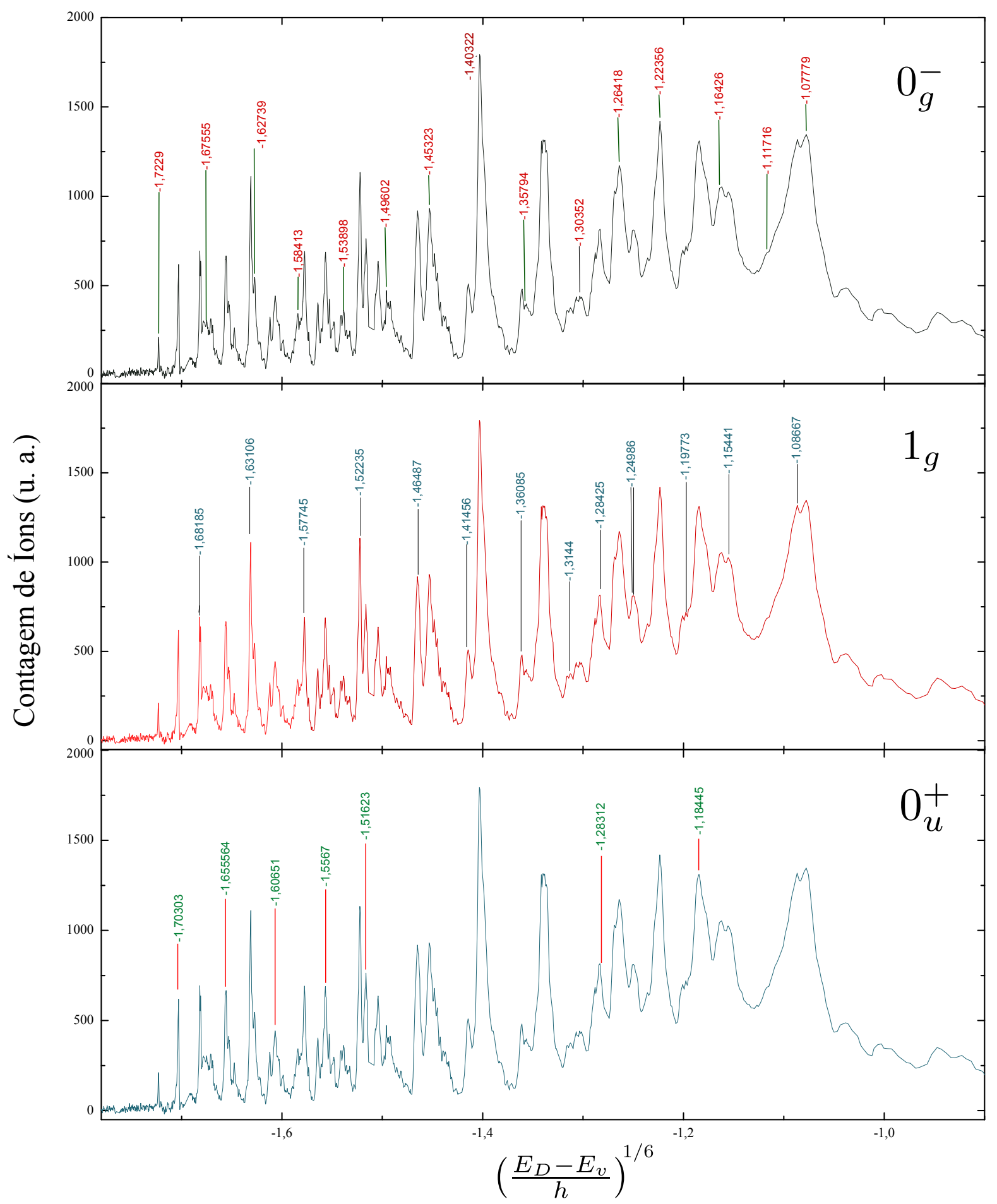

Figura 6.5.10 - Espectro das energias dos picos do espectro "B" elevadas ao exponente $1 / 6$. Novamente têm se etiquetado os picos com os valores do eixo das abscisas. 
original para assim ver se fica alguma série por ser identificada.

Na figura 6.5.12 pode ser visualizado o procedimento realizado. O espectro de baixo mostra os picos residuais depois de ter subtraído todas a séries identificadas. Os picos destacados por um círculo vermelho são picos que também obedecem a uma lei de escala como 1/6. Nada pode ser dito dos picos destacados pelos círculos azuis. No próximo capitulo, vamos ver que estas estruturas sem identificação voltam a aparecer quando reproduzimos os nossos espectros com a presença de um feixe azul intenso.

Com os valores para os picos das séries vibracionais para os espectros "A" e "B", como mostram as figuras 6.5.9 e 6.5.10, podemos fazer um gráfico que determina como as séries vibracionais estão igualmente espaçadas em um espectro com as dessintonias elevadas à $1 / 6$. Na figura 6.5.13 pode ser visto que a lei de escala se cumpre para ambos os espectros ("A" e "B") e que, além disto, são coincidentes para cada série vibracional. Aqui não temos levado em conta os valores dos números vibracionais para o estado $1_{g}$ -se fizéssemos isto teríamos os números vibracionais $v$ deste estado somados por 80 aproximadamente. Temos escolhido os números $v$ arbitrariamente, já que pretendemos aqui demonstrar a verificação da lei de escala e a identificação da série vibracional mais do que os números $v$ para cada estado.

Devemos considerar que outros tipos de efeitos não foram levados em conta na identificação deste espectro, como as mudanças induzidas pela presença da estrutura hiperfina, as colisões de átomos correspondentes ao estado hiperfino $F=2$, assim como os processos induzidos pelas limitações experimentais. É importante mencionar que no processo de fotoionização, o ideal era ter o MOT sem interagir com campos externos. Para isso seria ideal desligar os campos magnéticos no quadrupolo, os feixes de aprisionamento e rebombeio, assim como o fluxo de átomos. O nosso experimento foi realizado com todos esses campos estando presentes no MOT. No entanto, podemos dizer que os efeitos produzidos por eles são mínimos.

Se para a região explorada os números vibracionais reais do estado $1_{g}$ devem estar entre 80 e 100, para o estado $0_{u}^{+}$, os números vibracionais reais devem ser maiores que isto. Assim, temos comprovado a lei de escala para este estado mais profundo também. Contudo fica uma pergunta, a que séries correspondem os picos que obedecem também a lei de escala para os estados moleculares simplesmente excitado e que não são reconhecidos para pertencer a nenhum dos estados conhecidos? Sem um espectro de fotoionização mais resolvido, é difícil responder esta pergunta. No entanto, podemos nos aventurar a dizer que poderiam corresponder a um desvio nos picos pertencentes a algum estado, devido à presença do segundo passo feito pelo laser azul. Sabemos que a soma das frequências do laser de prova e o laser azul, $\omega_{A}+\omega_{L}$, é sempre fixa. Portanto, ao variar a frequência do laser de prova estamos variando também a soma das frequências da mesma forma. Com isto somos capazes de sintonizar em diferentes níveis vibracionais dos estados duplamente excitados, o que poderia causar a aparição de estruturas que não são próprias dos estados 


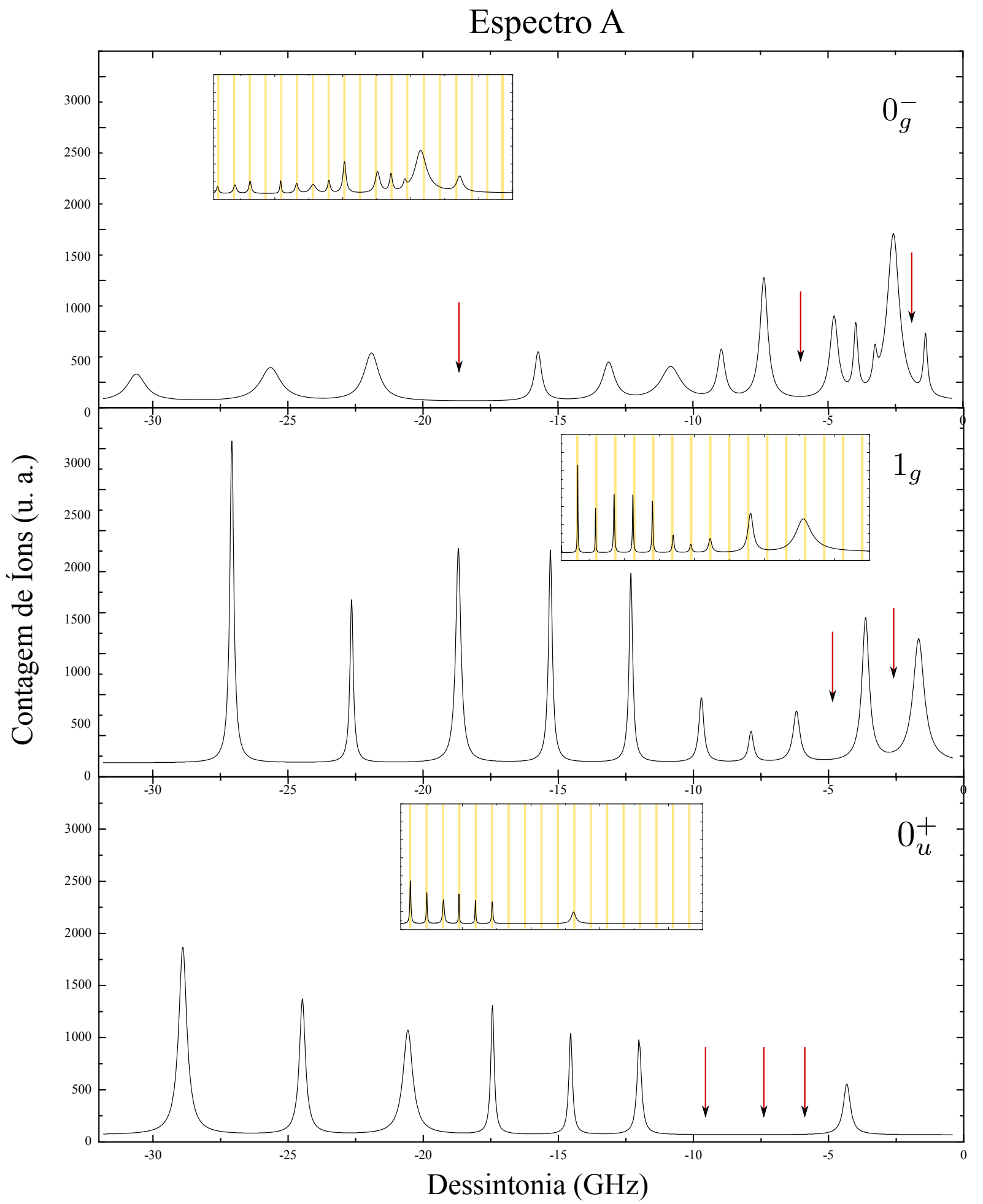

Figura 6.5.11 - Espectros para cada série vibracional reproduzidos com um ajuste por lorentzianas do espectro original do 0 até $-30 \mathrm{GHz}$. a) O espectro para o estado $0_{g}^{-}, b$ ) o espectro para o estado $1_{g}$ e $c$ ) espectro com as estruturas do estado $0_{u}^{+}$. Para cada estado temos incluído também um inset que verifica a lei de escala para estes estados de longo alcance. As setas vermelhas indicam onde falta um pico nas séries. 
Espectro A

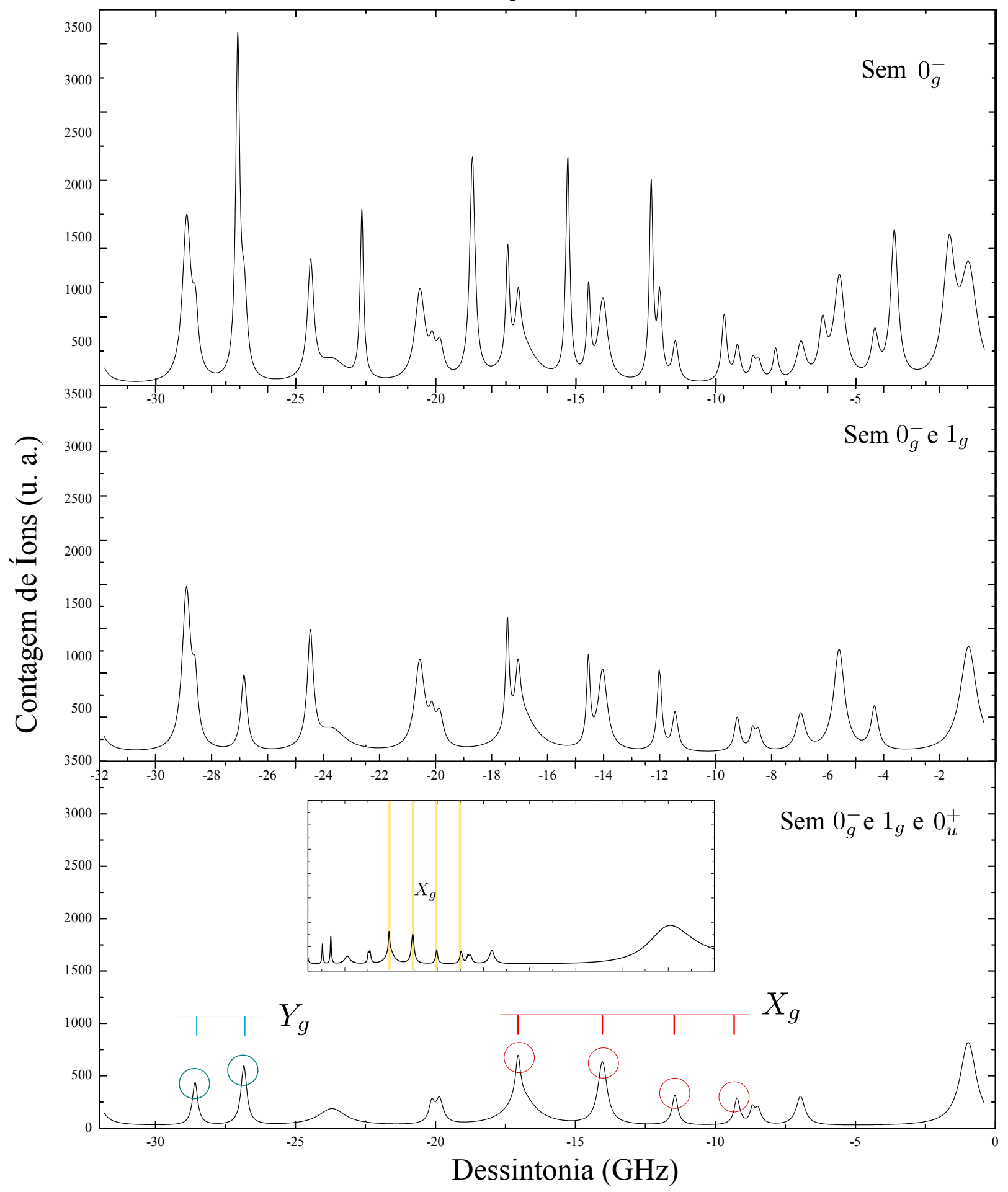

Figura 6.5.12 - Subtraímos progressivamente cada série vibracional para identificar os picos residuais no espectro. Pode-se ver que os picos marcados com os círculos vermelhos obedecem a uma lei de escala para estados intermediários, que chamamos de $X_{g}$, enquanto que os dois picos com os círculos azuis ficam sem identificação, e aqui os chamamos de $Y_{g}$. Um inset mostra a lei de escala se cumprindo para a série $X_{g}$. No capítulo 7 será visto que estes picos aparecem novamente no espectro. 


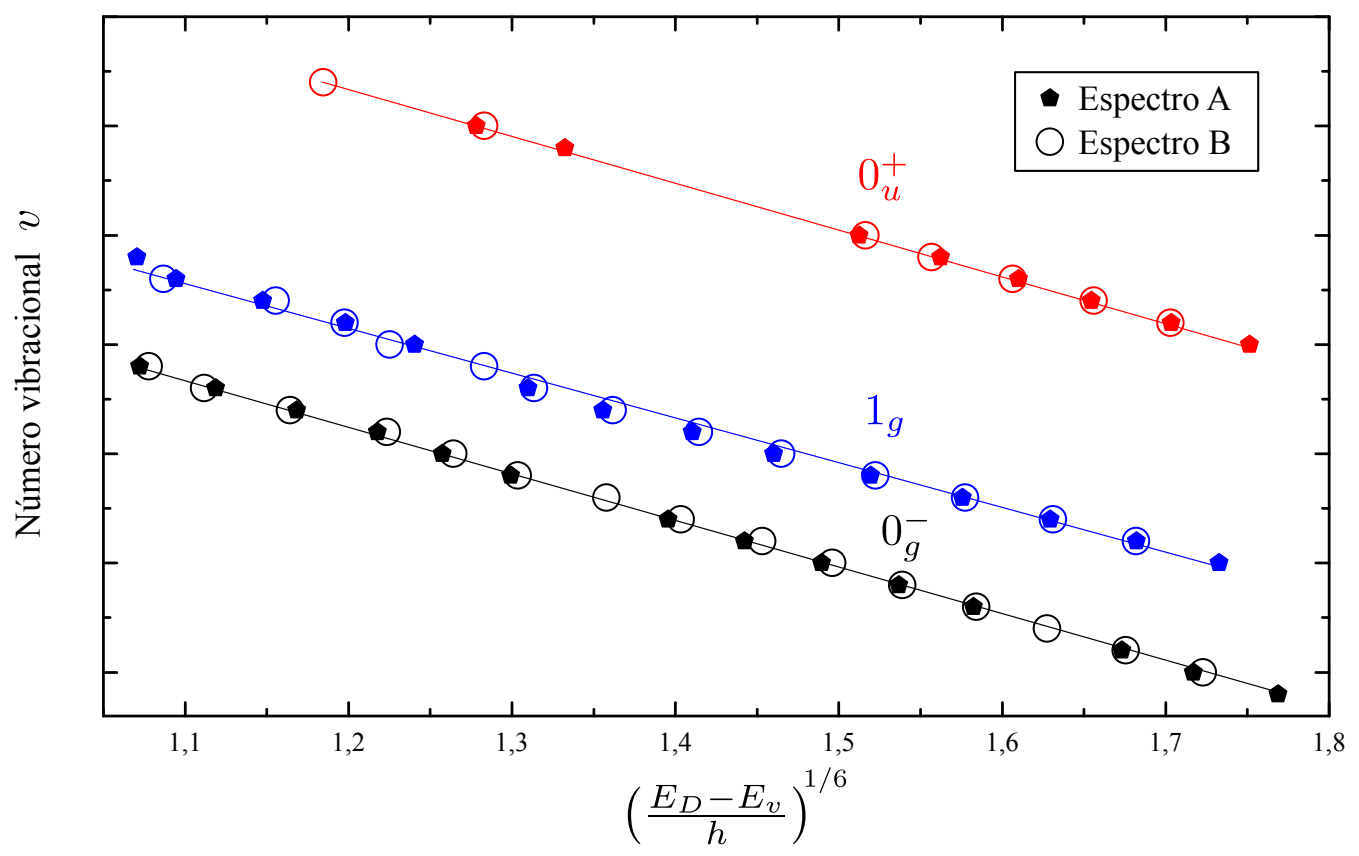

Figura 6.5.13 - Séries vibracionais obedecendo à lei de escala para estados intermediários de ambos os espectros, "A" e "B".

simplesmente excitados. Mas se isto fosse possível, estes deveriam obedecer a uma lei de escala para estados duplamente excitados e uma identificação mais rigorosa do mesmos está além do escopo deste trabalho.

Se compararmos os espectros "A" e "B" como mostra a figura 6.5.14, vemos que há uma mudança na posição dos picos de um espectro em relação ao outro espectro. Além das diferenças nos tamanhos dos picos, que podem ser devido às diferenças de potências usadas para gerar cada espectro, temos que há também um deslocamento da ordem de $\mathrm{MHz}$ entre os picos em ambos os espectros. Podemos apreciar que o espectro "A" tem um pico que coincide com o pico do espectro "B" em -23 GHz, aproximadamente. Pode-se ver adicionalmente na figura 6.5.15 os deslocamentos entre os picos correspondentes ao mesmo nível vibracional em cada um dos espectros analisados. Deslocamentos da ordem dos 200 $\mathrm{MHz}$ podem ser apreciados para picos na região em torno de $-9,5 \mathrm{GHz}$, os quais vão diminuindo conforme vamos indo mais longe do limite de dissociação até, a uma determinada frequência, ambos os espectros coincidir (foi visto para nossos dois espectros que isto é para acontecer em torno dos $-23 \mathrm{GHz}$ ). Para regiões mais longe desta frequência, onde os dois espectros coincidem, temos que os deslocamentos começam aumentar, desta vez com diferenças negativas. Isto quer dizer que se antes deste ponto se tinham deslocamentos para o vermelho entre os picos de um espectros e o outro, agora temos deslocamentos para o azul, que vão se incrementando conforme nos apartamos para frequências menores que $-23 \mathrm{GHz}$. Para a esquerda deste pico temos um deslocamento do espectro para o vermelho e para a direita, um deslocamento para o azul. Isto indica claramente que há uma modificação dos potenciais intermediários, segundo o nosso modelo apresentado 


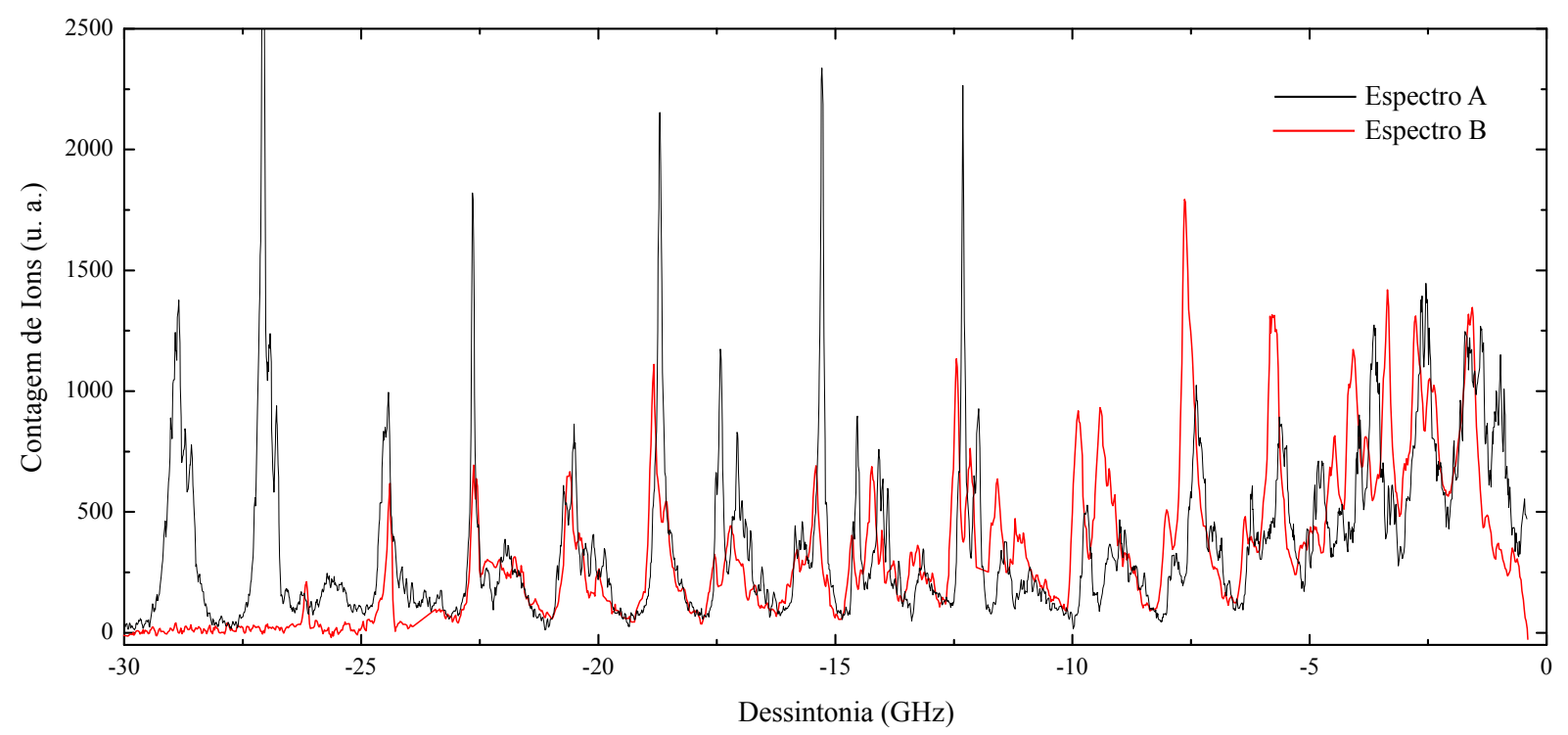

Figura 6.5.14 - Comparativo dos espectros "A" e "B" que mostra que existe um deslocamento entre estes a partir da frequência de -23 GHz. Os deslocamentos são tanto para o vermelho como para o azul, sendo essa frequência onde ambos os espectros coincidem.

no capítulo 5. Se lembramos que o nosso laser azul está fixado em uma frequência de aproximadamente $+30 \mathrm{GHz}$ de dessintonia para o azul da ressonância atômica, podemos pensar que ele é responsável pela modificação do potencial repulsivo, e isto cria efeitos no potencial atrativo também, modificando este de uma forma efetiva. De forma geral se tomam como sendo simétricos os potenciais atrativos e repulsivos. Se isto fosse assim poderíamos pensar que o nível vibracional que poderia não ser afetado deveria ser observado em torno dos $-30 \mathrm{GHz}$ e não nos $-24 \mathrm{GHz}$ como mostra a figura 6.5.14. Isto poderia ocorrer visto que na realidade o modelo que considera estes potenciais sendo simétricos não é válido para grandes dessintonias, como as usadas aqui. Assim temos já um indício de que o laser azul modifica realmente os potenciais intermediários, quando variamos a potência deste.

Poderíamos argumentar também que os deslocamentos no espectro se devem a uma diferença entre os nossas amostras usadas para cada espectro. Poderia ser que os átomos não estejam na mesma proporção no estado hiperfino fundamental $F=1$ quando se fez cada uma das medidas, mas isto não parece ser uma explicação satisfatória, já que as estruturas foram reproduzidas só com a diferença no tamanho dos picos e um deslocamento relativo dos mesmos. Se considerarmos efeitos da estrutura hiperfina do estado fundamental no processo de fotoionização associativa, também seríamos capazes de conjecturar alguma explicação a respeito. No entanto, tem se demonstrado que o principal efeito da estrutura hiperfina é a aparição de pequenos picos no espectro ao lado do pico principal como mostra a figura 6.5.16. Deste modo, tudo parece indicar que o efeito apreciado é exclusivamente devido à modificação dos potenciais intermediários pela presença do laser azul intenso. 

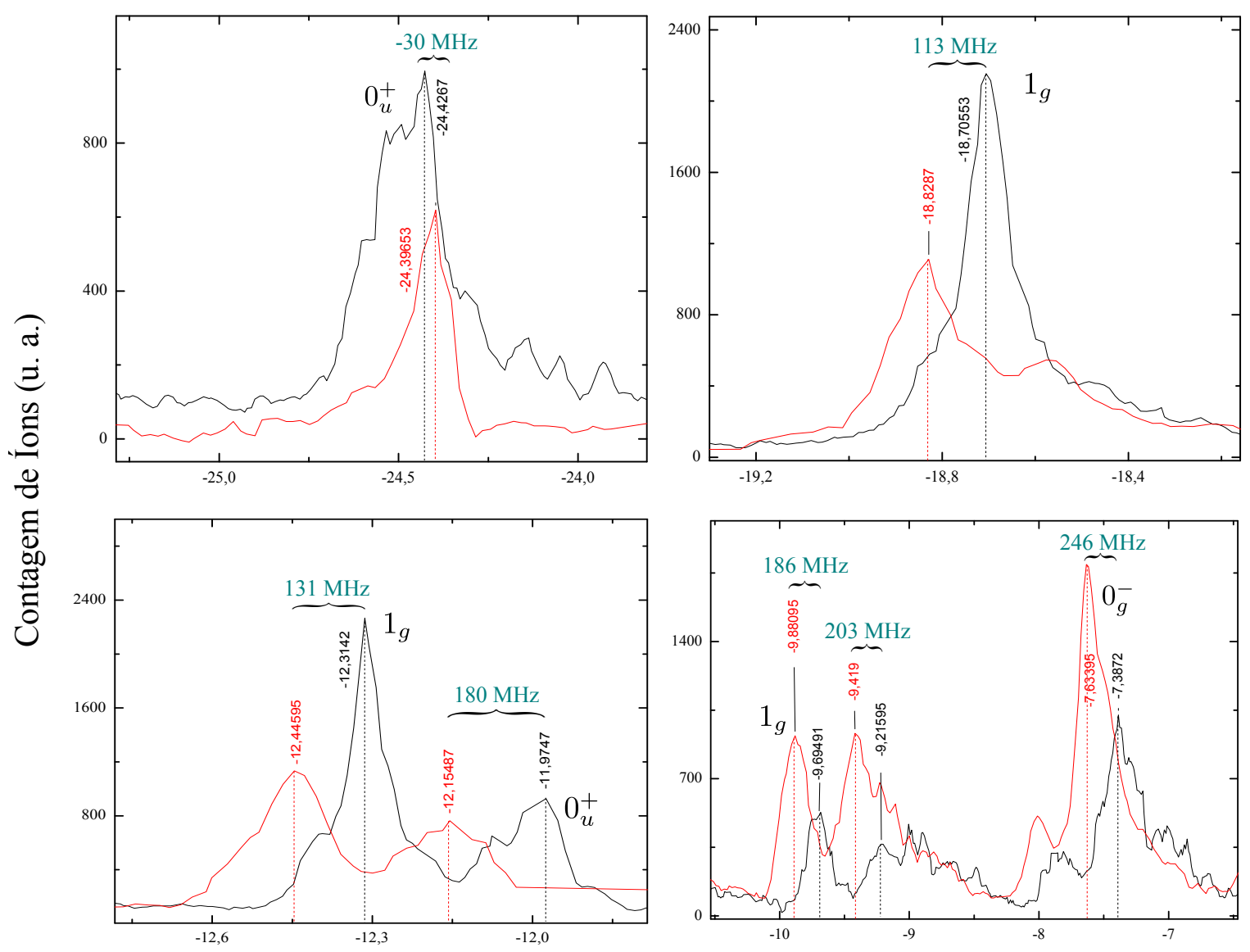

Dessintonia (GHz)

Figura 6.5.15 - Se podem ver os desvios entre os mesmos picos para cada espectro. Mas perto do limite de dissociação as diferenças entre um pico e seu análogo no outro espectro são maiores, se reduzindo conforme nos afastamos deste limite, até inverter e ir aumentando conforme nos afastamos. 


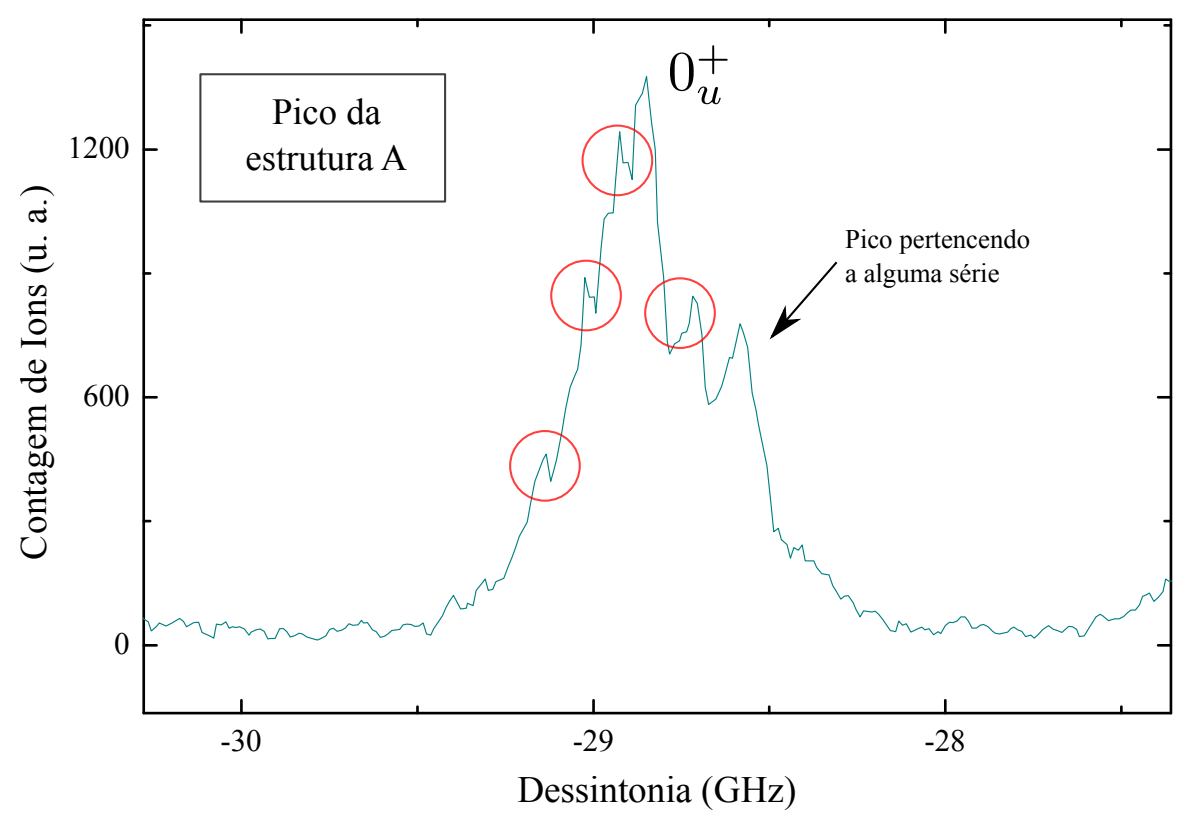

Figura 6.5.16 - Nesta figura mostramos os efeitos causados devido à presença de uma estrutura hiperfina. Os círculos vermelhos mostram os efeitos da estrutura hiperfina no espectro de fotoionização associativa.

Tendo identificado as séries vibracionais presentes no espectro de fotoionização associativa por dois fótons, podemos agora estudar os efeitos que acontecem quando campos intensos de luz estão presentes. A adição de um fóton vermelho pode induzir a formação de um novo estado molecular ligado, que chamamos de molécula fotônica, e a presença de um fóton azul adicional pode induzir processos de blindagem óptica. A seguir serão estudados os efeitos que fótons azuis intensos criam nos estados moleculares intermediários. 


\section{Alteração dos estados repulsivos na presença de campos de blindagem óptica}

Neste capítulo apresentaremos os resultados experimentais para a blindagem óptica em alguns picos das regiões intermediárias dos potenciais de longo alcance que acreditase que serão modificados na formação de uma molécula fotônica. Para isso, além dos lasers de prova e azul adicionamos outro laser azul (que chamaremos aqui de laser azul 2), o qual vai induzir a supressão das colisões inelásticas. É realizado um monitoramento dos picos e também dos deslocamentos dos mesmos em relação à intensidade do laser. Uma análise mostra que há efetivamente uma blindagem óptica, o que indica que estes estados são sensíveis à presença do laser azul, sendo este estudo útil para uma melhor compreensão sobre a formação da molécula fotônica. Brevemente descreveremos a teoria básica da blindagem óptica. Posteriormente apresentaremos os resultados experimentais obtidos. Por último, faremos uma análise de como estes resultados apresentam indícios da modificação dos potenciais intermediários na presença do laser azul.

\subsection{Colisões de átomos frios com laser com dessinto- nias para o azul}

O caso de colisões de átomos frios com laser com dessintonias para o azul da transição de ressonância tem sido estudado extensivamente, tanto experimental quanto teoricamente, por diversos autores (31, 33, 52, 54). A abordagem que se usa para tratar este tipo de fenômeno baseia-se em teorias dependentes do tempo. Se a intensidade da luz é suficientemente forte, os átomos nos seus estados fundamentais se aproximarão um do outro, se encontrando num potencial de interação repulsivo próximo de um ponto de Condon $R_{C}$, e serão repelidos. Isto dá surgimento ao fenômeno de blindagem óptica, já 
mencionada anteriormente, pelo qual a luz evita que os átomos se aproximem o suficiente de um ponto de Condon $R_{C}$, reduzindo assim a taxa de processos no estado fundamental que requerem átomos a uma distância menor que $R_{C}$. A luz também modifica a taxa de colisões elásticas no estado fundamental e o comprimento de espalhamento, e resulta na criação de átomos no estado excitado com a mesma energia cinética $\hbar \Delta_{A}$, com $\Delta_{A}$ sendo a dessintonia do laser azul.

Para átomos de sódio, um modelo de dois níveis é válido e pode ser usado para tratamento da blindagem óptica na presença de um laser azul (32). O modelo de dois níveis de Landau-Zener permite fazer um tratamento da blindagem óptica. Na figura 7.1.1 se mostra um esquema de como a presença de fóton azul modifica um estado repulsivo. Quando a intensidade do laser azul aumenta, o gap do cruzamento evitado ao redor do ponto de Condon aumenta, e a partícula semiclássica se move através da região acoplada, adiabaticamente. O fluxo entra e sai do estado fundamental nas mesma proporções, portanto a colisão é elástica. Pode ser mostrado que os processos de blindagem óptica tem um caráter inelástico. Depois que os átomos foram refletidos no potencial repulsivo, eles voltam passar pelo ponto de Condon $R_{C}$ e podem retornar para o estado fundamental seguindo essa rota. Uma parte do fluxo que não segue esta rota pode se manter no estado excitado e ir para distâncias $R \gg R_{C}$. Assim, a diferença de energia entre a energia do potencial no ponto de Condon $R_{C}$ e o limite de dissociação, $\hbar \Delta_{A}$, aumenta a energia cinética total do par atômico. Assim temos que se para grandes dessintonias $\Delta_{A}$ uma parte do fluxo de átomos consegue ficar no estado excitado para distâncias $R \gg R_{C}$, podemos ter perdas na armadilha; e com $\Delta_{A}$ pequenos um aquecimento da nuvem atômica aconteceria. Para distâncias menores que $R_{C}$ alguma parte do fluxo de átomos que não foi blindado pelo fóton azul volta para a região próxima do $R_{C}$. Assim podemos ter um processo de interferência entre os dois fluxos: um de átomos indo desde distâncias grandes para $R_{C}$ e outro vindo desde distâncias menores para $R_{C}$. Esta interferência de fluxos afeta a distribuição do fluxo saindo entre o estado excitado e o estado fundamental.

Para um melhor tratamento da blindagem óptica com sistemas de dois níveis, duas abordagens têm sido desenvolvidas, e em ambas o decaimento radiativo espontâneo será decisivo para qual caminho tomar. Para fracos decaimentos podemos usar uma abordagem na qual simplesmente ignoramos estes efeitos num modelo de dois níveis. Podemos resolver a equação de Schrödinger dependente do tempo com a Hamiltoniana $2 \times 2$ do sistema, conforme descrito no capítulo 2 para dessintonias com laser azul. Uma completa descrição do problema, através da mecânica quântica, deveria considerar aspectos tridimensionais da colisão, polarização da luz e momentos angulares relativos dos átomos. Napolitano tem abordado estes problemas e demonstrou a existência de efeitos dependentes da polarização da luz para colisões com um fóton azul (31, 33). O modelo que trata mais simplificadamente o fenômeno de blindagem óptica para decaimentos espontâneos fracos é o modelo semiclássico de Landau-Zener, no qual podemos ignorar efeitos 


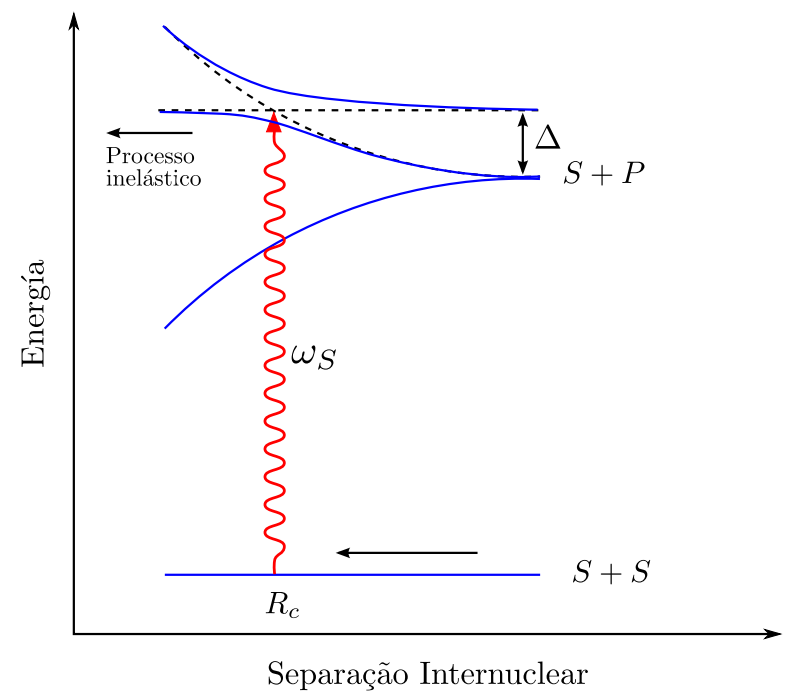

Figura 7.1.1 - Cruzamento evitado (avoiding crossing).

da dinâmica do pacote de ondas e assumir que podemos tratar posições bem localizadas (ou seja desconsideramos o princípio de incerteza de Heisenberg). Podemos assumir um pacote de ondas bem localizado com uma distribuição de momentos $W(\mathbf{p}, t)$, onde $\mathbf{p}$ é o momento, sendo tipo um pulso delta de Dirac, $W(\mathbf{p}, t)=\delta\left(p-p_{0}\right)$. Assumimos também que este pacote de onda segue trajetórias clássicas, assim o movimento em cada estado, ou toma lugar na presença de uma força exercida pela curva potencial do estado particular, ou obedece as leis de Newton. Quando o pacote alcança as curvas se cruzando em $R_{C}$, tal como se mostra na figura 7.1.1 e passando por elas com um momento $\mathbf{p}$, parte deste atingirá o estado excitado e o restante permanecerá no estado fundamental. A abordagem semiclássica é a seguinte: assumimos que a região de interação onde as curvas potenciais são fortemente acopladas $\left(\left|V_{e}-V_{g}\right| \lesssim \hbar \Omega / 2, \operatorname{com} \Omega\right.$ sendo a frequência de Rabi) é estreita, e dentro desta, as superfícies potenciais podem ser substituídas pelas suas tangentes em $R_{C}$. Assim, assumimos que o pacote de onda se movimenta através desta região, mantendo um momento $\mathbf{p}$ constante e qualquer aceleração sobre alguma outra curva potencial pode ser desconsiderada. Com estas condições, a trajetória clássica é $d \mathbf{R} / d t=\mathbf{p} / \mu$, com $\mu$ a massa reduzida do par, e colocamos isto no modelo de Landau-Zener para substituir a dependência temporal linear na estrutura de níveis e energia com dependência espacial linear. Com este modelo, a fração excitada do pacote de onda entrando através de tal nível linear cruzado é

$$
P_{e}=1-e^{-2 \pi \mu \hbar \Omega^{2} / \alpha|\mathbf{p}|}
$$

com

$$
\alpha=\left|\frac{\partial\left[V_{e}(R)-V_{g}(R)\right]}{\partial R}\right|_{R=R_{C}}
$$

A blindagem vem a ser neste caso só parcial quando a probabilidade de alcançar a 


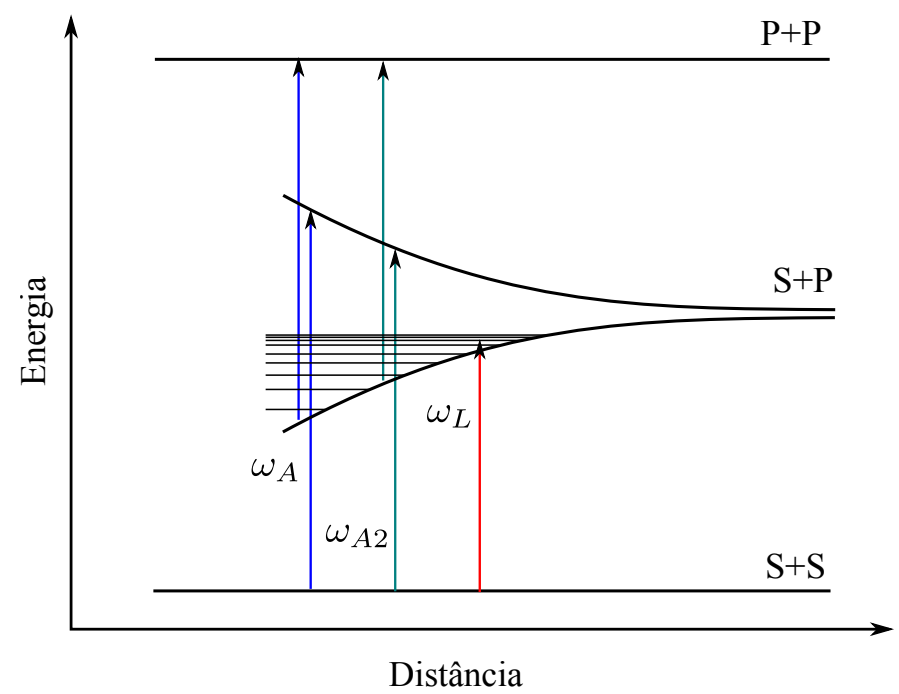

Figura 7.1.2 - Esquema que mostra como os dois lasers para o azul suprimem as colisões inelásticas.

região interna é

$$
P_{g}=1-P_{e}=e^{-2 \pi \mu \hbar \Omega^{2} / \alpha|\mathbf{p}|}
$$

Portanto, na ausência de decaimento espontâneo (ou fracos decaimentos espontâneos), definimos a medida da blindagem $P_{S}$ como igual a $P_{g}$. Usualmente, se considerarmos pacotes de onda quânticos no lugar dos clássicos considerados neste modelo, com variação de momento diferente do zero poderíamos esperar uma média das probabilidades $P_{e}$ e $P_{g}$ na distribuição de momentos inicial $W(\mathbf{p}, 0)$. Depois que a componente no estado excitado é refletida, esta passa pelo cruzamento das curvas por uma fração de tempo. Novamente podemos usar o modelo de Landau-Zener para estimar o fluxo voltando para o estado fundamental. Assim, temos que a probabilidade $P_{\infty}$ de uma parte do fluxo permanecer no estado excitado assintoticamente é dada por

$$
P_{\infty}=P_{e}\left(1-P_{e}\right)
$$

Esta é a probabilidade para que os dois átomos saiam da colisão com uma energia cinética compartilhada igual a $\hbar \Delta_{A}$. Contudo as componentes que permanecem no estado fundamental e eventualmente são refletidas podem também contribuir para $P_{\infty}$, o que resulta em um incremento desta probabilidade por um fator de 2.

Certas condições de validade necessitam ser satisfeitas quando este modelo é usado. Se os pontos de retorno para o pacote de onda entrando no estado excitado estão dentro da região de interação ao redor de $R_{C}$, o uso das trajetórias clássicas não serve.

Para átomos de sódio, de modo geral este modelo é válido e tem servido para explicar alguns resultados experimentais obtidos (52). Quando se consideram efeitos de decaimento espontâneo fortes, temos outro panorama para abordar o fenômeno. No entanto, o modelo aqui descrito serve para explicar os resultados obtidos para nosso experimento com átomos 
de sódio.

Para induzir a blindagem óptica no nosso experimento temos usado dois laser com dessintonias para o azul da transição atômica, um deles tendo uma dessintonia maior do que outro. Com isto podemos blindar o sistema entre dois pontos de Condon nos quais acada laser azul excita. Chamamos um de laser azul $\left(A_{1}\right)$ e que excita no ponto $R_{A 1}$ e o outro de laser azul $2\left(A_{2}\right)$ e que excita em $R_{A 2}$, sendo $R_{A 1}<R_{A 2}$, e a dessintonia do laser azul 2 menor do que o laser azul. Estes laser podem conetar o estado fundamental com o estado repulsivo intermediário criando rotas que levam o fluxo de pares a ser blindados. Isto ocorre da seguinte maneira: o fluxo de pares atômicos que vem se aproximando no estado molecular fundamental absorve o laser azul $A_{2}$ no ponto $R_{A 2}$, com o qual é levado até o estado repulsivo; o par continua se aproximando, pelo que gasta a sua energia cinética em subir pelo potencial até alcançar o ponto $R_{A 1}$ onde o laser azul $A_{1}$ levará o par atômico de volta para o estado fundamental. Com isto temos que na região entre $R_{1}$ e $R_{2}$ se têm uma diminuição de pares, o qual poderá se medido com contagem de íons. Outro processo que acontece na presença deste laser azul 2 é no segundo passo do PAI: quando o par atômico no estado simplesmente excitado (que previamente tem sido levado até ai pelo laser de prova) vai se aproximando por um potencial atrativo conetado com a assíntota deste potencial, pode sentir a presença do laser azul $2 A_{2}$ antes do que o laser azul $A_{1}$. Assim, o par atômico pode ser levado para o estado duplamente excitado pelo laser azul 2, mas devido a que este vai levar o par a uma distancia interatômica maior, o par pode não sobreviver até ionizar, e deste modo muitos pares não serão contados, o que evidenciaria uma diminuição na contagem de íon. Assim, o laser azul 2 vai induzir, efetivamente, processos de blindagem óptica que é o que queremos medir. A figura 7.1.2 mostra esquematicamente o processo que se terá no par atômico.

\subsection{Sistema Experimental}

Para poder realizar os nossos experimento de blindagem óptica desenvolvemos um sistema experimental que é basicamente o mesmo que será usado para a produção e detecção da molécula fotônica, porém com uma mudança: o laser vermelho (aquele com uma dessintonia para o vermelho da transição atômica, que ira a criar a molécula fotônica) é trocado por um laser com uma dessintonia para o azul (o laser azul 2), que induzirá os processos de blindagem óptica. A sequência temporal que usaremos para realizar excitação do estado repulsivo e tomar as medidas é:

- Passo 1: Se desliga o feixe de desaceleração dos átomos de sódio vindo do desacelerador Zeeman e se ligam os feixes azul e azul 2 por um intervalo de tempo. A 


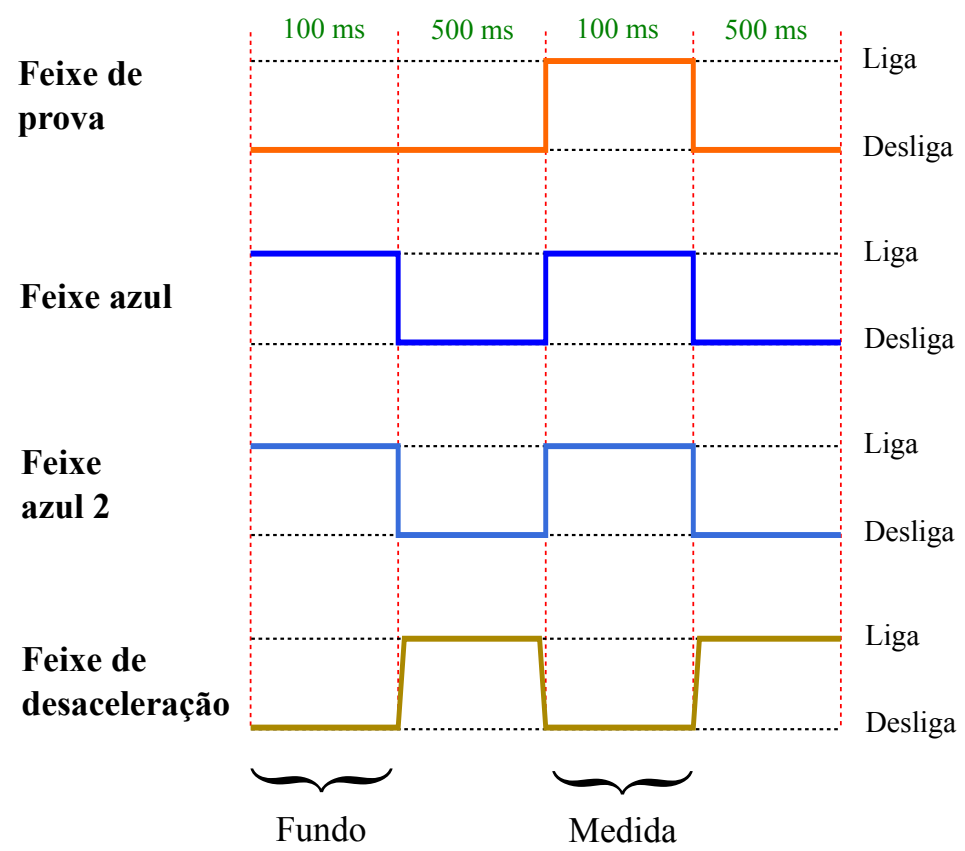

Figura 7.2.1 - Esquema da sequência temporal implementada para os estudos da blindagem óptica na presença de campos intensos e controlada pela interface comercial Labview®. "Fundo" indica a contagem de íons que será tomada como contagem de fundo, e "Medida" é a contagem total. A diferença desta contagem fornece o número de íons efetivos produzidos.

contagem de íons deste intervalo é realizada.

- Passo 2: Se desligam os feixes azul e azul 2 e se liga o feixe de desaceleração por um intervalo de tempo, para poder recuperar a amostra de átomos frios. Nenhuma medida é realizada neste intervalo.

- Passo 3: Se desliga novamente o feixe de desaceleração e se ligam os feixes azul, azul 2 e de prova pelo mesmo intervalo de tempo do Passo 1. É realizada a contagem de íons.

- Passo 4: Se desligam os feixes azul, azul 2 e de prova, e volta-se a ligar o feixe de desaceleração, deixando o sistema pronto para começar uma nova medida. Nenhuma medida é feita neste intervalo.

Na figura 7.2.1 mostra-se a sequência temporal para estas medidas. A sequência temporal foi controlada pela interface comercial Labview ${ }^{\circledR}$, assim como por shutters do fabricante Uniblitzer ${ }^{\circledR}$. Usamos a interface Labview ${ }^{\circledR}$ para controlar o laser de prova e o contador de íons, assim como para monitorar as medidas em tempo real. Este nos permite também adquirir os dados. A contagem de íons é realizada com um contador de íons, novamente sendo dada pela equação 5.1 .1 .

As medidas foram feitas variando a potência do laser azul 2. O laser azul tem uma dessintonia de $+30 \mathrm{GHz}\left(\omega_{A_{12}}\right)$, enquanto que o laser azul 2 tem uma dessintonia de +24 $\mathrm{GHz}\left(\omega_{A_{2}}\right)$. O laser de prova varre em regiões de -10 até -20 GHz e de -24 até -29,5 GHz. 


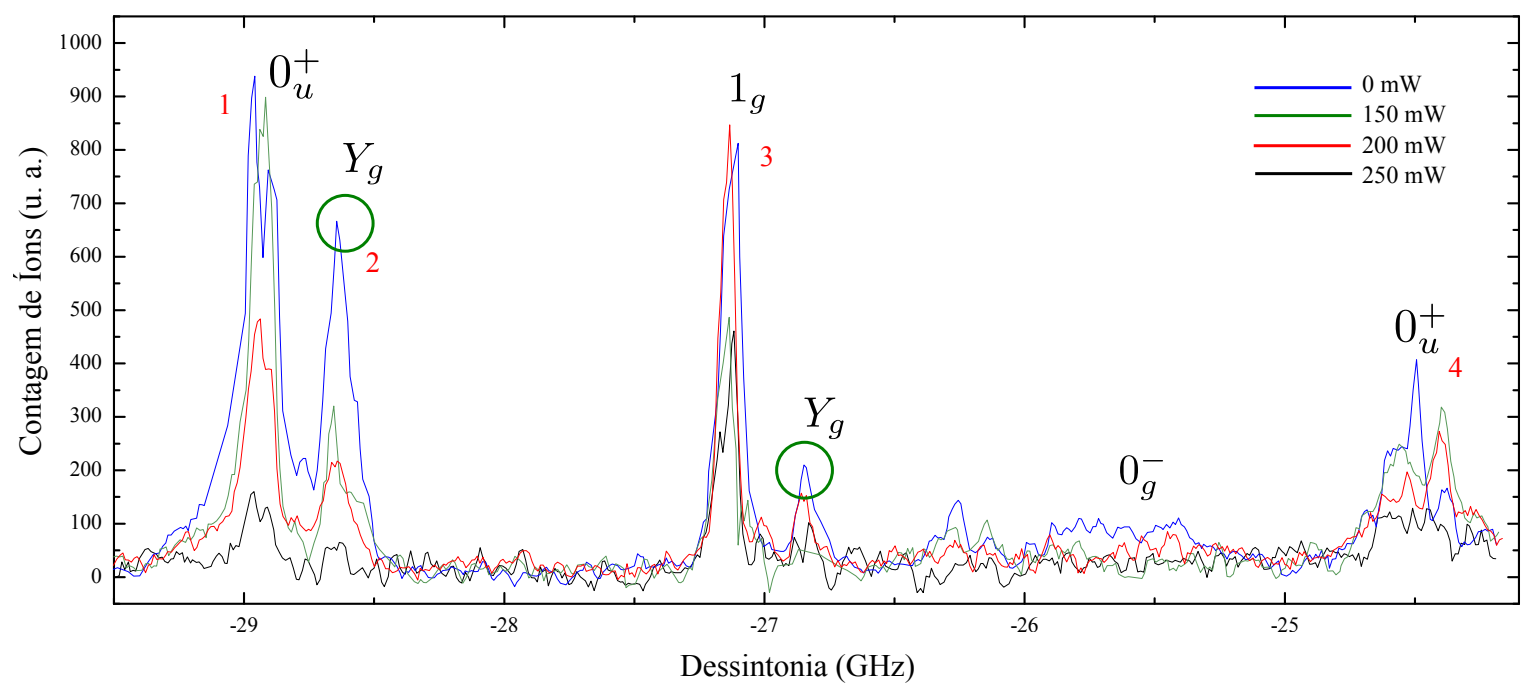

Figura 7.3.1 - Espectro mostrando os picos a serem estudados com efeito do laser azul 2. Os círculos em verde indicam os estados $Y_{g}$ não reconhecidos.

\subsection{Resultados experimentais}

Para o estudo da blindagem óptica se escolheu uma região, entre -24 até -29,5 GHz. Nesta região se identificaram alguns picos como pertencendo às séries vibracionais dos estados $0_{g}^{-}, 1_{g}, 0_{u}^{+}$e a série desconhecida que chamamos de $Y_{g}$ e que apareceu também no espectro "A" analisado no capítulo 6. O laser de prova foi varrido cerca de 5 vezes ao redor de cada pico para uma melhor média da contagem de íons. Os espectros obtidos foram processados para obter um só espectro. Na figura 7.3.1 mostram-se estes picos e a diminuição na contagem de íons com o aumento da potência do laser de blindagem.

Na figura 7.3 .2 pode se ver mais claramente os efeitos para um pico pertencendo ao estado $0_{u}^{+}$e ao lado uma estrutura que não foi identificada e chamada aqui de $Y_{g}$. Variamos o laser azul para as potências $0 \mathrm{~mW}, 150 \mathrm{~mW}, 200 \mathrm{~mW}$ e $250 \mathrm{~mW}$.

Da figura 7.3.1 temos escolhido os picos maiores para fazer uma análise. Temos plotado na figura 7.3.3 a dependência da contagem dos íons em cada pico escolhido como função da potência do laser azul 2. Podemos ver claramente a queda do número de íons produzidos. Um ajuste exponencial foi feito, e se comprova a queda como sendo exponencial decrescente, como esperado pelo modelo teórico de Landau-Zener. Estas curvas são comparadas na figura 7.3.4. Devemos levar em conta que temos 2 picos pertencendo ao estado $0_{u}^{+}$um, ao estado $1_{g}$ e um, ao estado desconhecido $Y_{g}$. Para todos eles se tem um efeito de blindagem. O pico pertencendo ao estado $Y_{g}$ é que tem uma maior queda com o aumento do laser supressor. Pode-se ver também que se tem um efeito de saturação da blindagem com o aumento da potência. 


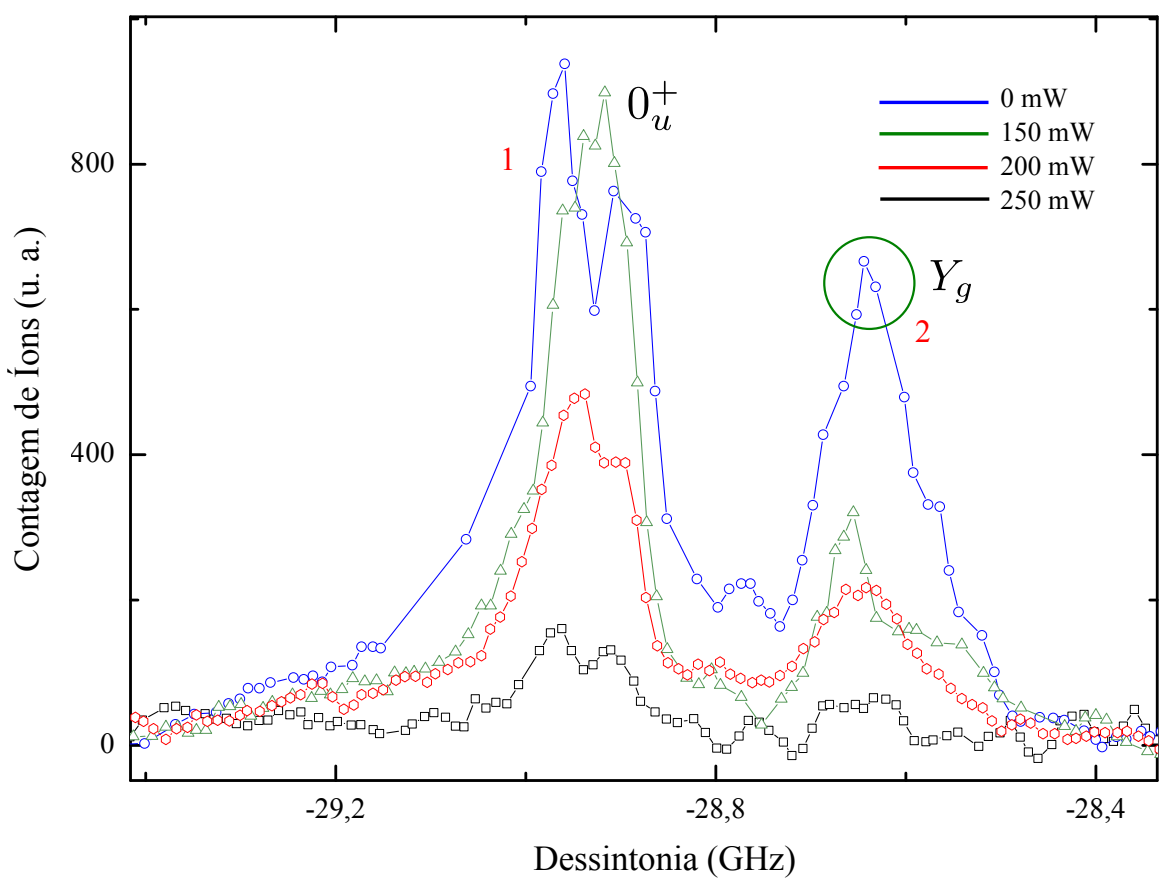

Figura 7.3.2 - Picos do estado $0_{u}^{+}$correspondentes às frequências de 28,9 GHz e 28,62 $\mathrm{GHz}$ de deslocamento para o vermelho, mostrando as mudanças no tamanho dos picos (a contagem de íons) pela ação da variação da intensidade do laser azul 2.

Com isto temos comprovado que o laser azul modifica as rotas de fotoionização associativa. Um segundo efeito do laser azul será também estudado através da escolha de outra região do espectro para análise. Aqui realizamos o mesmo experimento, com o intuito de ver mudanças nas posições dos picos. Temos já discutido que deslocamentos na posições dos picos indicam mudanças nos potenciais intermediários. Para ver isto, variamos o laser azul 2 para potências de 0, 100, 250 e $360 \mathrm{~mW}$, e varremos o laser de prova na região de -10 até -20 GHz. Nesta região, podemos reconhecer alguns picos pertencendo aos potenciais intermediários. Aparecem, no entanto, novamente os picos pertencendo à série desconhecida a qual se discutiu no capítulo 5. Estes picos, assim como os demais picos que aparecem na região varrida, podem ser observados na figura 7.3.5. Pode se observar também um efeito de blindagem dos picos com o aumento da intensidade do laser azul 2, como no caso do experimento anterior. Um pico do espectro foi extraído e é mostrado na figura 7.3.6, para observar mais claramente os efeitos de deslocamentos nos picos. Fazemos um ajuste por lorentzianas de cada pico do espectro para poder fazer um seguimento do desvio da posição de cada pico do espectro. Escolhemos 8 picos mais sobressalientes no espectro. A figura 7.3.7 mostra os desvios para cada pico em função da potência do laser azul 2. Para todos os picos pode ser observada uma mudança nas posições com deslocamentos da ordem de MHz. Isto evidencia duas coisas: primeiro, que o laser azul 2 modifica de modo diferente os potenciais intermediários, dependendo da potência com a qual o incidimos no MOT; e segundo, que não se tem uma variação 

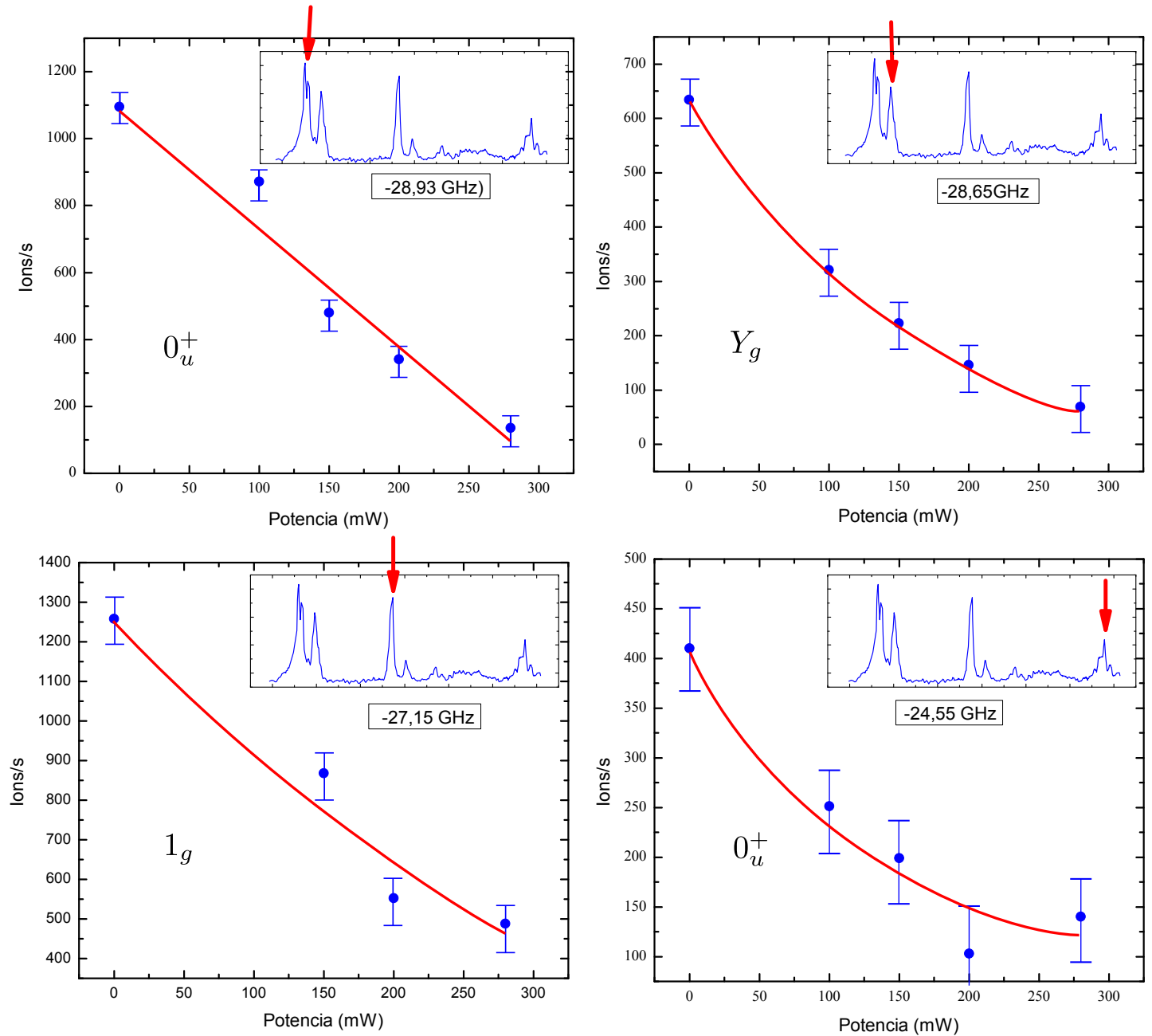

Figura 7.3.3 - Resultados obtidos para a blindagem nos 4 picos de interesse. Pode-se observar claramente a diminuição na contagem de íons com o aumento da potência do laser azul 2. Se vê também que para maiores potências há uma saturação no efeito de blindagem. 


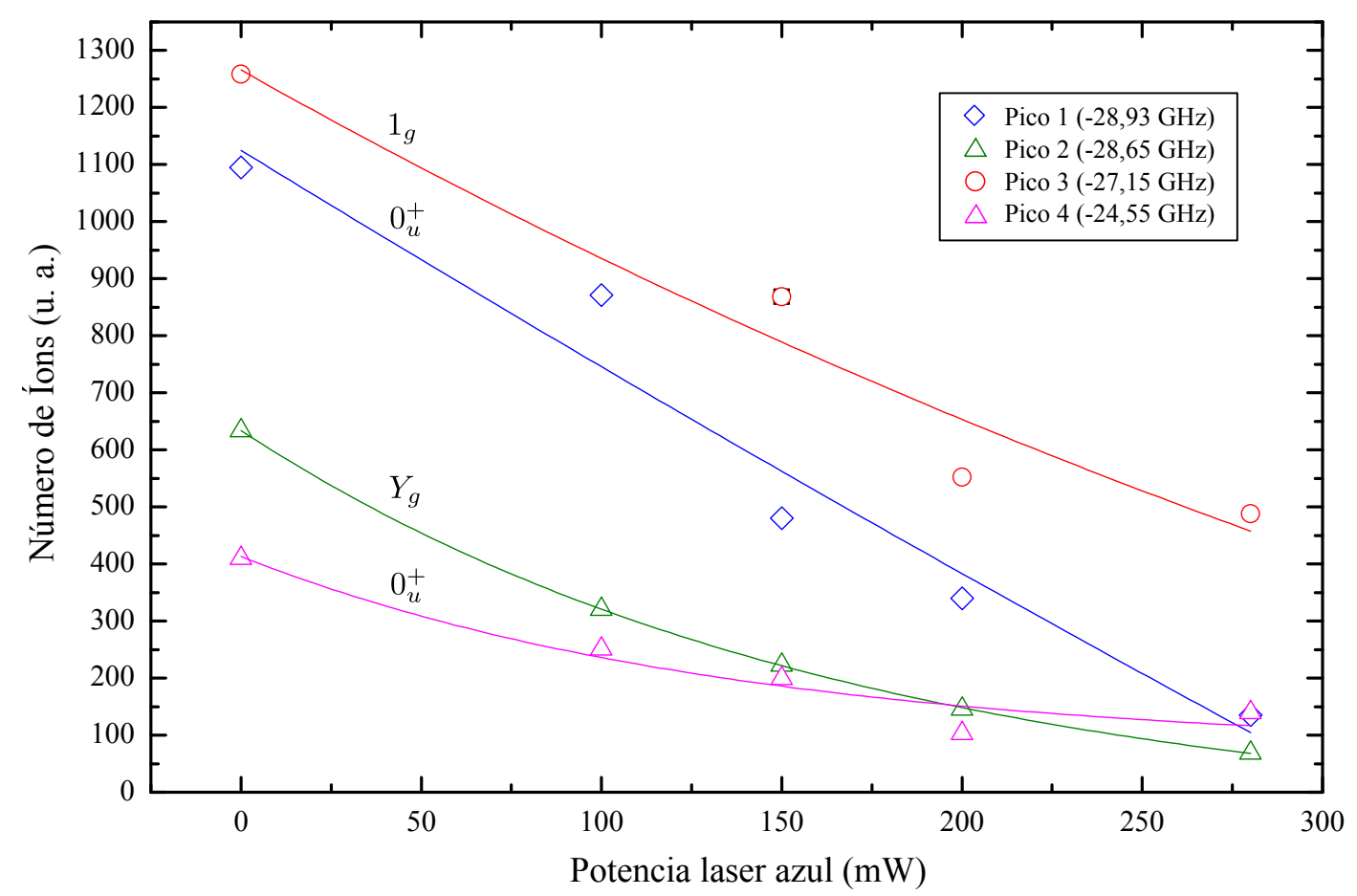

Figura 7.3.4 - Comparação das curvas da blindagem para cada pico.

homogênea para a posição dos picos. Isto mostra que se tem uma variação dos potenciais intermediários com a presença do laser azul.

Assim podemos dizer que fótons azuis (em relação à ressonância atômica) modificam os potenciais intermediários. Isto deixa clara a evidência da possibilidade da formação de uma molécula fotônica quando adicionarmos fótons com dessintonia para o vermelho. Os estudos realizados permitem saber que a presença de campos de luz intensos com dessintonias para o azul modificam os potenciais intermediários. 


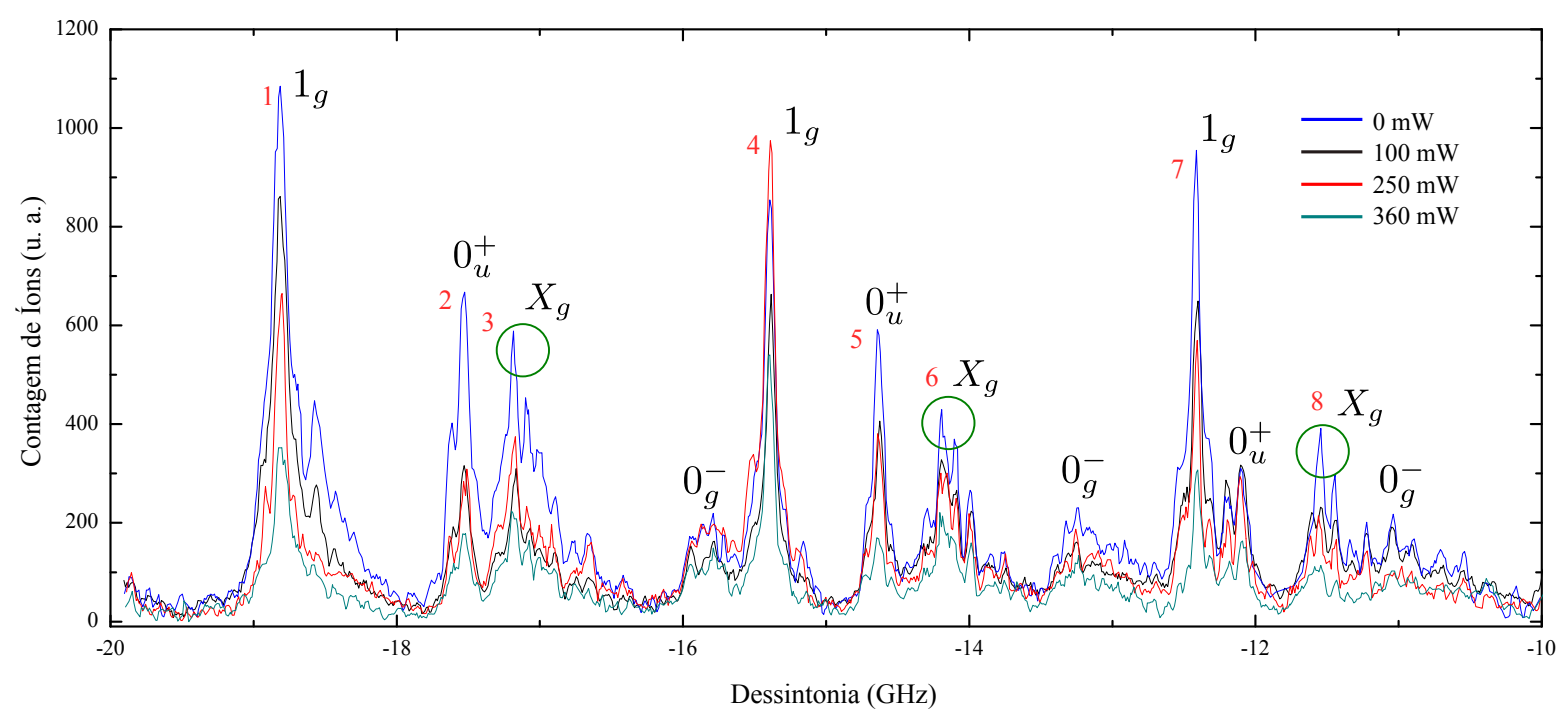

Figura 7.3.5 - Deslocamentos dos picos por efeito da variação da intensidade do laser azul 2. Os círculos em verde indicam a série vibracional não identificada, e que cumprem a lei de escala de potenciais intermediários.

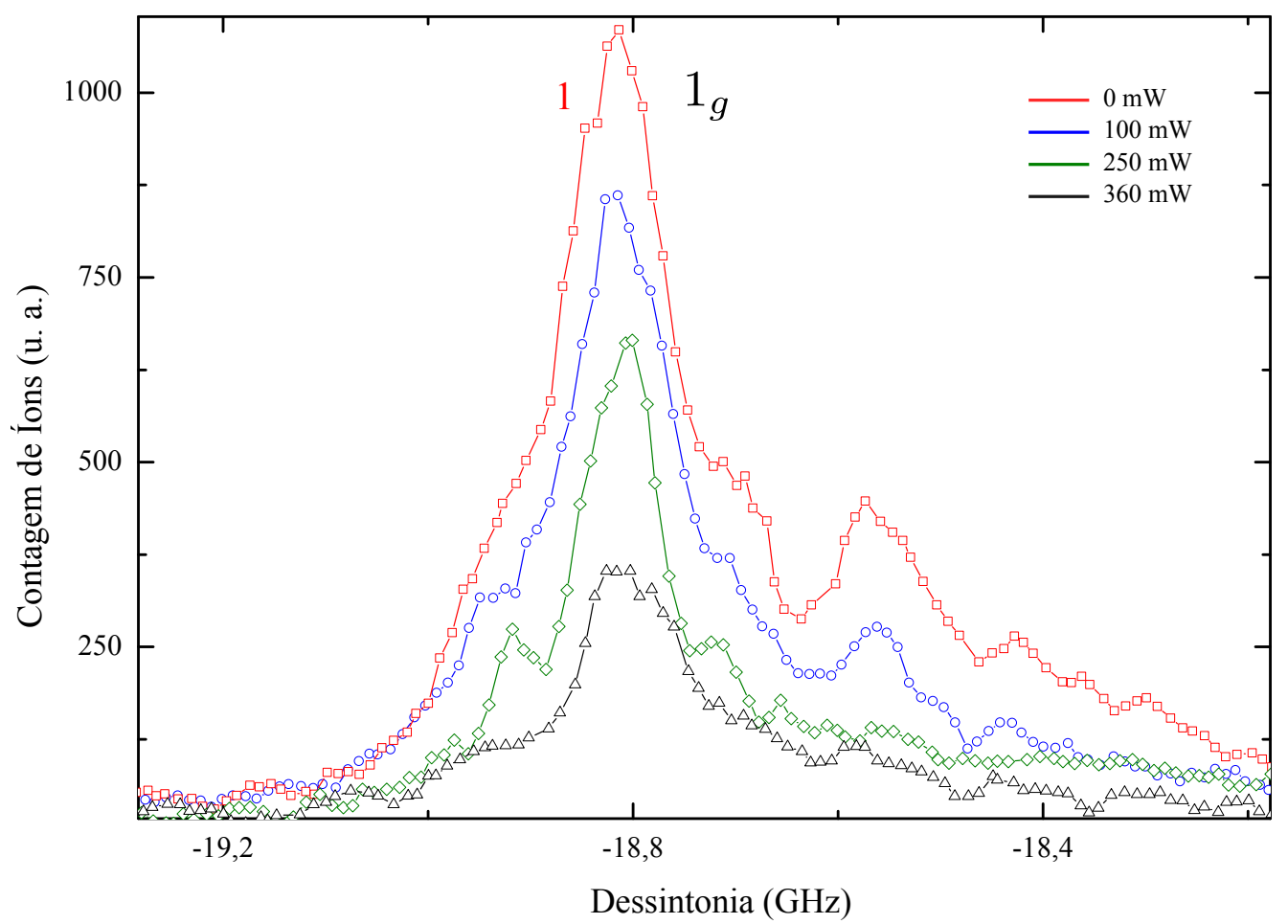

Figura 7.3.6 - Deslocamentos dos picos por efeito da variação da intensidade do laser azul 2. Zoom para um pico $1_{g}$. 


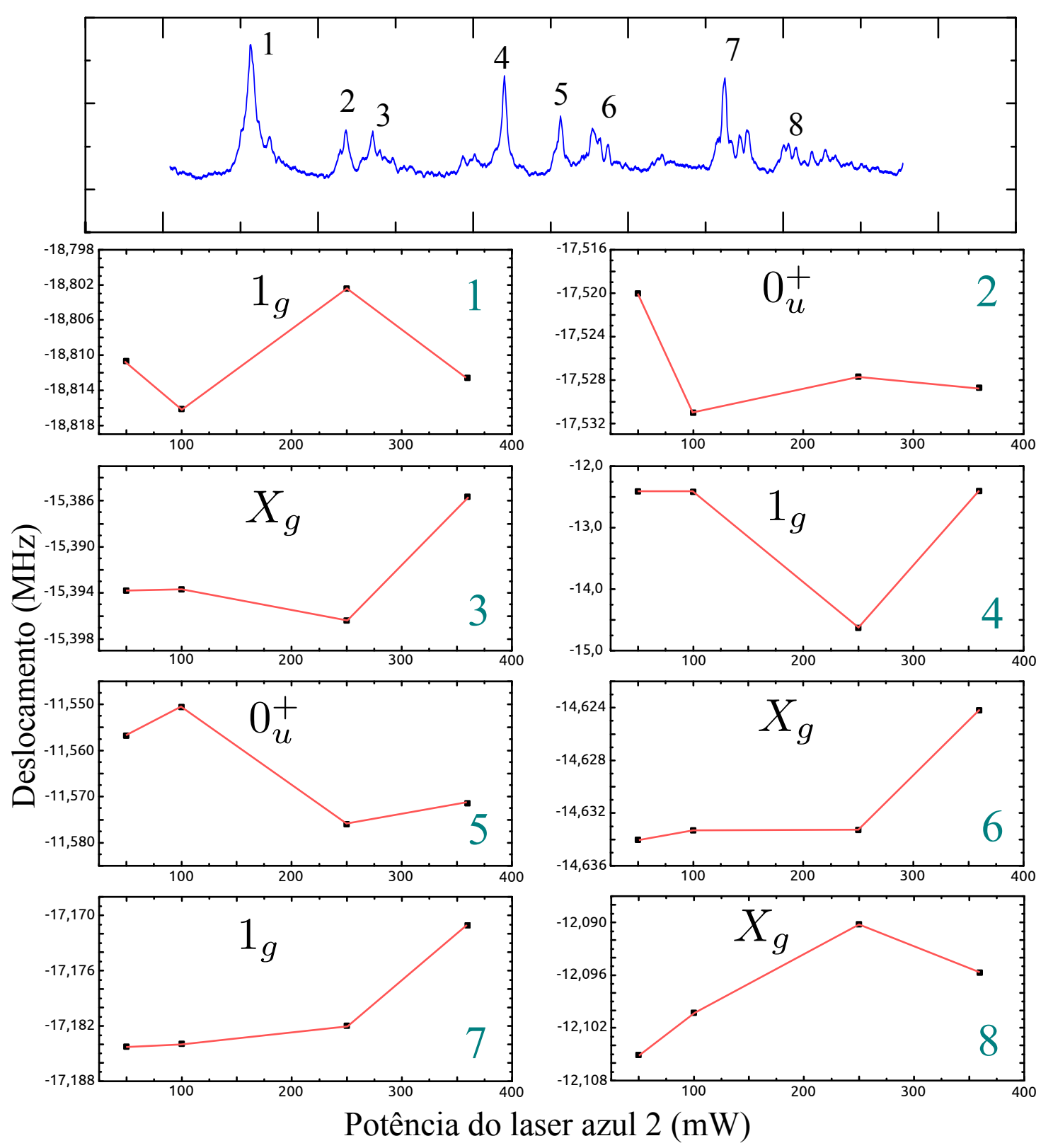

Figura 7.3.7 - Deslocamentos dos picos por efeito da variação da intensidade do laser azul 2. 


\section{Capítulo 8}

\section{Conclusões}

A produção de uma armadilha magneto óptica de sódio possibilitou os estudos das interações de átomos de sódio com feixes laser, como ocorrem os processos de fotoionização associativa e de blindagem óptica. Os estudos de fotoionização associativa foram monitorados mediante a contagem de íons produzidos no segundo passo, onde o estado duplamente excitado cruza com o estado autoionizante. Realizamos experimentos de fotoionização associativa por dois fótons com átomos de sódio para a região de 0 até $-30 \mathrm{GHz}$ de dessintonia com a frequência da ressonância atômica $3 S_{1 / 2}(F=2) \rightarrow 3 P_{3 / 2}\left(F^{\prime}=3\right)$. Uma identificação das séries vibracionais dos estados intermediários presentes nesta região foi realizada, fazendo uso da lei de escala para estados intermediários. Identificamos os estados moleculares intermediários de longo alcance $0_{g}^{-}$e $1_{g}$ e $0_{u}^{+}$, e duas séries não reconhecidas e que aqui chamamos de $X_{g}$ e $Y_{g}$. Além disso, foi feito também um estudo da estrutura resultante da blindagem óptica quando um segundo laser azul está presente num processo de fotoionização associativa por dois fótons. Os resultados mostraram efetivamente uma blindagem do número de íons produzidos em função da variação da potência do laser azul adicionado, assim como a saturação do efeito para maiores potências. Adicionalmente, se observou o deslocamento nas posições dos picos estudados com a variação da potência de um laser azul adicional. Isto mostra que há uma mudança nos potenciais pela ação de lasers com frequências para o azul da transição. Todos estes experimentos foram feitos em um MOT em configuração Dark MOT, com um sistema de automatização para as medidas monitorado através de uma interface de controle computadorizada. Também se apresentou uma idéia do que é uma molécula fotônica, o sistema experimental desenvolvido para a sua produção e uma análise qualitativa na modificação dos potenciais, sendo isto o que esperamos medir na molécula fotônica. Assim, os resultados experimentais aqui apresentados são um estudo que mostrou a viabilidade experimental de se produzir e medir estas moléculas fotônicas no laboratório. 


\section{REFERÊNCIAS}

1 THORSHEIM, H. R. et al. Laser-induced photoassociation of ultracold sodium atoms. Physical Review Letters, v. 58, n. 23 p. 2420-2423, 1987.

2 KREMS, R.V.; STWALLEY, W.C.; FRIEDRICH, B. Cold molecules: theory, experiment, applications. Boca Raton, Florida, USA: CRC Press, 2009.

3 WEIDEMÜLLER, M.; ZIMMERMANN C. Interactions in ultracold gases: from atoms to molecules. Weinheim: Wiley-VCH, 2003.

4 MOVRE, M.; PICHLER, G. Resonance interaction and self-broadening of alkali resonance lines. I. adiabatic potential curves. Journal of Physics B: atomic and molecular physics, v. 10, n. 13, p. 2631, 1977.

5 STWALley, W. C. et al. Pure long-range molecules. Physical Review Letters, v. 41, n. 17, p. 1164-1167, 1978.

6 WEINER, J.; BAGNATO, V. S.; ZILIO, S.; JULIENNE, P. S. Experiments and theory in cold and ultracold collisions. Reviews of Modern Physics, v. 71, n. 1, p. 1-85 1999.

7 MCKENZIE, C. et al. Photoassociation of sodium in a Bose-Einstein condensate. Physical Review Letters, v. 88, n. 12, p. 120403, 2002.

8 PHILLIPS, W. D. Nobel lecture: laser cooling and trapping of neutral atoms. Review of Modern Physics, v. 70, n. 3, p. 721-741, 1998. 
9 WAGSHUL, M. E. et al. Hyperfine effects on associative ionization of ultracold sodium. Physical Review Letters, v. 70, n. 14, p. 2074-2077, 1993.

10 NIKITIN, S. U. Theory of slow atomic collisions. Heilderberg: Springer, 1984.

11 DAVIS, K. B. et al. Bose-Einstein condensation in a gas of sodium atoms. Physical Review Letters, v. 75, n. 22, p. 3969-3973, 1995.

12 SOWIIFMmODE A. T. et al. Dipolar molecules in optical lattices. Physical Review Letters, v. 108, n. 11, p. 115301, 2012.

13 HAROCHE, S. et al. Modified Zeeman hyperfine spectra observed in $\mathrm{H}^{1}$ and $\mathrm{Rb}^{87}$ ground states interacting with a nonresonant rf field. Physical Review Letters, v. 24, n. 16, p. 861-864, 1970.

14 HOLMGREN, W. F. et al. Measurement of a wavelength of light for which the energy shift for an atom vanishes. Physical Review Letters, v. 109, n. 24, p. 243004, 2012.

15 FUHRMANEK, A. et al. Free-space lossless state detection of a single trapped atom. Physical Review Letters, v. 106, n. 13, p. 133003, 2011.

16 JULIENNE, P. S. Laser Modification of ultracold atomic collisions in optical traps. Physical Review Letters, v. 61, n. 6, p. 698-701, 1988.

17 ANDERSON, M. H. et al. Observation of Bose-Einstein condensation in a dilute atomic vapor. Science, v. 269, n. 5221, p. 198-201, 1995.

18 BRADLEY, C. C. et al. Evidence of Bose-Einstein condensation in an atomic gas with attractive interactions. Physical Review Letters, v. 75, n. 9, p. 1687-1690, 1995. 
19 BOHN, J. L.; JULIENNE, P. S. Semianalytic theory of laser-assisted resonant cold collisions. Physical Review A, v. 60, n. 1, p. 414-425, 1999.

20 SUOMINEN, K.-A. et al. Quantum and semiclassical calculations of cold-atom collisions in light fields. Physical Review A, v. 57, n. 5, p. 3724-3738, 1998.

21 BAND, Y. B.; JULIENNE, P. S. Ultracold-molecule production by laser-cooled atom photoassociation. Physical Review A, v. 51, n. 6, p. R4317-R4320, 1995.

22 CROFT, J. F. E.; HUTSON, J. M.; JULIENNE, P. S. Optimized multichannel quantum defect theory for cold molecular collisions. Physical Review A, v. 86, n. 2, p. 022711, 2012 .

23 CROFT, J. F. E. et al. Multichannel quantum defect theory for cold molecular collisions. Physical Review A, v. 84, n. 4, p. 042703, 2011.

24 JULIENnE, P. S.; SUOMINEN, K.-A.; BAND, Y. Complex-potential model of collisions of laser-cooled atoms. Physical Review A, v. 49, n. 5, p. 3890-3896, 1994.

25 MERZBACHER, E. Quantum mechanics. 3rd ed. New York, USA: Wiley, 1997.

26 SAKURAI, J. J.; NAPOLITANO, J. Modern quantum mechanics. 2nd ed. San Francisco, USA: Addison-Wesley, 2010.

27 MANAI, I. et al. Rovibrational cooling of molecules by optical pumping. Physical Review Letters, v. 109, n. 5, p. 183001, 2012.

28 JULIENNE, P. S.; HEATHER, R. Laser modification of ultracold atomic collisions: Theory. Physical Review Letters, v. 67, n. 16, p. 2135-2138, 1991. 
29 NAPOLITANO, R. et al. Line shapes of high resolution photoassociation spectra of optically cooled atoms. Physical Review Letters, v. 73, n. 10, p. 1352-1355, 1994.

30 BOHN, J. L.; JULIENNE, P. S. Semianalytic treatment of two-color photoassociation spectroscopy and control of cold atoms. Physical Review A, v. 54, n. 1, p. R4637-R4640, 1996.

31 NAPOLITANO, R.; WEINER, J.; JULIENNE, P. S. Theory of optical suppression of ultracold-collision rates by polarized light. Physical Review A, v. 55, n. 2, p. 1191-1207, 1997.

32 SuOminen, K.-A. et al. Optical shielding of cold collisions. Physical Review A, v. 51, n. 2, p. 1446-1457, 1995.

33 NAPOLITANO, R. New advances in multichannel and three-dimensional theories of ultracold atomic collision dynamics. 1995. Ph. D. Thesis (Physics) - University of Maryland, College Park, EUA, 1995.

34 PAIVA, R. R. Two photons and two atoms. 2013. Tese (Doutorado) - Instituto de Física de São Carlos, Universidade de São Paulo, São Carlos, 2013. (No prelo)

35 AMELINK, A. et al. Single-color photoassociative ionization of ultracold sodium: the region from 0 to -5 GHz. Physical Review A, v. 62, n. 1, p. 013408, 2000.

36 PEDROZO-PENÃFIEL, E. E. Absorção cooperativa de dois fótons em átomos frios. 2011. 94 p. Dissertação (Mestrado em Ciências) - Instituto de Física de São Carlos, Universidade de São Paulo, São Carlos, 2011.

37 PEDROZO-PEÑAFIEL, E. E. et al. Two-photon cooperative absorption in colliding cold Na atoms. Physical Review Letters, v. 108, n. 25, p. 253004, 2012. 
38 RAAB, E. L.et al. Trapping of neutral sodium atoms with radiation pressure. Physical Review Letters, v. 59, n. 23, p. 2631-2634, 1987.

39 NAIK, D. S. Bose-Einstein condensation: building the testbeds to study surperfluidity. 2006. 93 p. Ph. D. Thesis (Physics) - School of Physics, Georgia Institute of Technology, Georgia, 2006.

$40 \mathrm{CHU}$, S. et al. Experimental observation of optically trapped atoms. Physical Review Letters, v. 57, n. 3, p. 314-317,1986.

41 KETTERLE, W. et al. High densities of cold atoms in a dark spontaneous-force optical trap. Physical Review Letters, v. 70, n. 15, p. 2253-2256, 1993.

42 MIRANDA, S. G. et al. "Dark-spot" atomic-beam slowing for on-axis loading of traps. Physical Review A, v. 59, n. 1, p. 882-885, 1999.

43 DEMTRODER, W. Atoms, molecules and photons. 2nd ed. Heilderberg: Springer, 2010 .

44 HIRSCHFELDER, J. O.; MEATH, W. J. Advances in chemical physics: the nature of intermolecular forces. Hoboken, N. J., USA: John Wiley \& Sons, Inc., 2007. p. 3-106.

45 SCHNEIDER, B.; COHEN, J. S. Ground and excited states of $\mathrm{Ne}^{2}$ and $\mathrm{Ne}^{+2}$. II. spectroscopic properties and radiative lifetimes. The Journal of Chemical Physics, v. 61, n. 8 , p. 3240-3243, 1974.

46 BAGNATO, V. et al. Two-color spectroscopy of colliding ultracold atoms. Physical Review Letters, v. 70, n. 21, p. 3225-3228, 1993.

47 GOULD, P. L. et al. Observation of associative ionization of ultracold laser-trapped sodium atoms. Physical Review Letters, v. 60, n. 9, p. 788-791, 1988. 
48 LETT, P. D. et al. Spectroscopy of $\mathrm{Na}_{2}$ by photoassociation of laser-cooled Na. Physical Review Letters, v. 71, n. 14, p. 2200-2203, 1993.

49 MOLENAAR, P. A. et al. Long-range predissociation in two-color photoassociation of ultracold Na atoms. Physical Review Letters, v. 77, n. 8, p. 1460-1463, 1996.

50 AMELINK, A. Photoassociation of ultracold sodium atoms. Disponível em: <http:// testweb.science.uu.nl/AOUD/dissertationpdfs/id14.pdf>. Acesso em: 20 fev. 2012.

51 AMELINK, A. et al. Spectroscopy of autoionizing doubly excited states in ultracold $\mathrm{Na}_{2}$ molecules produced by photoassociation. Physical Review A, v. 61, n. 4, p. 042707, 2000 .

52 MARCASSA, L. et al. Optical suppression of photoassociative ionization in a magnetooptical trap. Physical Review Letters, v. 73, n. 14, p. 1911-1914, 1994.

53 ZILIO, S. C. et al. Polarization dependence of optical suppression in photoassociative ionization collisions in a sodium magneto-optic trap. Physical Review Letters, v. 76, n. 12, p. 2033-2036, 1996.

54 SUOMINEN, K.-A. Theories for cold atomic collisions in light fields. Journal of Physics B: atomic, molecular and optical physics, v. 29, n. 24, p. 5981, 1996. 